University of Louisville ThinkIR: The University of Louisville's Institutional Repository

$8-2016$

\title{
Nurses' intentions to initiate an antipsychotic or behavioral intervention with nursing home residents : the role of norms, being evaluated, self- efficacy, time pressures, and staffing.
}

Brian M. Ludwin

University of Louisville

Follow this and additional works at: https://ir.library.louisville.edu/etd

Part of the Clinical Psychology Commons

\section{Recommended Citation}

Ludwin, Brian M., "Nurses' intentions to initiate an antipsychotic or behavioral intervention with nursing home residents : the role of norms, being evaluated, self-efficacy, time pressures, and staffing." (2016). Electronic Theses and Dissertations. Paper 2528.

https://doi.org/10.18297/etd/2528

This Doctoral Dissertation is brought to you for free and open access by ThinkIR: The University of Louisville's Institutional Repository. It has been accepted for inclusion in Electronic Theses and Dissertations by an authorized administrator of ThinkIR: The University of Louisville's Institutional Repository. This title appears here courtesy of the author, who has retained all other copyrights. For more information, please contact thinkir@louisville.edu. 
NURSES' INTENTIONS TO INITIATE AN ANTIPSYCHOTIC OR BEHAVIORAL INTERVENTION WITH NURSING HOME RESIDENTS: THE ROLE OF NORMS, BEING EVALUATED, SELF-EFFICACY, TIME PRESSURES, AND STAFFING

By

Brian M. Ludwin

\author{
A Dissertation \\ Submitted to the Faculty of the \\ College of Arts and Sciences of the University of Louisville \\ for the Degree of \\ Doctor of Philosophy \\ in Clinical Psychology
}

Department of Psychological and Brain Sciences

University of Louisville

Louisville, KY

August 2016 
Copyright 2016 by Brian M. Ludwin

All rights reserved 

NURSES' INTENTIONS TO INITIATE AN ANTIPSYCHOTIC OR BEHAVIORAL INTERVENTION WITH NURSING HOME RESIDENTS: THE ROLE OF NORMS, BEING EVALUATED, SELF-EFFICACY, TIME PRESSURES, AND STAFFING

\author{
By \\ Brian M. Ludwin \\ A Dissertation Approved on
}

June 17, 2016

by the following Dissertation Committee:

Suzanne Meeks, Ph.D.

Dissertation Committee Chair

Rangaraj Gopalraj, M.D., Ph.D.

Richard Lewine, Ph.D.

Benjamin Mast, Ph.D.

Barbara Stetson, Ph.D. 


\section{ACKNOWLEDGEMENTS}

I would like to thank my primary mentor, Suzanne Meeks, for modeling how to integrate the science and art of psychology in the pursuit of understanding and improving our lives and for her support and guidance in my development as a clinical psychologist. I would like to thank my dissertation committee members, Benjamin Mast, Barbara Stetson, Rangaraj Gopalraj, and Richard Lewine, for their insights and encouragement. Words cannot express my gratitude to my parents, sisters, and partner for their encouragement, support, laughter, and love over the past five years and without whom this work would not have come to fruition.

This research was supported by funding from an intramural grant from the College of Arts and Sciences, University of Louisville and by the research funds of Suzanne Meeks, Ph.D. 


\begin{abstract}
NURSES' INTENTIONS TO INITIATE AN ANTIPSYCHOTIC OR BEHAVIORAL INTERVENTION WITH NURSING HOME RESIDENTS: THE ROLE OF NORMS, BEING EVALUATED, SELF-EFFICACY, TIME PRESSURES, AND STAFFING
\end{abstract}

\title{
Brian M. Ludwin
}

June 17, 2016

\section{Purpose of the Study: This experimental study examined whether exposure to an} injunctive norm against antipsychotic use and a sense of being evaluated influenced nurses' intentions to initiate an antipsychotic or behavioral intervention with nursing home residents who have dementia-related behavioral difficulties, and examined the interrelationships of perceived time pressures, staffing, self-efficacy, and the nurses' treatment intentions.

Design and Methods: A total of 158 nurses from 28 long-term care facilities were randomized to one of four conditions within a two (injunctive norm: salient vs. not salient) x two (sense of evaluation: salient vs. not salient) between-participants design in this cross-sectional study. The nurses responded to a case study that depicted a resident with dementia-related behavioral difficulties and the dependent variables were their intent to initiate an antipsychotic or a behavioral intervention. The nurses completed self-report measures of their self-efficacy, time pressures, perceived staffing, descriptive norms, 
attitudes, and outcome expectancies. Multi-level modeling was utilized to examine the effect of the two conditions and explore the correlates of the nurses' intentions.

Results: The provision of a salient injunctive norm and/or a sense of evaluation were not associated with lower intentions to initiate an antipsychotic or higher intentions to initiate a behavioral intervention. Individuals working in facilities with higher rates of antipsychotic use had greater intentions to utilize an antipsychotic when presented with an injunctive norm than individuals working in facilities with lower rates of antipsychotic use. The nurses' self-efficacy, attitudes, perceived descriptive norms, and outcome expectancies did not moderate the effect of an injunctive norm on their treatment intentions. Perceived staffing was related to intent to start an antipsychotic but not a behavioral intervention, and perceived time pressures were not related to the nurses' intentions.

Implications: Increasing the visibility of a message discouraging antipsychotic use may have limited utility in influencing nurses' intentions to use an antipsychotic and may even be detrimental in facilities with higher rates of antipsychotic use. Further research examining the effect of a sense of evaluation, time pressures, staffing, and self-efficacy on nurses' treatment intentions is needed. 


\section{TABLE OF CONTENTS}

\section{Page}

Acknowledgements .................................................... iii

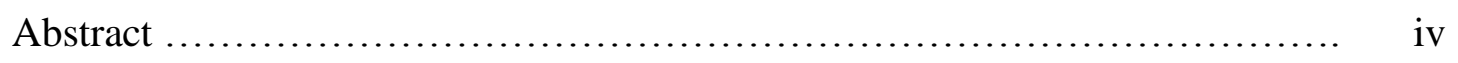

List of Tables ......................................................... vii

Introduction .............................................................

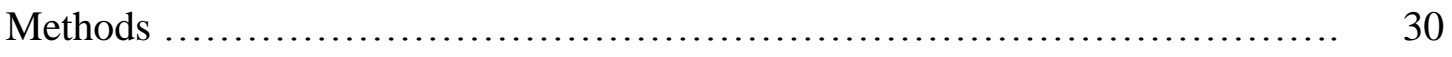

Results ...................................................................... 53

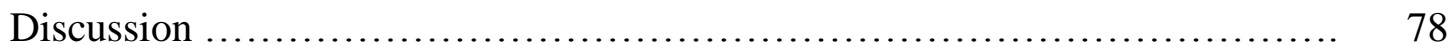

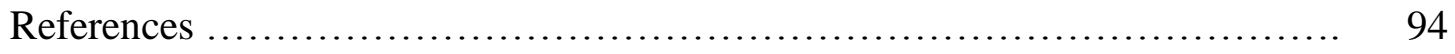

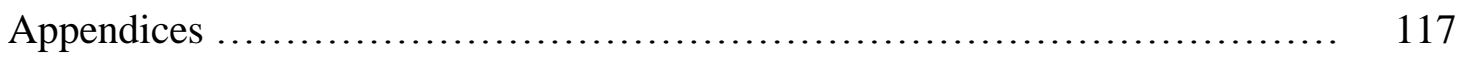

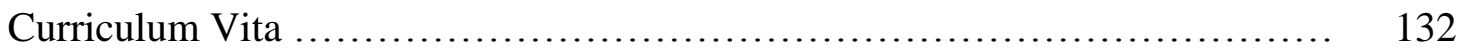




\section{LIST OF TABLES}

PAGE

1. Independent and dependent variables' descriptive statistics ............... 57

2. Interrelationships of independent variables ........................... 62

3. Antipsychotic initiation as a function of injunctive norm, sense of

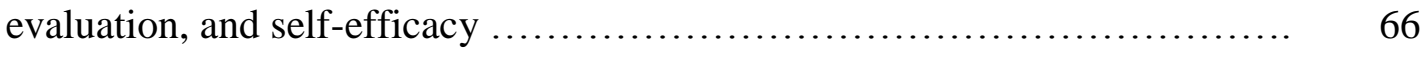

4. Antipsychotic initiation as a function of facility antipsychotic rate and

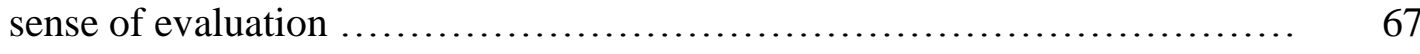

5. Antipsychotic initiation as a function of staffing and time pressures ........ 70

6. Antipsychotic initiation and staffing: Sensitivity analysis ................ 72

7. Behavioral intervention as a function of injunctive norm, sense of

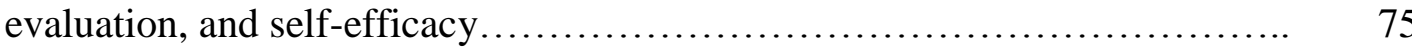




\section{INTRODUCTION}

Agitation, aggression, delusions, and hallucinations are common neuropsychiatric symptoms (NPS) among nursing home residents with dementia (Selbaek, Engedal, \& Bergh, 2013). In order to manage NPS among nursing home residents, physicians have commonly prescribed antipsychotics (Briesacher et al., 2005b; Ray, Federspiel, \& Schaffner, 1980; Stevenson et al., 2010). Although some data supports their efficacy to manage NPS (Schneider, Dagerman, \& Insel, 2006a), antipsychotics are associated with accelerated cognitive decline (Vigen et al., 2011), somnolence, extrapyramidal symptoms, cerebrovascular accidents (Schneider et al., 2006a), and death (Schneider, Dagerman, \& Insel, 2005) among older adults with dementia. Furthermore, an effectiveness trial comparing atypical antipsychotics to placebo in the management of NPS among people with dementia found antipsychotics do not provide a clinically significant benefit (Schneider et al., 2006b).

Despite evidence of their limited utility (Schneider et al., 2006b) and federal laws restricting their use in nursing homes (Centers for Medicare and Medicaid (CMS), 2013), the current national prevalence of antipsychotic use among nursing home residents is $20.2 \%$ (CMS, 2014). Epidemiological evidence suggests that up to $40 \%$ of prescribed antipsychotics are inappropriate among nursing home residents (Briesacher et al., 2005b; Stevenson et al., 2010). In order to ameliorate problematic prescribing practices, the federal government has mandated guidelines and medication reviews, and others have designed education-based programs. These attempts to modify staff behavior have been 
met with mixed and limited efficacy, which has led to a call for ways to improve the available interventions (Nishtala, McLachlan, Bell, \& Chen, 2008; Richter, Meyer, Möhler, \& Köpke, 2012).

The purpose of this study was to examine aspects of a psychological and behavioral model that seeks to explain why nursing home providers continue to prescribe antipsychotics inappropriately. The model originates in the theoretical and empirical literature of how norms, self-efficacy, time pressures, behavioral contingencies, and attitudes influence behavior. These constructs and principles will be used to provide a conceptual understanding of how the available interventions may be inducing change, to identify strengths and weaknesses in the existing interventions, and to suggest methods of improvement.

\section{Use of Norms to Encourage Reduced Antipsychotic Prescribing}

\section{Antipsychotic Use as a Facility Norm}

Recent studies have examined whether inappropriate prescribing aggregates in certain nursing homes. Rochon et al. (2007) reported that residents living in facilities with the highest rates of antipsychotic use were three times more likely to be prescribed an antipsychotic than residents living in facilities with the lowest rates, after adjusting for facility and resident characteristics. A subsequent study similarly demonstrated that after controlling for resident and facility factors, newly admitted residents in facilities with the highest prescribing rates in the previous year were 1.37 times more likely to be prescribed an antipsychotic than residents who were newly admitted to facilities with the lowest prescribing rates in the previous year (Chen et al., 2010). Similar outcomes occurred when they analyzed only dementia cases without psychosis and cases without 
dementia or psychosis. Their findings suggest that providers in some nursing homes have established a common and persistent pattern of prescribing antipsychotics that is independent of facility differences in resident and clinical characteristics (Grunier \& Lapane, 2008; Tjia, Gurwitz, \& Briesacher, 2012).

The presence of shared and persistent prescribing patterns within nursing homes is consistent with findings from early social psychology studies, which reported that individuals in a group will often spontaneously develop common patterns of behavior that persist over time (Sherif, 1936). Further research reported that individuals new to a group would adopt the group's pattern of behaviors (Asch, 1956). Although a group's patterned behavior can be resilient to changes in group membership over time (Jacobs \& Campbell, 1961), the introduction of new behaviors has been associated with substantial changes in behavior (Newcomb, 1967). Social psychologists have established the construct of norms to explain this behavioral phenomenon, and defined norms as a group's shared rules and standards of behavior (Fiske, 2010). Understanding antipsychotic prescribing as a facility norm can facilitate an analysis of interventions aimed at changing that behavior.

\section{Review of OBRA-87 and Related Interventions}

The Omnibus Budget Reconciliation Act of 1987 (OBRA-87) established guidelines on the appropriate use of antipsychotics in nursing homes, and mandated monthly medication reviews (Gurvich \& Cunningham, 2000). As a result of this legislation, consultant pharmacists may review nursing home residents' medications and provide written recommendations about problematic prescribing practices (Office of Inspector General Report, 1997).When annual inspections find evidence of nonadherence to prescribing guidelines, CMS (2014) can levy fines against the nursing 
home. One could understand these interventions as an attempt to change prescribing norms.

Studies examining antipsychotic use post-OBRA suggest that there may have been an initial decrease in prescribing. Shorr, Fought, and Ray (1994) found that the average rate of antipsychotic use per 100 days of residence declined 6.4 points over 30 months within a cohort of 9432 Medicaid-enrolled nursing home residents. However, at the facility level, one-quarter of nursing homes had no change or an increase in their rate of use. A large study of four cohorts of residents from 372 Minnesota nursing homes showed that the prevalence of antipsychotics declined from $23 \%$ to $15 \%$ between 1987 and 1991, which was significant after controlling for resident, nursing home, regional, and admission factors (Garrard, Chen, \& Dowd, 1995). However, a random sample of 254 nursing homes from 10 states based on independent cohorts from 1990 and 1993, found no change in antipsychotic prevalence after controlling for resident mental health diagnoses (Hawes et al., 1997).

Despite evidence of early changes in antipsychotic use in some nursing homes, a study of data from 2000 to 2001 reported that $27.6 \%$ of all nursing-home Medicare beneficiaries were prescribed an antipsychotic, and that $32 \%$ of the antipsychotic prescriptions were inappropriate per CMS guidelines (Briesacher et al., 2005b). Nationally representative data from 2004 found that $26 \%$ of nursing home residents were on an antipsychotic, and that $40 \%$ of the prescriptions were inappropriate (Stevenson et al., 2010). Additionally, an innovative, quasi-experimental study compared medication misuse between nursing home and assisted living residents after CMS implemented a series of new regulations in 1999 (Briesacher, Limcangco, Simoni-Wastila, Doshi, \& 
Gurwitz, 2005a). They found that medication misuse was generally higher among nursing home residents and did not decline after the new regulations. Thus, over time, implementing guidelines and pharmacy reviews do not appear to have substantially changed prescribing practices.

Two studies outside the U.S. used randomized, controlled trials (RCTs) to examine the impact of guidelines plus pharmacy reviews. Schmidt et al. (1998) enacted restrictive guidelines and monthly pharmacist-led medication reviews in 15 facilities. Over 12 months, the prevalence of antipsychotics declined from 40 to $33 \%$ in the intervention facilities, and it declined from 38 to $35 \%$ in the 18 control facilities. They did not statistically test the difference. In another study that matched facilities for staffing, location, and ownership type, eleven received monthly pharmacist medication reviews that used OBRA-87's guidelines and included informal discussions with the staff (Patterson et al., 2010). After adjusting for the effects of clustering, fewer residents in the intervention facilities (20\%) were inappropriately prescribed a psychotropic medication in comparison to residents in the control facilities (50\%) at post-intervention (OR 0.26, 95\% CI 0.14 to 0.49 ).

The reviewed studies present several sampling and methodological problems that warrant caution when interpreting their results. Three studies restricted their samples either to Medicaid (Shorr et al., 1994) or Medicare residents (Briesacher et al., 2005a; Briesacher et al., 2005b), and two used data from a single state (Garrard et al., 1995; Shorr et al., 1994). These samples introduce the possibility of cohort effects because antipsychotic misuse differs across regions and payer source (Stevenson et al., 2010). Several studies reported the overall prevalence or rate of antipsychotic use (Garrard et al., 
1995, Hawes et al., 1997; Schmidt et al., 1998; Shorr et al., 1994). Given antipsychotic use can be appropriate, an overall reduction in antipsychotics may not accurately demonstrate an interventions' effectiveness at reducing inappropriate prescriptions. However, Patterson et al. (2010) allowed for inappropriate use to improve by either discontinuing medications or improving documentation, which limits our ability to detect any effects that are specific to changing medications. Another critical limitation of all the studies examining OBRA-87 was their lack of a control group, which hinders our ability to judge what changes in antipsychotic use are directly attributable to OBRA-87 (Garrard et al., 1995). Finally, most of the studies examining the effect of OBRA-87 over time or its related interventions did not adjust for the effects of clustering in their analyses (Garrard et al., 1995; Hawes et al., 1997; Schmidt et al., 1998; Shorr et al., 1994), which could lead to an overestimation of their effects (Galbraith, Daniel, \& Vissel, 2010; Lee \& Thompson, 2005).

Overall, research suggests that regulation plus pharmacist review has the potential to change facility norms in the short run. However, these interventions are often inefficient in changing healthcare providers' behavior (Ivers et al., 2012), and can be expensive (CMS, 2014). An analysis of norm-related research can be helpful in understanding how these interventions might be strengthened and streamlined.

\section{Understanding OBRA-related Interventions in Terms of Research on Norms}

Norm Salience. Whether and how a norm becomes salient has important implications for its effect on behavior. The available literature provides little to no information about how OBRA-87 and its related interventions initially informed providers about the new guidelines, which hinders any analysis of whether they were able 
to optimally establish a new norm. However, by highlighting instances of noncompliance, medication reviews deliver information about the guidelines, which serve to increase providers' awareness of the norm against antipsychotic use. The following sections will review how effective medication reviews are at increasing the salience of a norm among nursing home providers.

Consultant pharmacists provide physicians with recommendations about how to improve their prescribing practices. Several lines of evidence suggest that this approach may be problematic. First, physicians do not routinely seek assistance from pharmacists when making decisions about medications (Office of the Inspector General, 1997). Second, providers are more likely to change their behavior if they receive feedback from a respected colleague or supervisor (Hysong, 2009; Ivers et al., 2012). Third, people are more likely to follow a norm enacted by someone with a similar social identity (Goldstein, Cialdini, \& Griskevicius, 2008). These findings suggest that matching providers could be more efficacious.

Although physicians are typically aware of a reviewer's recommendations, nurses infrequently receive or take note of them in the community (Office of the Inspector General, 1997). As a result, nurses are typically not exposed to the norm embedded in the recommendations. Their lack of exposure to the norm is problematic because they initiate a request for an antipsychotic in the majority of cases and may influence a physician's decision-making (Cohen-Mansfield, Jensen, Resnick, \& Norris, 2012; Cornegé-Blokland, Kleijer, Hertogh, \& van Marum, 2012). Attempts to increase nurses' awareness of the norm against antipsychotic use could decrease their requests for them. 
Pharmacists typically provide their recommendations in a written notice (Office of the Inspector General, 1997), but some studies include verbal discussions of the results (Patterson et al., 2010; Schmidt et al., 1998). Conveying feedback in the written or written plus verbal form is more effective than when only provided verbally (Hysong, 2009; Ivers et al., 2012), and norms can be effectively elicited through writing (Goldstein, Cialdini, \& Griskevicius, 2008; Schultz, 1998; Schultz, Nolan, Cialdini, Goldstein, \& Griskevcius, 2007). However, the content and wording of the recommendations, which often varies (Office of the Inspector General, 1997), is also important. Providing people with a clear behavioral goal and specific steps to achieve the goal enhances the likelihood of behavior change (Gollwitzer, 1999; Leventhal, Singer, \& Jones, 1965), and is effective with healthcare providers (Hysong, 2009; Ivers et al., 2012). Some evidence also indicates that negatively worded messages discouraging problematic behaviors are more effective than messages worded to encourage desirable conduct (Cialdini et al., 2006). These findings recommend that reviews include specific steps to achieve a behavioral target and should discourage problematic behaviors.

Finally, providers receive the recommendations after and only in the event of an inappropriate prescription, and their review of the recommendations may not occur in close proximity to when they would renew or administer an antipsychotic. Research demonstrates that people's awareness of norms varies substantially, and norms are most effective when they become salient in close proximity to and before the behavior of interest (Cialdini, Reno, \& Kallgren, 1990; Reno, Cialdini, \& Kallgren, 1993). Methods that elicit and maintain a norm's salience when providers prescribe or administer antipsychotics are more likely to reduce antipsychotic misuse. 
Injunctive vs Descriptive Norms. Guidelines that delineate what providers should do serve as injunctive norms. Injunctive norms describe what an individual ought to do in a given situation, and motivate action by providing social approval or disapproval (Cialdini et al., 1990; Reno et al., 1993). Research has found that injunctive norms can effectively reduce problematic behaviors even when they occur at a low base rate (Cialdini et al., 1990; Cialdini et al., 2006; Reno et al., 1993). Thus, the implementation of restrictive guidelines is appropriate for reducing antipsychotic misuse.

Descriptive norms are a second type of norm that describe what most people do in a situation and motivate behavior by signifying what others have found to be effective (Cialdini et al., 1990; Reno et al., 1993). Unlike injunctive norms, increased awareness of a problematic behavior often sustains or augments it (Cialdini et al., 2006). Additionally, injunctive and descriptive norms can conflict, and when presented with conflicting norms in non-distressing situations, people are more likely to conform to the injunctive norm (Cialdini et al., 1990). However, prescribing antipsychotics occurs in the context of resident behavior that is disruptive and distressing (Everitt, Fields, Soumerai, \& Avorn, 1991; Zuidema, de Jonghe, Verhey, \& Koopmans, 2011). Because their goal is to manage the distress and disruption, providers may be more inclined to follow a descriptive norm because it provides information about what is an effective action.

A classic line of research in social psychology examined circumstances where individuals were presented with conflicting descriptive and injunctive norms in the context of a distressing situation. In the original studies, participants faced a potentially dangerous situation in which the underlying injunctive norm was that the participant should seek or provide help (Darley \& Latané, 1968; Latané \& Darley, 1968). When 
alone, the majority of participants sought to help. However, when passive bystanders were present, only a minority of participants acted according to the injunctive norm. Researchers have replicated these findings across a range of helping-related scenarios (Latané \& Nida, 1981), and the inverse relationship between the presence of passive bystanders and helping behavior is moderate to strong ( $g=-0.53$ ) (Fischer et al., 2011). Although a descriptive norm may influence behavior in distressing situations, one could argue providers are likely not surrounded by others simultaneously making a similar decision, and thus, there is no behavior to mimic. Evidence, however, suggests that the direct presence of others is not necessary for a descriptive norm to influence behavior (Fischer et al., 2011; Garcia, Weaver, Moskowitz, \& Darley, 2002). These findings point out that methods reducing the influence of a contradictory descriptive norm may lead to improved outcomes.

Behavioral Contingencies. In two studies, providers did not incur consequences if they failed to comply with the guidelines (Patterson et al., 2010; Schmidt et al., 1998). CMS $(2013 ; 2014)$ annually reviews whether nursing homes have been compliant with its guidelines on prescribing antipsychotics. If they find evidence of inappropriate prescribing practices over the past year, they may levy a fine against the nursing home, not its providers. As a result, the fines do not directly punish providers for writing the prescription, and the punishment is incurred well after the antipsychotic is prescribed. The effectiveness of aversive consequences in reducing problematic behavior is attenuated when the consequences are not experienced directly or in close proximity to the behavior's occurrence (Bandura, 1969; Craighead, Kazdin, \& Mahoney, 1981). Increasing preferred behaviors is typically easier than decreasing problematic behaviors, 
and the effect of positive consequences on augmenting preferred behaviors is commonly predictable and efficient. Thus, interventions should provide positive consequences for compliance and avoid fines that do not directly punish providers.

Summary. The social psychological literature supports the issuance of guidelines in a written format, but suggests a number of changes to the available norm-based approaches. Interventions should systematically and consistently deliver the norm to nurses and physicians when they are initiating or administering antipsychotics, employ a mechanism to reduce the influence of conflicting descriptive norms, and provide staff with positive consequences for following the guidelines.

\section{Use of Behavioral Control and Attitudes to Reduce Antipsychotic Prescribing}

\section{Review of Education-based Interventions}

A second approach to modifying providers' behavior has employed educationbased interventions. The first such published intervention involved 15-minute sessions between trained physicians and 50 physicians who were among the highest prescribers of antipsychotics in one region of Tennessee (Ray, Blazer, Schaffner, \& Federspiel, 1987). Another high-prescribing 100 physicians from two other regions served as the control group. In the year following the visits, the intervention was not associated with any changes in the physicians' prescribing practices. A similar intervention occurred in twelve nursing homes in Southern Alberta, Canada (Hagen et al., 2005). During 30-to-45minute sessions with the medical, pharmacy, and nursing staff, trained pharmacists reviewed an algorithm outlining when to use an antipsychotic or a behavioral intervention. After the intervention, the prevalence of antipsychotics was not different between the intervention and twelve control facilities. 
Several studies in the United States (US) examined education-based interventions in the context of OBRA-87. In an uncontrolled trial, pharmacists visited physicians and nurses in 17 Maryland facilities to discuss the indications, side effects, and documentation of antipsychotics (Rovner, Edelman, Cox, \& Shmuely, 1992). After six months, the prevalence of antipsychotics declined from $25 \%$ to $16 \%$, and 10 months later, it was stable at 14\%. In twelve nursing homes, Avorn et al. (1992) examined their intervention in the context of a RCT that matched facilities for size, ownership type, and prevalence of psychotropic drug use. In the intervention, physicians received fliers about best practices for prescribing psychotropic medications, and some physicians with high prescribing rates received three visits from a pharmacist. Nursing staff participated in four sessions focusing on direct patient care, alternatives to medications, and recognition of adverse events. Using a psychoactive-drug-use score that assigned points for each use of a non-recommended drug and/or dosage, they found the intervention was associated with a significant reduction in inappropriate psychotropic medication use relative to the control facilities. The prevalence of antipsychotics dropped from $29 \%$ to $24 \%$ in the intervention group, whereas it declined from $26 \%$ to $25 \%$ in the control group.

Ray et al. (1993) piloted a program in two Tennessee nursing homes wherein medical and nursing staff received information about medical evaluations, provision-ofcare procedures, behavior management plans, gradual dose reduction trials, and appropriate antipsychotic dosing. Physicians met with a geriatric psychiatrist for 45 to 60 minutes, and for the nursing staff, a nurse educator offered six one-hour in-services over a three-week period with a follow-up session four weeks later. They also offered a fourhour consultation regarding quality control, relations with residents' families, and staff 
supervision, and after eight weeks, they met with staff to discuss residents with refractory behavior problems. Two other nursing homes matched for the number of beds and antipsychotic use and dose served as the control group. At post-intervention, the rate reduction in antipsychotic use of 21 days per 100 days of residence in the intervention facilities was significantly greater than the rate reduction of 4 days per 100 days of residence in the control homes. Meador, Taylor, Thapa, Fought, and Ray (1997) replicated Ray et al.'s (1993) pilot, and after matching for size and antipsychotic prevalence, they randomized twelve homes to the intervention or control group. Unlike the pilot study, the nurse-educator conducted five to six one-hour in-services over a week, and they did not include a treatment meeting after eight weeks. Over four months, antipsychotic use declined 5.6 days per 100 days of residence in the intervention facilities, which was significantly greater than the decrease of 0.2 days per 100 days of residence in the control facilities.

The most recent intervention in the US has occurred in the context of CMS's campaign to improve dementia care. Since 2012, CMS has provided nursing homes with resources to improve care practices, increase knowledge of antipsychotics, implement behavioral treatments, and stabilize staffing patterns (CMS, 2014; Mitka, 2012). Over the past 18 months, the national prevalence of antipsychotic use among long-term care residents decreased from 23.8\% to 20.2\% (CMS Division of Nursing Homes, personal communication, April 14, 2014).

Outside the US, several interventions have combined education, prescribing guidelines, and medication reviews. Monette et al. (2008) examined an intervention in a single nursing home that involved monthly, pharmacist-led medication reviews and 
education sessions about behavioral treatments and prescribing antipsychotics. A clinical nurse specialist conducted 45-minute sessions with personal care assistants and 90minute sessions with nurses. A geriatric psychiatrist ran 90-minute sessions for physicians and pharmacists. Among residents receiving an antipsychotic at baseline, $49 \%$ had their antipsychotic discontinued after seven months. Westbury, Jackson, Gee, and Peterson (2010) completed a non-randomized, controlled trial of an intervention comprising quarterly pharmacy-led medication reviews and education sessions about prescribing antipsychotics. After six months, the prevalence of antipsychotics declined $1 \%$ in the 13 intervention facilities, which was significantly greater than the $3 \%$ increase in antipsychotic prevalence among the 12 control facilities.

Fossey et al. (2006) conducted a cluster RCT that matched twelve nursing homes for location and baseline antipsychotic use. A psychologist, occupational therapist, or nurse worked two days per week for ten months in the intervention facilities, and they trained and supervised the staff in implementing a range of behavioral treatments. A geriatric psychiatrist completed quarterly medication reviews in both the control and intervention facilities. At post-intervention, there was an average and significant reduction of $19.1 \%$ (95\% CI $0.5 \%$ to $37.7 \%$ ) in the prevalence of antipsychotics that favored the intervention. The average prevalence of antipsychotic use decreased from $47 \%$ to $23 \%$ in the intervention facilities, and it decreased from $50 \%$ to $42 \%$ in the controls. One of two sensitivity analyses were supportive.

There are several sampling and methodological issues that warrant caution in interpreting the results of these trials. Most trials selected or recruited homes with at least $20 \%$ of their residents on an antipsychotic. However, a substantial proportion of nursing 
homes have antipsychotic rates below 20\% (Chen et al., 2010; Rochon et al., 2007), and some evidence indicates that homes with lower baseline antipsychotic rates may be less responsive to an intervention (Rovner et al., 1992). The reviewed studies did not provide information about facilities that elected not to participate. Thus, there may be systematic biases in the participating facilities, such as work cultures that promote quality care and best practices, which would increase the likelihood the interventions will work. In terms of outcomes, all of the trials reported the overall prevalence or rate of antipsychotic use, which may not provide an accurate representation of an intervention's effectiveness. Additionally, the majority did not include long-term outcomes after post-intervention, and none provided relevant process outcomes. Methodologically, only three trials utilized randomization (Avorn et al., 1992; Fossey et al.; 2006; Meador et al., 1997), and as a result, baseline or unmeasured differences may have biased their results. Most of the trials analyzed their outcomes at the level of the nursing home. However, the largest sample of nursing homes was 25 (Westbury et al., 2010), and only two trials controlled for the effects of clustering in their statistical analyses (Avorn et al., 1992, Fossey et al., 2006). Both small samples sizes (Ioannidis, 2005) and a lack of control over clustering (Galbraith et al., 2010; Lee \& Thompson, 2005) can produce inaccuracies in the estimates of an intervention's effectiveness.

In the context of restrictive prescribing guidelines and medication reviews, education-based interventions have produced small to moderate changes in antipsychotic use. However, at post-intervention, most facilities' antipsychotic use remained substantial. Similarly, evidence from a recent systematic review found that educationbased interventions are inefficient at changing problematic prescribing behaviors 
(O’Brien et al., 2007). Furthermore, the education-based interventions required significant time, resources, and money to implement (Avorn et al., 1992; Fossey et al., 2006; Ray et al., 1993). Understanding the mechanisms of change in such interventions might provide insight into how to increase their effectiveness and efficiency.

\section{Understanding Education-based Interventions in Terms of Behavioral Control and}

\section{Attitudes}

Knowledge and Skills. The reviewed interventions sought to enhance providers' knowledge of antipsychotics and in some cases behavioral treatments, but none reported relevant process outcomes. Surveys have found deficiencies in providers' knowledge of psychotropic medications (Anthierens, Grypdonck, De Pauw, \& Christiaens, 2009) and behavioral treatments (Cohen-Mansfield \& Jensen, 2008; Cohen-Mansfield, Jensen, Resnick \& Norris, 2011; Wood-Mitchell, James, Waterworth, Swann, \& Ballard, 2008). Continuing education programs in nursing homes enhance staff members' knowledge immediately after a program, but their knowledge retention varies over time (Aylward, Stolee, Keat, \& Johncox, 2003). Because changes in knowledge and skill are often prerequisites for behavior change (Ajzen, 1991; Bandura, 1982), the inefficient maintenance of new knowledge and skills may limit the interventions' efficacy. Interventions that included education about behavioral treatments (Avorn et al., 1992; Fossey et al., 2006; Meador et al., 1997; Monette et al., 2007; Ray et al., 1993) were all associated with changes in antipsychotic use; however, trials without this component produced limited to no changes (Hagen et al., 2005; Ray et al., 1987; Westbury et al., 2010) with the exception of one uncontrolled trial (Rovner et al., 1992). In order to explain the discrepancy in outcomes, it is helpful to consider that behavioral 
disturbances are associated with distress in staff (Everitt et al., 1991), which predicts antipsychotic use (Zuidema et al., 2011). Humans are powerfully motivated to ameliorate aversive stimuli, and behaviors that reduce and prevent distress are strongly reinforced (Bandura, 1969; Craighead, Kazdin, \& Mahoney, 1981). Such behaviors are difficult to extinguish unless individuals learn a new way to effectively reduce their distress. Interventions that include behavioral treatments, which can effectively manage NPS (O'Neil et al., 2011), are more likely to change providers' prescribing behaviors than interventions that do not provide an effective alternative.

Self-Efficacy. An important mediator between knowledge and behavior is selfefficacy, which is defined as one's “judgments of how well one can execute courses of action required to deal with prospective situations" (Bandura, 1982, p. 122). Self-efficacy predicts healthcare providers' behavior (Godin, Bélanger-Gravel, Eccles, \& Grimshaw, 2008) and their adherence to professional standards (Cabana et al., 1999). Nursing home staff members' perceived competence is associated with whether they implement behavioral treatments (Cohen-Mansfield \& Jensen, 2008), and is inversely associated with the use of psychotropic medications (Sonntag, Matschinger, Angermeyer, \& RiedelHeller, 2006).

The reviewed interventions did not measure providers' self-efficacy, but there is an important qualitative trend. Interventions with longer (Monette et al., 2007) or multiple meetings (Avorn et al., 1992; Meador et al., 1997; Ray et al., 1993) had improved outcomes relative to interventions with briefer visits (Hagen et al., 2005; Ray et al. 1987), and the presence of experts in behavioral treatments for two days per week over ten months was associated with the best outcomes (Fossey et al., 2006). Bandura's 
$(1977 ; 1982)$ theory of self-efficacy would predict a similar pattern of outcomes. The theory proposes that self-efficacy accrues from different forms of experience and that higher self-efficacy will lead to greater behavior change. Verbal persuasion, wherein people are led to believe they can accomplish a task, exerts often minimal influence over self-efficacy and behavior (Bandura, 1977), and would have been foundational in interventions with briefer sessions (Hagen et al., 2005; Ray et al., 1987). Watching others perform a behavior and performing a behavior oneself are associated with greater changes in self-efficacy and behavior (Bandura, 1977). Both forms of experience were included in several interventions (Fossey et al., 2006; Meador et al., 1997; Ray et al., 1993), but Fossey et al.'s (2006) intervention was associated with the best outcomes. The theory of self-efficacy would suggest two reasons for the difference. Significant changes in self-efficacy and behavior often occur incrementally, and would more likely occur with ten months of supervision than several skill development sessions. Changes in selfefficacy and behavior are also more likely when people practice a new behavior in vivo and with support, and direct supervision of actual resident care would likely be superior to skills training in a seminar.

Staffing and Time. External factors, such as resources and time, also influence whether people will act on their skills (Ajzen, 1991). Several interventions provided information to improve staffing patterns (CMS, 2014; Fossey et al., 2006; Meador et al., 1997; Ray et al., 1993), but did not report relevant process outcomes. Providers report low staffing levels prevent them from using behavioral treatments (Cohen-Mansfield et al., 2005; Cornegé-Blokland et al., 2012; Wood-Mitchell et al., 2008). However, while some empirical studies have reported higher staffing levels are inversely associated with 
antipsychotic use (Hughes, Lapane, and Mor, 2000; Shorr et al., 1994), others have not found a relationship (Garrard et al., 1995; Sonntag et al., 2006; Stevenson et al., 2010; Zuidema et al., 2011).The independent influence of staffing levels on antipsychotic misuse remains unclear.

Time pressures are a related but distinct factor that providers cite as to why they choose antipsychotics over behavioral interventions (Cohen-Mansfield et al., 2005; Cornegé-Blokland et al., 2012; Wood-Mitchell et al., 2008), which likely reflects the extra time required to implement a behavioral intervention (Cohen-Mansfield \& Jensen, 2008). No empirical studies have tested the relationship of time pressures and antipsychotic use, and none of the reviewed interventions discussed time pressures. A classic study in social psychology found that time pressures can substantially reduce the likelihood someone will follow an injunctive norm (Darley \& Batson, 1973). Time pressures among healthcare providers have also been positively associated with suboptimal compliance with handwashing guidelines (Pittet et al., 1999; Voss \& Widmer, 1997). Education-based interventions and the imposition of guidelines with oversight mechanisms did not produce substantial or lasting changes in rates of handwashing (Kretzer \& Larson, 1998). However, when hospitals introduced alcohol-based rubs, which required less time than traditional water and soap, they found substantial improvements in compliance (Bischoff, Reynolds, Sessler, Edmond, \& Wenzel, 2000; Hugonnet, Perneger, \& Pittet, 2002; Pittet et al., 2000). These findings propose that a mechanism to reduce an antipsychotic's time advantage over a behavioral treatment may be helpful. 
Attitudes. Attitudes, or people's positive or negative judgments about an object or action, can predict behavior when they are specific (Ajzen, 1991; 2001). Nursing home providers typically favor behavioral treatments over psychotropic medications (Burgio, Sinnott, Janosky, \& Hohman, 1992; Cohen-Mansfield \& Jensen, 2008; Cohen-Mansfield et al., 2011), but they often view psychotropic medications as acceptable (Anthierens et al., 2009; Burgio et al., 1992) and effective at treating NPS (Cornegé-Blokland et al., 2012). Unfortunately, the reviewed interventions did not measure attitudes, and no empirical studies have examined their relationship with antipsychotic use.

New information and experiences can modify attitudes (Festinger \& Carlsmith, 1959). The degree to which an attitude was formed affectively or cognitively moderates the effect of new information and experiences, such that providing information is more likely to alter cognitively formed attitudes (Edwards, 1990). While some staff may have formed their attitudes towards antipsychotics and behavioral treatments by cognitively processing associated changes in resident behavior, others may have formed their attitudes by affectively processing the reduction in distress. Fossey et al.'s (2006) intervention, which provided in vivo experience with treating behavioral disturbances, would have been more likely to change attitudes than the other interventions because it exposed staff to changes in resident behavior and reductions in distress.

While new information and experience may change problematic attitudes, the act of restricting antipsychotic use may have an opposing influence. When individuals experience a limitation in their access to an object, they tend to develop more positive attitudes toward it (Cialdini, 1995; Mazis, 1975; West, 1975) and will increase their efforts to use it (Brehm \& Brehm, 1981). None of the discussed studies directly measured 
the providers' sense of loss of freedom and control over their prescribing practices, and no substitute measures in the available data are adequate to analyze the factor of perceived freedom. However, it is possible that the loss of prescribing freedom could negatively impact an intervention's ability to modify providers' attitudes and behavior.

Summary. The psychological literature supports a number of methods that will enhance providers' ability to acquire and act on new knowledge and skills. First, interventions should provide structured, incremental, and in-vivo experiences with new skills in order to increase providers' self-efficacy and modify their attitudes. Second, interventions should employ mechanisms that moderate the effects of time pressures, limited staffing, and providers' sense of loss of freedom.

\section{Proposed Model for Reducing Antipsychotic Use}

\section{Model Description}

This review has identified how psychological constructs and behavioral principles can explain the continued misuse of antipsychotics and could be utilized to improve the reviewed interventions. Theoretical and empirical work has found that each construct or principle in isolation cannot fully explain behavior and that the reviewed constructs and principles are interrelated. In order to organize these relationships for the purposes of explaining antipsychotic misuse, the proposed model is grounded in Ajzen's (1991) theory of planned behavior (TPB). The TPB seeks to explain the occurrence of a behavior within a specific context, and proposes that an individual's intentions and perceived behavioral control (PBC) are immediate determinants of behavior. PBC is defined as a person's confidence in their ability to perform a behavior, and is a function of an individual's skill, knowledge, time, and resources. Intentions encapsulate an individual's 
plans and motivation to perform a behavior, and norms, attitudes, and PBC are its determinants. The TPB has received significant empirical support (Ajzen, 1991; Armitage \& Conner, 2001), and has been successful in explaining healthcare worker's behavior (Perkins et al., 2007).

The proposed model presents a system of factors and pathways that explain an individual healthcare provider's decision to prescribe an antipsychotic or utilize a behavioral intervention (Figure 1).

\section{Figure 1}

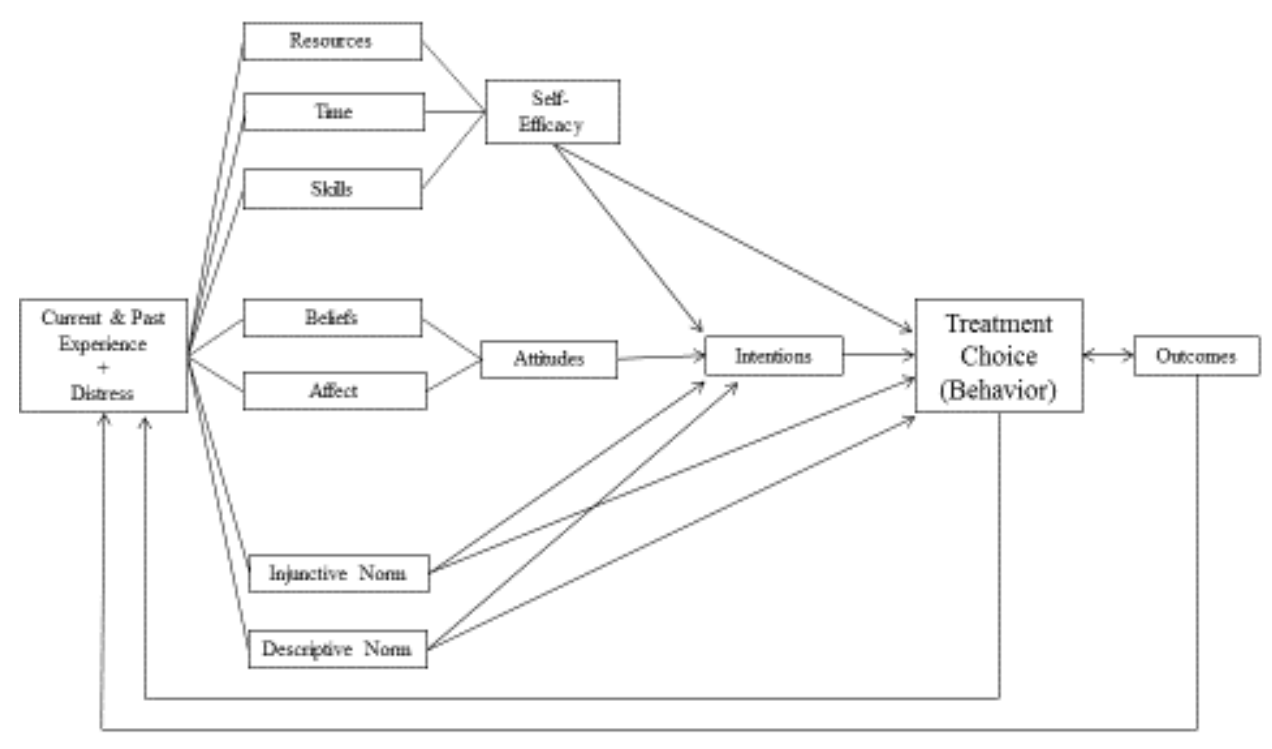

Psychological and Behavioral Model for Intervening with Healthcare Providers

The model includes three assumptions. First, no single factor or pathway is sufficient to explain antipsychotic prescribing. Second, the factors are dynamic such that they will vary with time and by situation. Third, the factors are expected to interact in a dynamic fashion. 
The TPB explains behavior contextually (Ajzen, 1991), and the inclusion of past experience and an individual's affect can increase the TPB's predictive validity (Conner \& Armitage, 1998). The model hypothesizes that the most relevant factors from the current situation include the frequency, severity, and type of a resident's disruptive behavior and the provider's level of distress, which are both known predictors of antipsychotic use (Briesacher et al., 2005b; Zuidema et al., 2011). Past experience encapsulates the outcomes of previous attempts to manage disruptive behaviors. Providers' current and past experiences are expected to inform and influence their sense of injunctive and descriptive norms, time pressures, resources, skill, beliefs, and affect. In line with the TPB (Ajzen, 1991), the model suggests that the four antecedents of behavior are PBC (represented as self-efficacy), norms, attitudes, and intentions. Ajzen (1991) originally conceptualized PBC as closely related to Bandura's (1977) construct of self-efficacy. Although some have proposed differentiating self-efficacy and perceived control within the larger construct of PBC (Conner \& Armitage, 1998), empirical evidence suggests that self-efficacy is a better predictor of intentions and behavior (Armitage \& Conner, 2001). The proposed model indicates that time, resources, and skills influence self-efficacy. The model defines skills as the knowledge and behaviors specific to implementing a treatment, and differentiates skills into those involving either initiating an antipsychotic or a behavioral treatment. The model also differentiates time and resources. Time is defined as a provider's workload, and resources are the environmental supports required to implement a treatment.

The TPB defined attitudes as a function of beliefs (Ajzen, 1991). However, affect can also influence attitudes (Fiske, 2010), and affectively and cognitively based attitudes 
may differentially respond to new experiences (Edwards, 1990). Thus, it is expected that beliefs and affect influence and inform providers' attitudes. The TPB described norms as the subjective experience of social pressure to enact a behavior (Ajzen, 1991), but the incremental validity of norms in the TPB has been weak, which may be a function of poor measurement (Armitage \& Conner, 2001). Research has shown that differentiating injunctive and descriptive norms increases their predictive validity and that increasing the salience of injunctive and descriptive norms is related to direct changes in behavior (Cialdini et al. 1990, Cialdini et al., 2006; Reno et al., 1993). As a result, the model differentiates descriptive and injunctive norms, and proposes that they influence both intentions and behavior. The original TPB (Ajzen, 1991) and proposed revisions (Conner \& Armitage, 1998) did not include behavioral outcomes as a factor. However, behavioral outcomes are empirically validated and well-established predictors of behavior, and modification of outcomes can explain subsequent changes in behavior (Bandura, 1969; Craighead et al., 1981). The model hypothesizes that a treatment's outcomes, such as avoidance of disciplinary action or a reduction in patient behavior or provider distress, will directly affect providers' behavior, and that outcomes are expected to inform the current situation and become assimilated into providers' past experience.

\section{Summary}

The review and model have proposed that several psychological constructs and behavioral principles can help to explain nursing home providers' decision to initiate an antipsychotic or a behavioral intervention with nursing home residents. All of the reviewed interventions have sought to modify norms regarding antipsychotic use. Empirical evidence indicates that an injunctive norm against a behavior can reduce 
problematic behaviors when it becomes salient (Cialdini et al., 1990; Reno et al., 1993). Salient descriptive norms are also important predictors of behavior (Cialdini et al., 1990; Reno et al., 1993), and may reduce the effectiveness of an injunctive norm (Cialdini et al., 2006), especially in a distressing situation (Darley \& Latané, 1968; Latané \& Darley, 1968). However, researchers have found that leading people to believe they can be held accountable for their behavior can moderate the influence of a salient descriptive norm (van Bommel, van Prooijen, Elffers, \& Van Lange, 2012; van Bommel, van Prooijen, Elffers, \& Van Lange, 2013). Efforts to increase the salience of an injunctive norm against antipsychotic use and to increase nurses' sense of being evaluated could reduce the likelihood they would seek an antipsychotic and increase the likelihood they would initiate a behavioral intervention. However, a descriptive norm promoting antipsychotic use could moderate the effect of an injunctive norm and a sense of being evaluated.

Self-efficacy can predict healthcare providers' behavior (Godin et al., 2008) and their adherence to professional standards (Cabana et al., 1999). Nursing home providers' self-efficacy has been associated with the utilization of psychotropic medications (Sonntag et al., 2006) and behavioral interventions (Cohen-Mansfield \& Jensen, 2008). The manipulation of time pressures has been associated with changes in people's behavior (Darley \& Batson, 1973), including healthcare workers compliance with guidelines (Bischoff et al., 2000; Hugonnet et al., 2002; Pittet et al., 2000). Perceived time pressures are commonly reported as a rationale for why providers elect to initiate antipsychotics instead of behavioral interventions (Cohen-Mansfield et al., 2005; Cornegé-Blokland et al., 2012; Wood-Mitchell et al., 2008). Resources, such as staffing, can influence whether people will utilize their skills (Ajzen, 1991). Although objective 
measures of staffing have been inconsistently associated with antipsychotic use (Garrard et al., 1995; Hughes et al., 2000; Shorr et al., 1994; Sonntag et al., 2006; Stevenson et al., 2010; Zuidema et al., 2011), qualitative research indicates that providers believe low staffing levels prevent them from using behavioral interventions (Cohen-Mansfield et al., 2005; Cornegé-Blokland et al., 2012; Wood-Mitchell et al., 2008). In light of these findings, self-efficacy, time pressures, and resources are expected to influence providers' intentions to use an antipsychotic or a behavioral intervention. The TPB (Ajzen, 1991) and proposed model would suggest that self-efficacy could interact with injunctive norms to influence intentions, and that self-efficacy mediates the relationship between time pressures and intentions, as well as between resources and intentions.

Together, these findings and the proposed model serve as the foundation for the following research aims and hypotheses.

\section{Aims and Hypotheses}

\section{Primary}

Aim 1: To determine whether manipulating the salience of an injunctive norm against antipsychotic use will produce differences in nurses' intentions to initiate an antipsychotic or a behavioral intervention for nursing home residents with dementia and neuropsychiatric symptoms (NPS). To establish whether nurses' self-efficacy to implement behavioral interventions moderates the influence of an injunctive norm on their intentions.

H1: The message with a salient injunctive norm will be associated with reduced intentions among nurses to request antipsychotics relative to the information-only 
message condition, and will be associated with increased intentions among nursing staff to use a behavioral intervention.

H2: The effect of an injunctive norm on nurses' intentions to initiate an antipsychotic or a behavioral intervention will be moderated by the nurses' selfefficacy to perform behavioral interventions, such that a salient injunctive norm will be more influential among nurses with greater self-efficacy.

Aim 2: To determine whether manipulating the perception that their behavior is being directly evaluated will produce differences in nurses' intentions to initiate an antipsychotic.

H3: The perception of being directly evaluated will reduce nurses' intentions to seek an antipsychotic in comparison to being made aware that pharmacy and nursing staff will work more collaboratively.

Aim 3: To determine whether combining an injunctive norm against antipsychotic use with the perception that their behavior is being directly evaluated will produce differences in nurses' intentions to initiate an antipsychotic or a behavioral intervention. H4: There will be a stronger negative effect of a message with a salient injunctive norm on nurses' intentions to seek an antipsychotic when the nurses perceive their behavior is being directly evaluated than when the nurses are made aware that pharmacy and nursing staff will work more collaboratively. 
H5: There will be a stronger positive effect of a message with a salient injunctive norm on nurses' intentions to utilize a behavioral intervention when the nurses perceive their behavior is being directly evaluated than when the nurses are made aware that pharmacy and nursing staff will work more collaboratively.

Aim 4: To determine whether nurses' perceived time pressures and perceived resources are associated with their intentions to initiate an antipsychotic or a behavioral intervention. To determine whether their self-efficacy to implement behavioral interventions mediates the relationship between perceived time pressures and resources and the nurses' intentions to initiate an antipsychotic or a behavioral intervention.

H6: Nurses with greater perceived time pressures will have greater intentions to request an antipsychotic and will have lower intentions to employ a behavioral intervention.

H7: Nurses with lower perceived resources will have greater intentions to request an antipsychotic and will have lower intentions to employ a behavioral intervention.

H8: Nurses' self-efficacy to use a behavioral intervention will mediate the relationship between perceived time pressures and resources and their intentions to request an antipsychotic or utilize a behavioral intervention.

\section{Exploratory}


Aim 1a: To explore whether a facility's descriptive norm regarding antipsychotic use moderates the influence on an injunctive norm on nurses' intentions.

E1: The effect of an injunctive norm on nurses' intentions to initiate an antipsychotic or a behavioral intervention will be moderated by the nurses' perceived rate of antipsychotic use, such that an injunctive norm will be less influential with nurses who perceive higher rates of antipsychotic use in their facility. A similar effect will occur when examining the actual facility rates of antipsychotic use.

Aim 2a: To explore whether a facility's descriptive norm regarding antipsychotic use moderates the influence of being directly evaluated on nurses' intentions to request an antipsychotic.

E2: The effect of the perception of being directly evaluated on nurses' intentions to initiate an antipsychotic will be moderated by the nurses' perceived rate of antipsychotic use, such that a sense of being evaluated will be more influential with nurses who perceive higher rates of antipsychotic use in their facility. A similar effect will occur when examining the actual facility rates of antipsychotic use. 


\section{METHODS}

\section{Study Design and Sample}

This cross-sectional, questionnaire-based study involved randomizing a sample of long-term care nurses to one of four conditions within a two (injunctive norm: salient vs. not salient) by two (sense of evaluation: salient vs. not salient) between-participants design. Recruitment occurred in metro-Louisville nursing homes, and was supplemented with e-mail advertisements through the listserves of two national professional nursing organizations: the National Association of Directors of Nursing in Long Term Care and American Association for Long Term Care Nursing. To be included, all participants were either a registered nurse or licensed practical nurse, currently working at least part-time on a long-term care unit, and English-speaking.

\section{Measures}

Background Information. Socio-demographic and nursing background. Sociodemographic information was collected through self-report, and a form requested information about the nurses' age, gender, race/ethnicity, type of nursing degree, type of nursing licensure, full-time or part-time status, the typical shift worked, and the pursuit of a more advanced nursing degree (Appendix A). The nurses were asked to provide the their current job title, number of years worked as a nurse, number of years working in a long-term care environment, number of years working in the current facility, and the name of the facility in which they currently worked. The question about the nurses' job 
title was added in the midst of the study, and a total of 46 individuals did not provide that information.

Facility information. CMS publishes information about nursing homes via the Nursing Home Compare website (CMS, 2014). Several pieces of information were acquired through this public, online resource about each nursing facility: star ratings (overall, health inspection, staffing, quality measures), type of ownership, number of certified beds, number of residents, RN minutes per resident per day, LPN minutes per resident per day, total number of licensed nursing staff minutes per resident per day, CNA minutes per resident per day, percentage of long-stay residents who received an antipsychotic medication, and percentage of short-stay residents who received an antipsychotic medication. The state and national averages for each of these variables were obtained.

Manipulated, Independent Variables. Injunctive norm. Injunctive norms describe what an individual ought to do in a given situation (Cialdini et al., 1990; Reno et al., 1993). Efforts to increase the salience of an injunctive norm against a specific behavior have been found to reduce a range of problematic behaviors (Cialdini et al., 1990; Cialdini et al., 2006; Kallgren, Reno, \& Cialdini, 2000; Reno et al., 1993; Schultz et al., 2007; Schultz, Khazian, \& Zaleski, 2008). Injunctive norms have also been found to more reliably and predictably reduce problematic behaviors than descriptive norms (Cialdini et al., 1990; Cialdini et al., 2006; Reno et al., 1993). Methods to increase the salience of an injunctive norm have frequently relied on written messages embedded in signs, fliers, or posters. Some research has found that a negative language frame ("please don't remove the petrified wood from the park") more effectively reduced a problematic 
behavior than a positive language frame ("please leave petrified wood in the park") (Cialdini et al., 2006).

Nurses were presented with a poster that either did or did not include a salient injunctive norm. In the salient injunctive-norm condition, nurses saw a poster ascribed with the following header, which was printed in red: "Avoid Using Antipsychotics With Our Residents." Below this was a picture of a prescription pad that listed several common antipsychotics used with nursing home residents (Briesacher et al., 2005b) and that was overlaid with a red circle and cross-bar (Appendix B). After seeing the poster, the nurses were asked to answer the following neutral filler question: "Where would nurses most likely see and read this poster in your nursing home?" The answer set was $1=$ break room, 2 = hallway walls, $3=$ medicine carts, $4=$ bathroom, and $5=$ other (please describe location). In the non-salient condition, nurses were presented with information only, and saw a poster ascribed with the following header: "Examples of Antipsychotics" (Appendix C). Below the header was a list of several common antipsychotics used with nursing home residents (Briesacher et al., 2005b). After seeing the poster, the nurses were asked to answer the following neutral filler question: "Where would nurses most likely see and read this poster in your nursing home?" The answer set was $1=$ break room, $2=$ hallway walls, $3=$ medicine carts, $4=$ bathroom, and $5=$ other (please describe location).

As an initial internal validity check, an independent, convenience sample of senior nursing students $(n=79)$ were randomized to the salient and non-salient injunctive-norm conditions. They were then asked the following question: "To what extent does this poster indicate you should avoid using antipsychotics?" A five-point rating-scale $(1=$ not at all; $5=$ very much so $)$ was used to quantify their responses. The 
results suggested that the poster with the salient condition $(\mathrm{M}=4.45, \mathrm{SD}=1.04)$ indicated antipsychotics should be avoided to a greater extent than the poster with the non-salient condition $(\mathrm{M}=1.38, \mathrm{SD}=1.02), F(1,71)=173.06, p<.001, \omega^{2}=.71$.

As an internal validity check within the primary study, the nurses were asked the following question: "Earlier, you were presented with a poster about antipsychotics. To what extent did the poster indicate you should avoid using antipsychotics with your residents?" A five-point rating-scale $(1=$ not at all; 5 = very much so $)$ was used to quantify their responses. The findings are presented in the subsequent Results section.

Sense of Evaluation. In the presence of problematic behaviors, increasing the salience of a descriptive norm will often maintain if not augment the behavior (Cialdini et al., 2006). Furthermore, descriptive norms that conflict with an injunctive norm may be more likely to supersede the injunctive norm's effect in a distressing situation (Fischer et al., 2011; Latané \& Nida, 1981). As a result, presenting information to healthcare providers about the high prevalence of antipsychotic misuse among nursing home residents would likely be counterproductive. However, efforts to counteract the effect of problematic descriptive norms would be beneficial. Researchers have defined accountability cues as signals that indicate to people their behavior can be detected, evaluated, and ascribed to them at an individual level (Prentice-Dunn \& Rogers, 1982; van Bommel et al., 2013). Research has found that a sense of being evaluated can moderate the influence of problematic descriptive norms (Garcia, Weaver, Darley, \& Spence, 2009; Schwartz \& Gottlieb, 1976; van Bommel et al., 2012; van Bommel et al., 2013). One method to increase a sense of being evaluated involved methods wherein 
participants were asked to imagine a scenario in which they could be evaluated (Garcia et al., 2009; Schwartz \& Gottlieb, 1976).

Following from this previous research, the original study proposed that the nurses be exposed to a sense of direct or indirect evaluation. The direct evaluation condition included the following statement: "As part of a new dementia-care program and your annual performance review, imagine that your nurse manager will be evaluating whether you have helped to reduce your facility's use of antipsychotics." The indirect evaluation condition involved the following statement: "As part of a new dementia-care program, imagine that pharmacists will continue to conduct medication reviews." As an initial internal validity check, an independent, convenience sample of senior nursing students ( $n$ = 79) was randomized to one of these two conditions, and asked the following question: "To what extent is this a situation where your work as a nurse would be evaluated?" A five-point rating-scale $(1=$ not at all $; 5=$ very much so $)$ was used to quantify their responses. Two of the nursing students did not provide a response to the question, and the analyzed sample size was 77 . The results indicated that the direct evaluation condition $(\mathrm{M}=3.18, \mathrm{SD}=1.20)$ was not significantly different from the indirect evaluation condition $(\mathrm{M}=3.41, \mathrm{SD}=0.97), F(1,69)=1.26, p=.27, \omega^{2}=.02$.

As a result of the failed internal validity test, the condition was modified such that the salience of the sense of evaluation was manipulated. In the salient evaluation condition, the nurses read the following statement: "As part of a new dementia-care program, imagine that your nurse manager will be monitoring whether you have asked a physician to prescribe an antipsychotic, and that this information will be included in your annual performance review." After the scenario, the nurses were asked to answer the 
following neutral filler question: "How often would you prefer to meet with your nurse manager?" The answer set was $1=$ biweekly, $2=$ monthly, $3=$ quarterly, and $4=$ yearly . In the non-salient evaluation condition, the nurses read the following statement: "As part of a new dementia-care program, imagine that your unit will be emphasizing greater collaboration between nursing and pharmacy." After the scenario, the nurses were asked to answer the following neutral filler question: "How often would you prefer to meet with a pharmacist?" The answer set was $1=$ biweekly, $2=$ monthly, $3=$ quarterly, and $4=$ yearly. A second, independent sample of senior nursing students was not available to test the internal validity of the modified condition.

As an internal validity check in the main study, the nurses were asked the following question: "Earlier, we asked you to imagine a new dementia care program. As part of the program, to what extent did you feel your work as a nurse was to be evaluated?" A five-point rating-scale $(1=$ not at all; $5=$ very much so $)$ was used to quantify their responses. The findings are presented in the subsequent Results section.

Non-manipulated, Independent Variables. Self-efficacy. Self-efficacy is defined as one's "judgments of how well one can execute courses of action required to deal with prospective situations" (Bandura, 1982, p. 122). Following from this definition, this study examined nurses' judgments as to how well they can implement behavioral interventions with a resident with dementia and behavioral disturbances. Two previous studies operationalized and measured staff self-efficacy differently. Cohen-Mansfield and Jensen (2008) had providers indicate how familiar they were with a diverse range of nonpharmacological approaches. Based on Bandura's (2006) suggestions for constructing a self-efficacy scale, the rating of "familiarity" may not accurately tap the construct of self- 
efficacy as self-efficacy is best operationalized in terms of an individual's confidence that s/he can complete a task. Sonntag et al. (2006) used a single item asking the nursing staff to rate "how well do you feel trained for your job." The use of a single, global item is less likely to be a valid measure of self-efficacy because self-efficacy is "not a global trait but a differentiated set of self-beliefs linked to distinct realms of functioning" (Bandura, 2006, p. 307).

Because of these methodological problems, a new scale of staff self-efficacy to implement behavioral interventions was developed using Bandura's (2006) approach. The scale consisted of 12 items reflecting different behavioral interventions nurses may use (Appendix D). The choice of behavioral treatments was based on literature reviews (Brodaty \& Arasaratnam, 2012; Logsdon, McCurry, \& Teri, 2007; O'Neil et al., 2011) and on approaches medical professionals commonly utilize (Cohen-Mansfield \& Jensen, 2008). The choices and wording were further refined through qualitative pilot testing with six long-term care nurses from two facilities. After reading each item, the nurses were asked to rate how confident they were that they could implement each intervention in order to manage the behavioral disturbances of a resident with dementia. The provided scale ranged from 0 to 100 , and included the following descriptive anchors: "cannot do at all" near 0 to 10 , "moderately certain can do" near 40 to 60 , and "highly certain can do" near 90 to 100 . The responses to the items were summed and averaged, and higher values indicate greater self-efficacy to implement behavioral interventions.

Time pressures. Perceived time pressures are commonly reported as a reason why providers choose antipsychotics over behavioral interventions (Cohen-Mansfield et al., 2005; Cornegé-Blokland et al., 2012; Wood-Mitchell et al., 2008), but their association 
with antipsychotic use has not been empirically examined. This study operationalized time pressures as providers' perceived workload, which was measured using the Quantitative Workload Inventory (QWI) ${ }^{1}$ (Spector \& Jex, 1998). The QWI is a measure of perceived amount of work in terms of both volume and pace, and has been administered to a wide range of professions (Spector \& Jex, 1998), including nurses (Klainin, 2009; Unruh \& Zhang, 2013). The scale consists of five items, and respondents are asked to indicate how often each statement occurs using a 5-point rating scale ranging from $1=$ less than once per month or never to $5=$ several times per day. Qualitative pilot testing with six long-term care nurses at two facilities found the anchors to be inadequate. With the permission of the QWI's author, the anchors were changed. The provided scale ranged from 0 to 100, and included five descriptive anchors (Appendix E). Using metaanalytic techniques to examine data from 15 studies of 3,728 participants, the QWI has been shown to be internally consistent (Cronbach's alpha $=0.86$ ). The QWI has demonstrated moderate associations with work hours per week $(r=.33)$, frustration $(r=$ $.46)$, anxiety $(r=.40)$, and role conflict $(r=.38)$, which suggests adequate convergent validity (Spector \& Jex, 1998). In terms of discriminant validity, the QWI has been minimally related to job autonomy $(r=-.04)$ and role ambiguity $(r=.13)$ (Spector \& Jex, 1998). The responses to the items were summed and averaged, and higher values indicate greater time pressures.

Resources. Research has been mixed as to whether objective staffing levels, such as nurse-to-resident ratios, are associated with antipsychotic use (Garrard et al., 1995; Hughes et al., 2000; Shorr et al., 1994; Sonntag et al., 2006; Stevenson et al., 2010;

\footnotetext{
1 ( ) 1997, Paul E. Spector and Steve M. Jex, All rights reserved. The primary author has granted permission to utilize and modify this scale.
} 
Zuidema et al., 2011). However, providers commonly report that low staffing levels prevent them from using behavioral treatments (Cohen-Mansfield et al., 2005; CornegéBlokland et al., 2012; Wood-Mitchell et al., 2008). These findings suggest that there may be a conceptual difference between objective and perceived staffing levels. Consistent with this idea, a study of over 1500 nurses from 68 US hospitals found that the association between perceived and actual staffing levels was small to moderate $(r=-.23)$ (Mark, 2002). Following from these findings, Kramer and Schmalenberg (2005) have argued that perceived staffing reflects the process of providing nursing care within the organizational and physical properties of the care environment, which are reflected in the objective measures of nursing.

The proposed model defined resources as the environmental supports required to implement a treatment approach for a disruptive behavior. For the purpose of this study, resources were operationalized as perceived adequacy of staffing. Similar to Mark's (2002) work, perceived adequacy of staffing was measured using a single item, and following the recommendations of Kramer and Schmalenberg (2005), the item specified what the staffing is adequate to accomplish. The item read "Inadequate staffing hinders my ability to manage behavioral disruptions without medications." The nurses were asked to indicate the degree to which they agreed with the statement using a 5-point rating scale ranging from $1=$ strongly disagree to $5=$ strongly agree $($ Appendix $\mathrm{F})$.

Descriptive norm. Descriptive norms describe what most people do in a situation (Cialdini et al., 1990; Reno et al., 1993), and they have been found to influence a range of behaviors (Cialdini et al., 1990; Cialdini et al., 2006; Fischer et al., 2011; Goldstein et al., 2008; Haines \& Spear, 1996; Schultz, 1998; Schultz et al., 2007). Methods to increase 
people's awareness of a descriptive norm have included priming methods. For example, after being asked to imagine the presence of others, participants' behavior changed in line with a descriptive norm (Garcia et al., 2002; Garcia et al., 2009; Schwartz \& Gottlieb, 1976). A large meta-analysis found that the implied presence of others had a reliable and moderate effect ( $g=-0.47)$ on helping behavior (Fischer et al., 2011).

This study used a priming method to increase the nurses' awareness of their facility's descriptive norm regarding the management of behavioral difficulties. In the instructions for the case study, the nurses were asked to "Please imagine that this case is about a resident living at your facility. After reading the following case study, think about how you would handle a case like this as a nurse at your facility." Consistent with previous measures of perceived descriptive norms (e.g., Haines \& Spear, 1996; Nolan, Schultz, Cialdini, Goldstein, \& Griskevivius, 2008; Perkins, Haines, \& Rice, 2005), the nurses were asked to estimate the prevalence of antipsychotic use at their facility and to estimate the percentage of other nurses at their facility who would request an antipsychotic or try a behavioral intervention (Appendix G). The nurses provided a response from 0 to 100 . This measure was included immediately after completion of the case study.

Additionally, this study used each facility's rate of antipsychotic use to quantify the descriptive norm. Previous research has shown that higher facility rates of antipsychotic use are predictive of higher rates of antipsychotic use among newly admitted nursing home residents independent of facility differences in resident and clinical characteristics (Chen et al., 2010). Researchers have interpreted these findings as suggestive of a shared and persistent prescribing pattern (Chen et al., 2010; Grunier \& 
Lapane, 2008; Tjia et al., 2012), which is consistent with the social psychological construct of descriptive norms.

A potential limitation of this measure (actual facility rates of antipsychotic use) is that a facility's descriptive norm could change between when the rate was posted and the nurses participated in the study. For example, since the most recent listing, a facility may have implemented a new antipsychotic-reduction program. In order to measure and control for this possibility, the nurses were asked the following question: "In the last six months, has your facility implemented a new program or changed its policies in order to reduce antipsychotic use and increase the use of behavioral interventions?" The nurses were asked to respond either "yes" or "no" and to specify the nature of any changes. The nurses were asked "Has your own practice of using antipsychotics changed in the past six month" and then asked "Has your own practice of using behavioral interventions changed in the past six months?" The nurses could respond "yes" or "no" and were asked to specify the nature of any changes in their practices. Six months was chosen because the available data on CMS's Nursing Home Compare website was six months behind at the start of the study. After completion of the study, the facility data was downloaded in August 2015, and the data was current as of March 31, 2015, which was within the estimated six month window.

Attitudes and Outcome Expectancies. Attitudes are defined as people's positive or negative judgments about an object or action, and they can influence people's behavioral intentions (Ajzen 1991; 2001). Previous research has found that nursing home providers favor behavioral treatments over psychotropic medications (Burgio et al., 1992; Cohen-Mansfield \& Jensen, 2008; Cohen-Mansfield et al., 2011), but nonetheless, they 
retain positive attitudes towards psychotropic medications (Anthierens et al., 2009; Burgio et al., 1992). The influence of providers' attitudes on their behavioral intentions has not been subjected to empirical examination. This study used a 6-item scale to assess the nurses' attitudes towards antipsychotics and behavioral interventions. The item content was based on or modified from the work of Anthierens et al. (2009), Burgio et al. (1992), Cohen-Mansfield and Jensen (2008), and Cohen-Mansfield et al. (2011). The nurses rated the extent to which they agreed with each statement using a 5-point rating scale from $1=$ strongly disagree to $5=$ strongly agree (Appendix H). The 3 items reflecting attitudes towards antipsychotic were summed and averaged, and the same occurred with the three items reflecting attitudes towards behavioral interventions. Higher scores reflect more favorable attitudes towards antipsychotics or behavioral interventions.

Outcome expectancies are defined as a "person's estimate that a given behavior will lead to certain outcomes" (Bandura, 1977, p. 193). Some research has found that medical professionals believe psychotropic medications are effective at treating NPS (Cornegé-Blokland et al., 2012). Providers' outcome expectancies regarding antipsychotics and behavioral interventions have largely been understudied and not examined empirically. A scale of outcome expectancies was developed for this study. Previous research has highlighted the possibility that the following outcomes may impact providers' decisions: the likelihood an intervention will be associated with behavioral changes or side effects (Anthierens et al., 2009; Cohen-Mansfield et al. 2005; CornegéBlokland et al., 2012; Wood-Mitchell et al., 2008), amount of time to implement an intervention (Cohen-Mansfield et al., 2005; Cornegé-Blokland et al., 2012; Wood- 
Mitchell et al., 2008), provider distress (Zuidema et al., 2011), and whether the intervention improves the ability of nurses to provide care (Anthierens et al., 2009). Utilizing these findings, the scale included twelve possible outcomes that may be associated with antipsychotics and behavioral interventions (Appendix I). The nurses were asked to rate the extent to which they believe each outcome would occur. A 5-point rating scale was provided ranging from $1=$ strongly disagree to $5=$ strongly agree. The format and answer key were partially based on another measure designed to examine nursing assistants' outcome expectancies for restorative care activities (Resnick, Galik, \& Rogers, 2008; Resnick \& Simpson, 2003). The items were summed and averaged separately for antipsychotics and behavioral interventions. Higher scores indicate the belief that antipsychotics or behavioral interventions are associated with more favorable outcomes.

Dependent Variable. Behavioral intentions encapsulate an individual's plans and motivation to perform a behavior, and are influential predictors of human behavior (Ajzen, 1991; Armitage \& Conner, 2001). Theoretical work has differentiated goal and implementation intentions (Gollwitzer, 1999). Goal intentions indicate an end point, and are commonly phrased as "I intend to achieve $x$." Implementation intentions are subordinate to goal intentions, and they specify when, where, or how a response will occur. They are commonly phrased as "I intend to do $y$ when situation $z$ is encountered." Empirical work has found that implementation intentions are more predictive of subsequent behavior than goal intentions (Gollwitzer \& Brandstätter, 1997).

The primary outcome of this study was the nurses' implementation intentions. Each nurse was presented with a case study, which standardized the encountered situation 
(Appendix J). The details of the case study were based on known predictors of antipsychotic use. More specifically, younger residents, especially those less than 75 years old (Chen et al., 2010; Rochon et al., 2007; Stevenson et al., 2010), and residents with dementia are more likely to receive an antipsychotic (Briesacher et al., 2005b; Stevenson et al., 2010). Moderate to severe behavioral problems (Chen et al., 2010) and verbal and physical aggression, restlessness, unsociability, and uncooperativeness (Briesacher et al., 2005b) are associated with antipsychotic use.

After reading the case study, the nurses were asked two questions. First, they were asked to rate the likelihood they would call a physician and request an antipsychotic. A 10-point rating scale was provided ranging from $1=$ not at all likely to $10=$ highly likely . Second, they were asked to the rate the likelihood they would try a different behavioral intervention with the resident. The same 10-point rating scale was provided after this question.

\section{Procedures}

The administrators of the University of Louisville School of Nursing were asked permission to recruit nursing students from their program for the internal validity study. After receiving administrative approval, the research team recruited the students en masse at the end of a class. The students were given a verbal and written description of the study. Consent was obtained through the students' completion of the packet. The nursing students were randomized to one of four conditions wherein they received one of the four posters/scenarios. A simple randomization pattern was applied to the packets.

The administrators and directors of nursing (DON) of metro-Louisville nursing homes were contacted, and informed of the study's aims and protocol. After receiving 
approval, the research team worked with the DON to determine appropriate times for recruiting nurses. Nurses recruited in person were provided a verbal and written description of the study. The nurses provided consent by completing the packet. Given the brevity of the packet, the team encouraged the nurse to complete packet then; however, if the nurse could not complete the packet then, the team member coordinated a time and location to pick it up. This arrangement was not a concern because no identifying information about the nurse was included on the packet. In the case of nurses recruited through advertisements distributed among the professional nursing organizations, the advertisement included a hyperlink to an online version of the study. After entering the hyperlink, the nurses were presented with a written description of the study's purpose and procedures. The nurses provided consent by completing the online survey, which was developed through Qualtrics' website. The length of time to complete the packet varied by nurse and situation, but the reported length was typically 15 to 25 minutes.

The nurses were randomized to one of four conditions within a two (injunctive norm: salient vs. not salient) by two (sense of evaluation: salient vs. not salient) betweenparticipants design. The order of the conditions was also systematically varied. For nurses recruited in person, a simple randomization pattern was applied to the packets. Before distribution, the printed packets were labeled as " 1 " through " 8 " and using a computerbased random-number generator, the packets were placed in a random order. Similarly, the Qualtrics-based survey randomly assigned participants to one of the four conditions. After the outcome measure, some of the independent-variable measures (self-efficacy, time pressures, perceived staffing) were counterbalanced, and were followed by the 
questions testing internal validity and recent changes in policies and practices surrounding antipsychotic and behavioral intervention use. The descriptive-norm measures were always presented immediately after the outcome measure. Because of the nurses' time limitations, the attitudes and outcome expectancy measures were optional.

Pilot testing revealed that nurses often discussed the study amongst their colleagues who had not participated in the pilot. To help reduce the chance these conversation influenced the responses of subsequent participants, the nurses were asked not to talk about the study with their colleagues until the study was completed.

The Institutional Review Board of the University of Louisville reviewed and approved this study.

\section{Data Analyses}

Data were analyzed using IBM's SPSS 22.0, SAS, and R. Data from the paperbased and online surveys were analyzed together. Descriptive statistics were conducted for all of the variables to examine for normality, outliers, and missing data. The type of nursing degree variable was left out of the analyses because it was found to be unreliable. At the conclusion of the study, it was discovered that the original survey did not include LPN certificate as an option. Without the option, some nurses with LPN licenses skipped the item, and others checked ADN, which is inaccurate. The reliability of the self-

efficacy, time pressures, attitudes, and outcome expectancies scales were computed with Cronbach's $\alpha$ and omega. Omega is a measure of internal consistency with fewer assumptions and biases than Cronbach's $\alpha$. For a conceptual overview of omega, its relative advantages, and the procedures used to calculate it for this study, see Dunn, Baguley, and Brunsden (2014). Confidence intervals for Cronbach's $\alpha$ and omega were 
calculated based on the work of Iacobucci and Duhachek (2003) and Dunn et al., (2014), respectively. Corrected item-total correlations were provided to supplement the reliability statistics. Items with non-significant or low correlations were excluded from the scales after consideration of their conceptual relevance. The interrelationships of the independent and dependent variables was computed utilizing parametric and nonparametric statistics. A two-tailed alpha was set at .05 for all tests.

\section{Analyses for Aims 1 through 3}

Multiple nurses were recruited from the same nursing home, and it was expected their responses would be correlated. In order to correct for this dependency, a multi-level modeling approach was employed using restricted maximum likelihood (REML). The significance of fixed effects was evaluated with Wald tests (e.g., estimate/standard error) with Satterhwaite denominator degrees of freedom. Participants were randomized to one of four conditions within a two (injunctive norm: salient vs. not salient) by two (sense of evaluation: salient vs. not salient) between-participants design, and this design was tested based on the main effect of an injunctive norm (Hypothesis 1), main effect of a sense of evaluation (Hypothesis 3), and their interactive effect (Hypothesis 4) on nurses' intentions to initiate an antipsychotic. The four conditions were dummy coded into three variables, and then entered into a model. Facility effects were modeled as a random effect (level-2 random intercept variance), which corrected for any dependency resulting from recruiting nurses of the same facility. An identical multi-level model was conducted to test the main effect of an injunctive norm (Hypothesis 1) on nurses' intentions to initiate a behavioral intervention, and whether a sense of evaluation moderates the effect of an injunctive norm (Hypothesis 5). The behavioral intervention initiation responses were 
negatively skewed, and were subjected to reflection and then a logarithmic transformation. In order to test hypothesis 2 , the self-efficacy variable and an interaction term of self-efficacy by injunctive norm were added to the original models for initiating an antipsychotic and a behavioral intervention. The self-efficacy variable was negatively skewed, and subjected to reflection and then a square-root transformation. Post-hoc analyses were conducted using a multi-level modeling approach.

\section{Analyses for Aim 4}

Hypothesis 6 specifies that perceived time pressures would be associated with nurses' intentions to request an antipsychotic or try a behavioral intervention. A multilevel model examined whether the independent variable, perceived time pressures, predicted nurses' intentions to either use an antipsychotic or a behavioral intervention. The time pressures variable was negatively skewed, and was reflected and then logarithmically transformed. The manipulated independent variables were not included in the model because they were not associated with both outcomes.

A multi-level model was used to determine whether the independent variable, perceived resources, predicted nurses' intentions to use an antipsychotic or a behavioral intervention (Hypothesis 7). The staffing variable was dummy coded with the reference value being individuals who indicated they were undecided. The manipulated independent variables were not included in the model because they were not related to both outcomes. A sensitivity analysis controlled for the effects of the perceived descriptive norm regarding antipsychotic use, recent facility program or policy changes, nursing characteristics (pursuing advanced degree, race, shift, years as a nurse, job title), 
and a facility characteristic (total number of licensed nursing staff minutes per resident per day).

Hypothesis 8 suggested that self-efficacy mediates the relationship between perceived time pressures and resources and nurses' intentions to request an antipsychotic or a behavioral intervention. Mediation analyses were to be conducted within a multilevel model. In order to test for mediation, the following equations were to be tested: 1) regression of the mediator on the independent variable; 2) regression of the dependent variable on the independent variable; 3 ) regression of the dependent variable on both the independent variable and the mediator (Baron \& Kenny, 1986). Mediation would be indicated when the association between the independent variable and dependent variable is reduced or becomes non-significant after controlling for the effects of mediator on the dependent variable.

\section{Exploratory Analyses for Aims 1a and 2a}

Hypothesis E1 anticipated that perceived and actual facility rates of antipsychotic use would moderate the effect of an injunctive norm on nurses' intentions to initiate an antipsychotic or a behavioral intervention. In two separate models, an interaction variable of perceived or actual facility rates by injunctive norm was created and then added to the original model. In a test of Hypothesis E2, multi-level models were utilized wherein an interaction term for perceived or actual facility rates by sense of evaluation was added. The models examining the actual facility rates of antipsychotic use controlled for any recent changes in their facility's descriptive norm by entering a dummy-coded variable that measured whether the facility had implemented a new program or policy surrounding the use of antipsychotics and behavioral interventions in the past six months. 


\section{Power and Sample Size}

\section{Hypotheses 1, 3, 4, and 5}

These hypotheses were analyzed within two separate models, each with injunctive norms (salient vs. not salient), sense of evaluation (salient vs. not salient), and their interaction as predictors. Previous research into injunctive norms has found their influence to vary from small-to-medium (Cramer's V $=.2$; Reno et al., 1993) to mediumto-large (Cohen's $d=.6$; Schultz et al., 2007), and these effects were found in the context of littering behavior and electricity usage, respectively. Prior research evaluating the effect of a sense of evaluation indicated its influence varied from medium $\left(\omega^{2}=.064\right.$; van Bommel et al., 2012) to large ( $\mathrm{OR}=.216$; van Bommel et al., 2013), when examining the outcomes of sending help messages on an internet forum and whether someone reported a staged robbery, respectively. No studies have examined the interaction of an injunctive norm and sense of evaluation, and none have tested these principles with nurses or within a nursing home. Based on previous results, this study expected there to be a medium effect for an injunctive norm and sense of evaluation, and surmised a medium effect for their interaction. The analyses involved entering dummy coded versions of the four conditions into a multiple regression equation with a continuous variable as the dependent variable. For a multiple linear regression analysis with three predictors, G*Power analyses demonstrated that a sample size of 77 was needed to detect a medium effect size $\left(\mathrm{f}^{2}=.15\right)$ with a power of .80 and a type-I error rate of .05 (Faul, Erdfelder, Lang, \& Buchner, 2009). In order to correct for the effects of clustering, the previous regression equation was conducted within a multilevel model. Several studies (e.g., Chen et al., 2010; Rochon et al., 2007; Stevenson et al., 2012) examining models predicting 
antipsychotic use in nursing homes have not reported the intra-class correlation coefficient (ICC), but Zuidema et al. (2011) reported an ICC of .07 in their model predicting antipsychotic use based on patient-level and facility-level factors. Assuming an ICC of .07 and an average of 10 nurses were recruited from each facility, the sample size of 77 was expected to be inflated by a factor of $1+(10-1)(.07)=1.63$. Thus, a total sample size of 126 nurses (1.63 x 77) was required to achieve adequate power.

\section{Hypothesis 2}

This hypothesis was tested by adding self-efficacy and its interaction with injunctive norms to the original model. In a meta-analytic review of the TPB, Armitage and Conner (2001) found that perceived behavioral control was significantly associated with behavioral intentions $(r=.43)$, and when examining self-efficacy, they found a similar association with intentions $(r=.44)$. A meta-analytic review of predicting healthcare providers' intentions and behavior using the TPB found self-efficacy was significantly associated with their behavioral intentions ( $r=.46$; Godin et al., 2008). Based on these studies, it was assumed self-efficacy would have at least a medium effect within this study. G*Power analyses revealed that in order to find a medium effect size $\left(\mathrm{f}^{2}=.15\right)$ for five predictors with a power of .80 and type-I error rate of .05 , a sample of 92 would be required (Faul et al., 2009). In order to correct for the effects of clustering, the sample size of 92 was multiplied by a factor of 1.63 , which resulted in a total sample size of 150 .

\section{Hypotheses 6, 7, 8}

In order to test Hypothesis 6, perceived time pressures was added to the original model, which was expected to control for the two manipulated variables. In a study of 
whether seminary students help a person in need, Darley and Batson (1973) found that perceived time pressures were significantly related to reduced helping behavior $(r=-.37)$. When examining healthcare providers' compliance with handwashing guidelines, Pittet et al. (1999) demonstrated that the odds of non-compliance were greater in units with high activity levels than units with low activity levels $(\mathrm{OR}=2.12)$. No research has empirically examined the role of time pressures on antipsychotic use. Assuming time pressures will have a similar influence, this study expected time pressures to have a medium effect. In order to find a medium effect size $\left(\mathrm{f}^{2}=.15\right)$ for four predictors with a power of .80 and type-I error rate of $.05, \mathrm{G} *$ Power analyses demonstrated that a sample of 85 would be necessary (Faul et al., 2009). After correcting for the effects of clustering by a factor of 1.63 , a total sample size of 139 was necessary.

Hypothesis 7 predicted that perceived staffing would be associated with the use of antipsychotics and behavioral interventions after controlling for the manipulated variables. Prior work has utilized objective measures of staffing, and the results have been mixed (Garrard et al., 1995; Hughes et al., 2000; Shorr et al., 1994; Sonntag et al., 2006; Stevenson et al., 2010; Zuidema et al., 2011). Because perceptions of staffing may be conceptually different from objective measures, the use of effect sizes from these studies could be problematic. To the knowledge of this author, the role of perceived staffing has only been studied qualitatively when evaluating nursing home nurses' behavior. The study assumed perceived staffing would have a medium effect. With a power of .80 and a type-I error rate of $.05, \mathrm{G} *$ Power analyses indicated that a sample of 85 would be necessary to evidence a medium effect size $\left(\mathrm{f}^{2}=.15\right)$ (Faul et al., 2009). After correcting for clustering, a total sample size of 139 was necessary. 
Hypothesis 8 expanded on Hypotheses 6 and 7 by introducing self-efficacy as a mediating factor. In order to test the third regression equation based on Baron and Kenny's (1986) approach, a total of five predictors were to be added. Two were expected to account for self-efficacy and either perceived resources or time pressures, and three were expected to account for the manipulated variables and their interaction. Assuming a medium effect for these variables, $G *$ Power analyses suggested that a sample of 92 was required with a power of .80 and type-I error rate of .05 (Faul et al., 2009). A total sample of 150 was needed after correcting for the effects of clustering. 


\section{RESULTS}

\section{Sample characteristics}

In the greater Louisville area, twenty-six facilities were contacted regarding the

study, and eleven agreed to allow recruitment. Two declined to participate due to lack of time, one because of too few dementia patients, and one did not specify a reason. The other eleven facilities did not respond to phone and e-mail messages. In the 11 participating facilities, 256 nurses were approached to participate in the study. Seventeen nurses declined to participate due either to a lack of time $(n=8)$ or interest $(n=9)$. Of the 239 nurses who received a survey, 137 completed the survey for an overall response rate of $53.5 \%$.

Eight state and national nursing organizations were contacted for recruitment purposes. Two organizations (The National Association Directors of Nursing Administration Long Term Care and the American Association for Long Term Care Nursing) agreed to distribute the survey. Two organizations declined due to membership issues; one did not allow the distribution of research surveys through their listserv; three did not respond. Through the two organizations, twenty-one nurses responded to the email advertisement, and completed the online version of the survey. Three nurses began the survey but did not complete it. Neither organization responded to requests for information about the number of individuals on their listserves.

The final sample included 158 nurses working in long-term facilities, who were recruited from March 2015 to August 2015. The sample's mean age was 41.69 years (SD 
$=11.06)$, and the majority of the nurses were female $(88.6 \%)$ and white $(74.7 \%)$. The sample was split between LPNs (55.1\%) and RNs (43.0\%), and included two APRNs (1.3\%). About one-third of the sample (31.6\%) was seeking a more advanced degree, mostly either an ADN or BSN. The nurses worked a wide range of positions, including as a floor nurse $(34.8 \%)$, charge nurse $(16.5 \%)$, and administrative nurse $(19.0 \%)$. The majority worked full-time $(94.3 \%)$ during either a 12-hour day shift (31\%) or an 8-hour first shift $(50.0 \%)$. The nurses had practiced a median of 10.00 years (IQR $=5.00$ to $21.75)$ as a nurse. They had worked a median of 10.00 years (IQR $=5.00$ to 18.00$)$ in the long-term care environment and a median of 3.00 years (IQR $=.75$ to 10.00$)$ in their current facility.

The majority of the nurses $(n=153)$ worked in one of 28 facilities providing long-term care services. Two of the nurses worked in a local hospice group that consulted across multiple facilities, and three nurses did not provide identifying information about their facilities. Among the 25 facilities with available information through the CMS Nursing Home Compare website, the median size was 107 beds (IQR = 78.50 to 123.00) with a median of 90.00 residents (IQR $=56.50$ to 115.00$)$. The facilities' ownership was diverse with $41.4 \%$ for-profit, $31.0 \%$ non-profit, and $13.8 \%$ government-owned. The median overall CMS star rating was $3.00(\mathrm{IQR}=1.50$ to 4.00$)$, indicating average overall quality of care. The median staffing CMS star rating was $3.00(\mathrm{IQR}=3.00$ to 4.00$)$ across the facilities. The mean total number of licensed nursing staff minutes per resident per day was $92.56(\mathrm{SD}=29.05)$, and the median CNA minutes per resident per day was 153.00 (IQR $=136.50$ to 177.00$)$. In comparison, facilities across the United States averaged 101 licensed nursing staff minutes per resident per day and 148 CNA minutes 
per resident per day. Among long-term residents, an average of $16.58 \%$ residents of these facilities ( $\mathrm{SD}=6.37$ ) were on an antipsychotic, and a median of $1.05 \%$ of short-stay residents (IQR $=.60$ to 2.25$)$ were on an antipsychotic. In comparison, the national average of antipsychotic use among long-stay residents is $19.00 \%$ and among short-stay residents is $2.30 \%$.

\section{Variable descriptive statistics}

Dependent variables. Table 1 shows the descriptive statistics of all study dependent and independent variables. The participating nurses indicated they were somewhat likely to request an antipsychotic and were highly likely to initiate a new behavioral intervention when presented with a case study about a resident with dementia experiencing behavioral difficulties.

Independent variables. The participating nurses tended to agree that inadequate staffing hinders their ability to manage behavioral disruptions without medications. The nurses were asked three questions about their facilities' descriptive norms regarding interventions for residents with dementia and behavioral disturbances. They believed about half of nurses at their facility would request an antipsychotic for the resident in the case study, and that about half of nurses at their facility would try a different behavioral intervention. The nurses reported a quarter of their residents were on an antipsychotic, which on average is higher than the mean rates of antipsychotic use for the sample's facilities.

The nurses completed twelve items assessing their confidence to implement behavioral interventions, and they reported moderate-to-high levels of self-efficacy. The internal consistency of the self-efficacy scale was good-to-excellent, $\Omega=.89,95 \% \mathrm{CI}$ 
[.85 .93] or Cronbach's $\alpha=.90,95 \%$ CI [.87 .92]. The corrected item-total correlations ranged from .46 to .72 .

Across five items measuring perceived time pressures, the nurses reported moderate-to-high time pressures. The internal consistency was good, $\Omega=.84,95 \% \mathrm{CI}$ [.79 .88] or Cronbach's $\alpha=.83,95 \%$ CI [.79 .88]. Spector and Jex, (1998) reported a similar internal consistency value (Cronbach's $\alpha=0.86$ ) for the Quantitative Workload Inventory (QWI), which provided the item content for the scale reported here. The corrected item-total correlations ranged from .58 to .75 .

A little over half of the nurses denied any changes to their facilities' programs or policies regarding the use of antipsychotics or behavioral interventions over the past six months. The majority of the nurses also denied any changes in their own practices employing antipsychotics or behavioral interventions over the past six months.

The nurses completed three items assessing their attitudes towards antipsychotics and three items regarding their attitudes towards behavioral interventions. The nurses' attitudes towards antipsychotics were neither favorable nor unfavorable. The internal consistency was acceptable-to-good, $\Omega=.80,95 \%$ CI [.71 .86] or Cronbach's $\alpha=.80$, 95\% CI [.73 .86]. The corrected item-total correlations ranged from .58 to .69. Their attitudes towards behavioral interventions were favorable. The internal consistency was acceptable, $\Omega=.75,95 \%$ CI [.63 .82] or Cronbach's $\alpha=.75,95 \%$ CI [.67 .83]. The corrected item-total correlations ranged from .56 to .60 .

The nurses were presented with twelve items assessing their outcome expectancies of antipsychotics for residents with dementia. Three items (associated with serious side effects, difficult to implement on nights and weekends, and less effective on 
nights and weekends) were found to be non-significantly or minimally correlated with the other items, and were dropped from subsequent analyses, leaving nine items for analysis. The nurses' outcome expectancies of antipsychotics were, on average, neither positive nor negative. The internal consistency was acceptable, $\Omega=.78,95 \%$ CI [.68 .85] or Cronbach's $\alpha=.79,95 \%$ CI [.73 .84]. The corrected item-total correlations ranged from .35 to .59 .

The nurses completed twelve items examining their outcome expectancies of behavioral interventions for residents with dementia. Four items (associated with serious side effects, treat the etiology of the behavior, difficult to implement on nights and weekends, and less effective on nights and weekends) were found to be non-significantly or minimally correlated with many of the other items, and were dropped from subsequent analyses, leaving eight items for analysis. Their outcome expectancies of behavioral interventions were slightly positive. The internal consistency was good, $\Omega=.82,95 \% \mathrm{CI}$ [.75 .87] or Cronbach's $\alpha=.83,95 \%$ CI [.78 .87]. The corrected item-total correlations ranged from .39 to .72 .

Table 1. Independent and dependent variables' descriptive statistics

\begin{tabular}{|c|c|c|c|c|}
\hline Variable & $n^{1}$ & $\begin{array}{c}\text { Mean } \\
\text { (Median) }\end{array}$ & $\begin{array}{l}\text { Std Dev } \\
(I Q R)\end{array}$ & Range \\
\hline $\begin{array}{l}\text { Likelihood would request an } \\
\text { antipsychotic }\end{array}$ & 158 & 5.33 & 2.77 & 1.00 to 10.00 \\
\hline $\begin{array}{l}\text { Likelihood would try a different } \\
\text { behavioral intervention }\end{array}$ & 158 & $\begin{array}{l}8.15 \\
(9.00)\end{array}$ & $\begin{array}{c}2.00 \\
(7.00 \text { to } 10.00)\end{array}$ & 1.00 to 10.00 \\
\hline Perceived inadequate staffing & 158 & $\begin{array}{c}3.47 \\
(4.00)\end{array}$ & $\begin{array}{c}1.34 \\
(2.00 \text { to } 5.00)\end{array}$ & 1.00 to 5.00 \\
\hline $\begin{array}{l}\text { Self-efficacy to implement behavioral } \\
\text { interventions }\end{array}$ & 153 & $\begin{array}{c}82.69 \\
(85.00)\end{array}$ & $\begin{array}{c}14.94 \\
(73.33 \text { to } 94.58)\end{array}$ & 16.67 to 100.00 \\
\hline Perceived time pressures & 156 & 71.56 & 18.40 & 20.00 to 100.00 \\
\hline
\end{tabular}




\begin{tabular}{|c|c|c|c|c|}
\hline Variable & $n^{1}$ & $\begin{array}{c}\text { Mean } \\
\text { (Median) }\end{array}$ & $\begin{array}{c}\text { Std Dev } \\
(I Q R)\end{array}$ & Range \\
\hline \multicolumn{5}{|l|}{ Perceived descriptive norms } \\
\hline $\begin{array}{l}\% \text { other nurses request an } \\
\text { antipsychotic }\end{array}$ & 155 & 55.70 & 28.92 & 0.00 to 100.00 \\
\hline $\begin{array}{l}\% \text { other nurses try a new } \\
\text { behavioral intervention }\end{array}$ & 155 & 53.47 & 27.76 & 0.00 to 100.00 \\
\hline $\begin{array}{l}\% \text { of residents on an } \\
\text { antipsychotic }\end{array}$ & 139 & $\begin{array}{l}36.72 \\
(25.00)\end{array}$ & $\begin{array}{c}25.89 \\
(15.00 \text { to } 52.00)\end{array}$ & 2.00 to 99.00 \\
\hline \multicolumn{5}{|l|}{ Practice changes } \\
\hline \multicolumn{5}{|c|}{ Change in facility programs or policies } \\
\hline Yes & 57 & $36.1 \%$ & -- & -- \\
\hline No & 93 & $58.9 \%$ & -- & -- \\
\hline \multicolumn{5}{|l|}{ Change in own use of antipsychotics } \\
\hline Yes & 36 & $22.8 \%$ & -- & -- \\
\hline No & 116 & $73.4 \%$ & -- & -- \\
\hline \multicolumn{5}{|l|}{$\begin{array}{l}\text { Change in own use of behavioral } \\
\text { interventions }\end{array}$} \\
\hline Yes & 50 & $31.6 \%$ & -- & -- \\
\hline No & 101 & $63.9 \%$ & -- & -- \\
\hline \multicolumn{5}{|l|}{ Attitudes } \\
\hline Towards antipsychotics & 121 & 2.80 & 0.97 & 1.00 to 5.00 \\
\hline Towards behavioral interventions & 121 & $\begin{array}{c}4.16 \\
(4.00)\end{array}$ & $\begin{array}{c}0.69 \\
\text { (3.67 to } 5.00)\end{array}$ & 2.33 to 5.00 \\
\hline \multicolumn{5}{|l|}{ Outcome expectancies } \\
\hline For antipsychotics & 124 & 3.08 & 0.66 & 1.22 to 4.78 \\
\hline For behavioral interventions & 123 & 3.50 & 0.68 & 1.63 to 5.00 \\
\hline \multicolumn{5}{|c|}{ Abbreviations: IQR: interquartile range; n: sample size; Std Dev: standard deviation } \\
\hline $\begin{array}{l}\text { Notes: } \\
{ }^{1} \text { Sample sizes vary due to missing }\end{array}$ & & & & \\
\hline
\end{tabular}

\section{Interrelationships of independent variables}

Table 2 shows the interrelationships of all the independent variables. Nurses with heightened perceptions of inadequate staffing had lower self-efficacy to implement behavioral interventions, $r_{s}=-.24, p=.003$, and believed fewer nurses at their facility would try a different behavioral intervention, $r_{s}=-.19, p=.02$. Increased perceptions of 
inadequate staffing were associated with greater perceived time pressures, $r_{s}=.28, p<$ .001 , and more favorable outcome expectancies of antipsychotics, $r_{s}=.27, p=.002$. Nurses who reported their facility had implemented a new program or policy to reduce antipsychotics or increase the use of behavioral interventions in the past six months $(M d n$ $=3.00$ ) had reduced perceptions of inadequate staffing compared to those did not report such a program or policy $(M d n=4.00), U=2026.50, z=-2.487, p=.01, r=-.20$.

Nurses who believed a greater percentage of the residents in their facility were on an antipsychotic were more likely to believe a higher percentage of nurses in their facility would request an antipsychotic, $r_{s}=.35, p<.001$, to have more positive attitudes towards antipsychotics, $r_{s}=.31, p=.001$, and to have more favorable outcome expectancies of antipsychotics, $r_{s}=.31, p=.001$. If a nurse believed the percentage of residents in their facility on an antipsychotic was higher, s/he was more likely to have a more negative attitude towards behavioral interventions, $r_{s}=-.21, p=.03$. Beliefs about the base rate of antipsychotic use varied between nurses who reported their facility had implemented a new program or policy to reduce antipsychotics or increase the use of behavioral interventions in the past six months $(M d n=20.00)$ and those did not report a new program of policy $(M d n=40.00), U=1544.50, z=-2.75, p=.006, r=-.24$. The nurses' beliefs about the percentage of other nurses in their facility who would request an antipsychotic were negatively related to their beliefs about how many other nurses in their facility would try a new behavioral intervention, $r=-.54, p<.001$.

Nurses with a more positive attitude towards antipsychotics were more likely to have a more negative attitude towards behavioral interventions, $r_{s}=-.61, p<.001$, and less favorable outcome expectancies of behavioral interventions, $r=-.33, p<.001$. Their 
attitudes towards antipsychotics were positively associated with their outcome expectancies of antipsychotics, $r=.21, p=.02$. Attitudes towards antipsychotics were more negative among nurses whose facility had implemented a new program or policy $(M=2.26)$ than those whose facility had not $(M=3.15), r_{p b}=-.45, p<.001$. Similarly, attitudes towards antipsychotics were more negative among nurses who had changed their use of behavioral interventions $(M=2.48)$ than those who had not $(M=2.94), r_{p b}=$ $-.22, p=.02$.

Nurses' attitudes towards behavioral interventions were negatively correlated with perceived time pressures, $r_{s}=-.23, p=.01$, and their beliefs about the percentage of nurses in their facility who would initiate an antipsychotic, $r_{s}=-.20, p=.03$. Attitudes towards behavioral interventions were more favorable among nurses whose facility had implemented a new program or policy $(M d n=4.67)$ than those whose facility had not $(M d n=4.00), U=916.00, z=-3.80, p<.001, r=-.35$.

Nurses with more favorable outcome expectancies of behavioral interventions typically had a more positive attitude towards behavioral interventions, $r_{s}=.53, p<.001$, and were more likely to believe other nurses in their facility would utilize a new behavioral intervention, $r=.20, p=.03$. Nurses with more favorable outcome expectancies of antipsychotics were more likely to believe other nurses in their facility would request an antipsychotic, $r=.21, p=.02$.

There was a significant association between whether a nurse had changed his/her own practice of using antipsychotics in the past six months and whether a facility had implemented a new program or policy to reduce antipsychotic use or increase the use of behavioral interventions, $\chi^{2}(1)=14.32, p<.001$. The odds a nurse changed his/her 
practice of using antipsychotics were 4.45 times higher if the facility had implemented a new policy or program than if the facility had not. There was a significant relationship between whether a nurse changed his/her own practice of using behavioral interventions in the past six months and whether a facility had implemented a new program or policy, $\chi^{2}(1)=18.57, p<.001$. The odds of a nurse changing his/her practice of using behavioral interventions were 4.77 times higher if the facility had implemented a new policy or program than if the facility had not. There also was a significant association between whether a nurse had changed his/her own practice of using antipsychotics in the past six months and whether the nurse had changed his/her own practice of using behavioral interventions, $\chi^{2}(1)=45.22, p<.001$. The odds of a nurse changing his/her practice of using antipsychotics was 17.09 times higher if the nurse had changed his/her practices with behavioral interventions than if the nurse had not. 
Table 2. Interrelationships of independent variables

\begin{tabular}{|c|c|c|c|c|c|c|c|c|c|c|c|c|c|}
\hline & Staff & S-E & Time & $\begin{array}{c}\text { Other } \\
\text { Anti }\end{array}$ & $\begin{array}{c}\text { Other } \\
\text { Beh }\end{array}$ & $\begin{array}{l}\text { Resi } \\
\text { Anti }\end{array}$ & $\begin{array}{c}\text { Fac } \\
\text { Chan }\end{array}$ & $\begin{array}{l}\text { Anti } \\
\text { Prac }\end{array}$ & $\begin{array}{c}\text { Beh } \\
\text { Prac }\end{array}$ & $\begin{array}{l}\text { Att } \\
\text { Ant }\end{array}$ & $\begin{array}{l}\text { Att } \\
\text { Beh }\end{array}$ & $\begin{array}{l}\text { O-E } \\
\text { Ant }\end{array}$ & $\begin{array}{l}\text { O-E } \\
\text { Beh }\end{array}$ \\
\hline Staff & -- & $\begin{array}{c}-.24^{* *} \\
\mathrm{~b}\end{array}$ & $\begin{array}{c}.28^{* * *} \\
b\end{array}$ & $\begin{array}{c}.02 \\
\mathrm{~b}\end{array}$ & $-{ }_{b}^{-19^{*}}$ & $\begin{array}{c}.05 \\
\mathrm{~b}\end{array}$ & $\begin{array}{c}-.20^{*} \\
\mathrm{~d}\end{array}$ & $\begin{array}{c}-.11 \\
\mathrm{~d}\end{array}$ & $\begin{array}{c}-.08 \\
\mathrm{~d}\end{array}$ & $\begin{array}{c}-.02 \\
\mathrm{~b}\end{array}$ & $\begin{array}{c}-.07 \\
b\end{array}$ & $\begin{array}{c}.27^{* *} \\
\mathrm{~b}\end{array}$ & $\begin{array}{c}-.01 \\
\mathrm{~b}\end{array}$ \\
\hline S-E & & -- & $\begin{array}{c}-.11 \\
\mathrm{~b}\end{array}$ & $\begin{array}{c}-.06 \\
\mathrm{~b}\end{array}$ & $\begin{array}{c}.16 \\
\mathrm{~b}\end{array}$ & $\begin{array}{c}.04 \\
\mathrm{~b}\end{array}$ & $\begin{array}{c}-.05 \\
\mathrm{~d}\end{array}$ & $\begin{array}{c}-.07 \\
\mathrm{~d}\end{array}$ & $\begin{array}{c}-.03 \\
\mathrm{~d}\end{array}$ & $\begin{array}{c}-.01 \\
b\end{array}$ & $\begin{array}{c}.16 \\
\mathrm{~b}\end{array}$ & $\begin{array}{c}-.17 \\
b\end{array}$ & .13 \\
\hline Time & & & -- & $\begin{array}{c}.11 \\
\mathrm{a}\end{array}$ & $\begin{array}{c}-.11 \\
\mathrm{a}\end{array}$ & $\begin{array}{c}.08 \\
\mathrm{~b}\end{array}$ & $\begin{array}{c}-.13 \\
\mathrm{c}\end{array}$ & $\begin{array}{c}.06 \\
\mathrm{c}\end{array}$ & $\underset{\mathrm{c}}{-.01}$ & $\begin{array}{c}.17 \\
\mathrm{a}\end{array}$ & $\underset{b}{-.23^{*}}$ & $\begin{array}{c}.13 \\
\mathrm{a}\end{array}$ & $\begin{array}{c}-.09 \\
\mathrm{a}\end{array}$ \\
\hline $\begin{array}{c}\text { Other } \\
\text { Anti }\end{array}$ & & & & -- & $\begin{array}{c}-.54^{* * * *} \\
\mathrm{a}\end{array}$ & $\begin{array}{c}.35^{* * * *} \\
\mathrm{~b}\end{array}$ & $\begin{array}{c}-.09 \\
\mathrm{c}\end{array}$ & $\begin{array}{c}.06 \\
\mathrm{c}\end{array}$ & $\stackrel{.05}{\mathrm{c}}$ & $\begin{array}{c}.16 \\
\mathrm{a}\end{array}$ & $-\mathrm{-.20}_{\mathrm{b}}^{*}$ & $\underset{\mathrm{a}}{.21^{*}}$ & $\begin{array}{c}-.16 \\
\mathrm{a}\end{array}$ \\
\hline $\begin{array}{c}\text { Other } \\
\text { Beh }\end{array}$ & & & & & -- & $\underset{\mathrm{b}}{-.15}$ & $\begin{array}{c}.11 \\
\mathrm{c}\end{array}$ & $\underset{c}{-.13}$ & $\begin{array}{c}-.08 \\
\mathrm{c}\end{array}$ & $\begin{array}{c}-.11 \\
\mathrm{a}\end{array}$ & $\begin{array}{c}.05 \\
\mathrm{~b}\end{array}$ & $\begin{array}{c}.04 \\
\mathrm{a}\end{array}$ & $\underset{\mathrm{a}}{.20^{*}}$ \\
\hline $\begin{array}{l}\text { Resi } \\
\text { Anti }\end{array}$ & & & & & & -- & $\begin{array}{c}-.24^{* *} \\
\mathrm{~d}\end{array}$ & $\begin{array}{c}-.01 \\
\mathrm{~d}\end{array}$ & $\begin{array}{c}-.08 \\
\mathrm{~d}\end{array}$ & $\underset{\mathrm{b}}{.31^{* *}}$ & $\underset{\mathrm{b}}{-.21^{*}}$ & $\underset{\mathbf{b}}{.31^{* *}}$ & $\underset{\mathrm{b}}{-.13}$ \\
\hline $\begin{array}{c}\text { Fac } \\
\text { Chan }\end{array}$ & & & & & & & -- & $.31_{\mathrm{e}}^{\text {**** }}$ & $\begin{array}{c}.36^{* * * *} \\
\text { e }\end{array}$ & $\begin{array}{c}-.45^{* * * *} \\
\mathrm{c}\end{array}$ & $\begin{array}{c}-.35^{* * * *} \\
\mathrm{~d}\end{array}$ & $\begin{array}{c}-.17 \\
\mathrm{c}\end{array}$ & $\begin{array}{c}.09 \\
\mathrm{c}\end{array}$ \\
\hline $\begin{array}{l}\text { Anti } \\
\text { Prac }\end{array}$ & & & & & & & & -- & $\begin{array}{c}.55^{* * * *} \\
\mathrm{e}\end{array}$ & $\begin{array}{c}-.10 \\
c\end{array}$ & $\begin{array}{c}-.04 \\
\mathrm{~d}\end{array}$ & $\begin{array}{c}-.08 \\
\mathrm{c}\end{array}$ & $\begin{array}{c}.06 \\
\mathrm{c}\end{array}$ \\
\hline $\begin{array}{c}\text { Beh } \\
\text { Prac }\end{array}$ & & & & & & & & & -- & $\underset{\mathrm{c}}{-.22^{*}}$ & $\begin{array}{c}-.16 \\
\mathrm{~d}\end{array}$ & $\begin{array}{c}.05 \\
\mathrm{c}\end{array}$ & $\begin{array}{c}.14 \\
\mathrm{c}\end{array}$ \\
\hline $\begin{array}{l}\text { Att } \\
\text { Ant }\end{array}$ & & & & & & & & & & -- & $\mathbf{- . 6 1}_{\mathrm{b}}^{\text {*****}}$ & $\underset{\mathrm{a}}{.21^{*}}$ & $\begin{array}{c}-.33^{* * * *} \\
\mathrm{a}\end{array}$ \\
\hline $\begin{array}{l}\text { Att } \\
\text { Beh }\end{array}$ & & & & & & & & & & & - & $\underset{\mathrm{b}}{-.15}$ & $\begin{array}{c}.53^{* * * *} \\
\text { b }\end{array}$ \\
\hline $\begin{array}{l}\text { O-E } \\
\text { Ant }\end{array}$ & & & & & & & & & & & & -- & .08 \\
\hline $\begin{array}{l}\text { O-E } \\
\text { Beh }\end{array}$ & & & & & & & & & & & & & -- \\
\hline
\end{tabular}

Abbreviations: Anti Prac: change in own practice of using of antipsychotics; Att Ant: attitudes towards antipsychotics; Att Beh: attitudes towards behavioral interventions; Beh Prac: change in own practice of using of behavioral interventions; Fac Chan: change in facility programs or policies towards antipsychotics or behavioral interventions; $O-E$ Ant: outcome expectancies for antipsychotics ; $O-E \mathrm{Beh}$ : outcome expectancies for behavioral interventions; Other Anti: belief about percent of other nurses who would request an antipsychotic; Other Beh: belief about percent of other nurses who would try a new behavioral intervention; Resi Anti: belief about percent of residents on an antipsychotic; $S$-E: self-efficacy to implement behavioral interventions; Staff: perceived inadequate staffing; Time: perceived time pressures

Notes:

${ }^{*} p<.05$

${ }^{* *} p<.01$

*** $p<.001$

${ }^{a}$ Pearson correlation coefficient

${ }^{\mathrm{b}}$ Spearman correlation coefficient

${ }^{\mathrm{c}}$ Point-biserial correlation

${ }^{\mathrm{d}}$ Mann-Whitney test; $r$ computed using the following formula: $\frac{Z}{\sqrt{N}}$

e Phi for $2 \times 2$ Pearson's chi-square test

\section{Antipsychotic Initiation}

Correlates. The nurses' intentions to initiate an antipsychotic did not vary significantly as a function of whether they completed the survey on paper $(\mathrm{M}=5.49, \mathrm{SD}=$ 2.76) or online $(\mathrm{M}=4.29, \mathrm{SD}=2.70), F(1,156)=3.51, p=.06, \omega^{2}=.02$. The subsequent 
analyses utilized the sample as a whole. The nurses' intentions to initiate an antipsychotic varied as a function of their race, $F(2,155)=8.75, p<.001, \omega^{2}=.09$. Post-hoc tests using the Scheffé test revealed that nurses who identified as black $(\mathrm{M}=6.94, \mathrm{SD}=2.69)$ were more likely to request an antipsychotic than a nurse who identified as white $(\mathrm{M}=$ 4.83, $\mathrm{SD}=2.63), t(150)=-4.10, p<.001, r=.32$. Nurses' decisions about seeking an antipsychotic differed as a function of their job title, $F(2,109)=6.73, p=.002, \omega^{2}=.09$. Post-hoc tests using the Scheffé test indicated that administrative nurses $(\mathrm{M}=3.87, \mathrm{SD}=$ 2.41) were less likely to seek an antipsychotic than floor nurses $(\mathrm{M}=5.98, \mathrm{SD}=2.93), t$ $(84)=-3.50, p=.003, r=.36$, and charge nurses $(\mathrm{M}=5.87, \mathrm{SD}=2.42), t(55)=-2.79, p$ $=.02, r=.35$. The intention to initiate an antipsychotic was different across shift, $F$ $(4,152)=3.46, p=.01, \omega^{2}=.06$. Post-hoc tests using the Scheffé test did not reveal any significant differences among the groups. Further analyses were run to establish whether the category of race differed by job title or shift as the finding of a difference across race in antipsychotic initiation could be an overlapping finding with those found with job title and shift. Race did not differ significantly by job title, $\chi^{2}(2)=2.54, p=.29$, or by shift, $\chi^{2}$ (2) $=0.54, p=.87$. Nurses who were pursuing a more advanced degree $(\mathrm{M}=6.03, \mathrm{SD}$ $=2.87)$ were more likely to request an antipsychotic than those who were not $(\mathrm{M}=5.00$, $\mathrm{SD}=2.69), r=.17, p=.03, R^{2}=.03$. However, nurses who had worked longer as a nurse, $r=-.26, p=.001, R^{2}=.07$, and worked longer in a long-term care environment, $r$ $=-.20, p=.01, R^{2}=.04$, were less likely to initiate an antipsychotic.

The nurses' intentions to initiate an antipsychotic were positively associated with their beliefs about the percentage of residents on an antipsychotic in their facility, $r=.29$, $p=.001, r^{2}=.08$, and with their beliefs about the percentage of their fellow nurses who 
would initiate an antipsychotic, $r=.54, p<.001, r^{2}=.29$. Their beliefs about the percentage of their fellow nurses who would try a new behavioral intervention were inversely related to whether the nurses intended to use an antipsychotic, $r=-.23, p=$ $.005, r^{2}=.05$. Nurses who reported a change in their facility's policies or programs related to antipsychotics or behavioral interventions were less likely to initiate an antipsychotic, $r=-.25, p=.002, r^{2}=.06$. Nurses' attitudes towards antipsychotics were positively correlated with antipsychotic initiation, $r=.35, p<.001, r^{2}=.12$, and their attitudes towards behavioral interventions were negatively correlated with antipsychotic initiation, $r=-.38, p<.001, r^{2}=.14$. Nurses' who had more favorable outcome expectancies of antipsychotics were more likely to initiate an antipsychotic, $r=.42, p<$ $.001, R^{2}=.17$. Their intentions to utilize an antipsychotic were not associated with their self-efficacy to implement behavioral interventions, sense of time pressures, perceptions of inadequate staffing, and outcome expectancies of behavioral interventions.

After aggregating the nurses' responses at the facility level, facilities with a higher number of LPN minutes per resident per day, $r=.56, p<.01, r^{2}=.31$, and facilities with a higher total number of licensed staff minutes per resident per day, $r=.58$, $p<.01, r^{2}=.33$, had more nurse respondents who were anticipating initiating an antipsychotic. Although not statistically significant, there were moderate effect sizes for the number of beds $(r=.33)$, number of CMS stars for quality measures $(r=-.39)$, number of CNA minutes per resident per day $(r=-.27)$, and percent of short-stay residents on an antipsychotic $(r=.40)$. However, caution is warranted in interpreting all of these facility-level values because of the small sample size (see Ioannidis, 2005). 
Salience and evaluation. An internal validity check was performed for the injunctive norm condition, and $96 \%$ of the sample $(n=151)$ completed the question regarding the extent to which they perceived the poster as indicating they should avoid antipsychotics. The results suggested that the poster with the salient condition $(M=4.11$, $\mathrm{SD}=1.29$ ) indicated antipsychotics should be avoided to a greater extent than the poster with the non-salient condition $(\mathrm{M}=1.87, \mathrm{SD}=1.35), F(1,143)=109.69, p<.001, \omega^{2}=$ 43. A similar check was performed for the evaluation condition, and $95 \%$ of the sample ( $n=150)$ answered the question regarding the extent to which they perceived that they would be evaluated in a new dementia care program. The results indicated that the salient evaluation condition $(\mathrm{M}=3.58, \mathrm{SD}=1.03)$ was not significantly different from the nonsalient evaluation condition $(\mathrm{M}=3.49, \mathrm{SD}=1.08), F(1,142)=0.25, p=.62, \omega^{2}=.002$. Together, these results provide evidence to support the internal validity of the manipulation of an injunctive norm, and indicate that the manipulation of the sense of evaluation was not successful.

The intraclass correlation (ICC) for the facility effect was .04, indicating $4 \%$ of the variance in antipsychotic initiation was between facilities. There was no main effect of an injunctive norm or a sense of being evaluated on the nurses' intention to initiate an antipsychotic (Table 3: Model 1). There was no interactive effect of being evaluated and presented with an injunctive norm on the nurses' intent to start an antipsychotic. None of the between-facility or contextual effects were significant. Within a multilevel model, a post-hoc analysis wherein the injunctive norm condition was dummy coded and the sense 
of evaluation variable was not entered did not reveal any significant differences between the salient and non-salient injunctive norm conditions. ${ }^{2}$

The self-efficacy variable was negatively skewed, and subjected to reflection and then a square-root transformation for the following analysis. Self-efficacy did not moderate the effect of an injunctive norm on intention to initiate an antipsychotic, and there were no significant between-facility or contextual effects for the interaction (Table 3: Model 2). Within a multilevel model, a post-hoc analysis that included only a dummy coded version of the injunctive norm variable did not demonstrate a moderating effect of self-efficacy on the effect of an injunctive norm.

Table 3. Antipsychotic initiation as a function of injunctive norm, sense of evaluation, and selfefficacy

\begin{tabular}{|c|c|c|c|}
\hline \multicolumn{4}{|c|}{ Model 1: Conditions only } \\
\hline Variable & Estimate & Standard Error & p value \\
\hline Intercept & 4.63 & 0.49 & -- \\
\hline Inj. norm (within facility effect) ${ }^{1}$ & 0.95 & 0.66 & .16 \\
\hline Inj. norm (between facility effect) ${ }^{2}$ & 0.01 & 1.63 & .99 \\
\hline Inj. norm (contextual effect) ${ }^{3}$ & -0.94 & 1.76 & .60 \\
\hline Evaluation (within facility effect) & 1.12 & 0.68 & .10 \\
\hline Evaluation (between facility effect) & -0.51 & 1.50 & .74 \\
\hline Evaluation (contextual effect) & -1.63 & 1.64 & .34 \\
\hline Evaluation and Inj. norm (within facility effect) & 0.13 & 0.67 & .84 \\
\hline Evaluation and Inj. norm (between facility effect) & 0.75 & 1.61 & .64 \\
\hline Evaluation and Inj. norm (contextual effect) & 0.62 & 1.74 & .72 \\
\hline \multicolumn{4}{|c|}{ Model 2: Conditions and Self-Efficacy ${ }^{4}$} \\
\hline Variable & Estimate & Standard Error & p value \\
\hline Intercept & 4.71 & 0.50 & -- \\
\hline Inj. norm (within facility effect) & 1.00 & 0.68 & .14 \\
\hline Inj. norm (between facility effect) & 1.19 & 1.99 & .55 \\
\hline Inj. norm (contextual effect) & 0.19 & 2.10 & .93 \\
\hline Evaluation (within facility effect) & 1.20 & 0.70 & .09 \\
\hline Evaluation (between facility effect) & -1.05 & 1.64 & .52 \\
\hline Evaluation (contextual effect) & -2.25 & 1.78 & .21 \\
\hline Evaluation and Inj. norm (within facility effect) & 0.18 & 0.69 & .80 \\
\hline Evaluation and Inj. norm (between facility effect) & -0.03 & 1.80 & .99 \\
\hline
\end{tabular}

\footnotetext{
${ }^{2}$ Results for post-hoc analyses are not provided unless found to be significant, and can be made available upon request.
} 


\begin{tabular}{|c|c|c|c|}
\hline Variable & Estimate & Standard Error & p value \\
\hline Evaluation and Inj. norm (contextual effect) & -0.20 & 1.93 & .92 \\
\hline Self-efficacy (within facility effect) & -0.10 & 0.19 & .61 \\
\hline Self-efficacy (between facility effect) & 0.41 & 0.42 & .33 \\
\hline Self-efficacy (contextual effect) & 0.51 & 0.44 & .25 \\
\hline Self-efficacy $x$ Inj. norm (within facility effect) & 0.10 & 0.34 & .76 \\
\hline Self-efficacy x Inj. norm (between facility effect) & 1.82 & 1.40 & .20 \\
\hline Self-efficacy $x$ Inj. norm (contextual effect) & 1.72 & 1.43 & .23 \\
\hline
\end{tabular}

Abbreviations: Evaluation: sense of evaluation condition; Inj. Norm: injunctive norm condition

Notes:

${ }^{1}$ The within- facility effect indicates whether nurses with higher values on the predictor have higher outcome values than the other nurses in the same facility.

${ }^{2}$ The between- facility effect indicates whether facilities with higher predictor values than other facilities have higher outcome values.

${ }^{3}$ The contextual effect indicates whether after controlling for the nurse's score on the predictor, there is an incremental contribution of being a nurse in a facility with a higher facility mean of the predictor.

${ }^{4} n=153$ due to missing data

Two a priori exploratory analyses examined whether descriptive norms about antipsychotic use and facility rates of antipsychotic use (Table 4) moderated the effect of an injunctive norm or sense of evaluation on the nurses' intent to utilize an antipsychotic.

There was a significant interaction of facility rate and injunctive norm wherein individuals working in facilities with higher rates of antipsychotic use had greater intentions to utilize an antipsychotic when presented with an injunctive norm than individuals working in facilities with lower rates of antipsychotic use. There was not a significant interaction of facility rates and sense of evaluation. The findings did not demonstrate a significant interaction of perceived descriptive norms and the salience of an injunctive norm or a sense of evaluation.

Table 4. Antipsychotic initiation as a function of facility antipsychotic rate and sense of evaluation

\begin{tabular}{|c|c|c|c|}
\hline \multicolumn{4}{|c|}{ Model 1: Facility rate by injunctive norm ${ }^{4}$} \\
\hline Variable & Estimate & Standard Error & $p$ value \\
\hline Intercept & 5.63 & 0.51 & -- \\
\hline Inj. norm (within facility effect) ${ }^{1}$ & 0.87 & 0.68 & .20 \\
\hline Inj. norm (between facility effect) ${ }^{2}$ & -0.22 & 1.85 & .90 \\
\hline Inj. norm (contextual effect) ${ }^{3}$ & -1.09 & 1.97 & .58 \\
\hline Evaluation (within facility effect) & 0.96 & 0.69 & .17 \\
\hline
\end{tabular}




\begin{tabular}{|c|c|c|c|}
\hline Variable & Estimate & Standard Error & p value \\
\hline Evaluation (between facility effect) & -0.41 & 1.56 & .79 \\
\hline Evaluation (contextual effect) & -1.37 & 1.70 & .42 \\
\hline Evaluation and Inj. norm (within facility effect) & -0.32 & 0.69 & .65 \\
\hline Evaluation and Inj. norm (between facility effect) & -0.27 & 1.62 & .87 \\
\hline Evaluation and Inj. norm (contextual effect) & 0.05 & 1.76 & .98 \\
\hline Fac. rate & -0.02 & 0.05 & .75 \\
\hline Fac. rate $x$ Inj. norm (within facility effect) & 0.28 & 0.12 & .02 \\
\hline Fac. rate $x$ Inj. norm (between facility effect) & -0.38 & 0.33 & .26 \\
\hline Fac. rate $x$ Inj. norm (contextual effect) & -0.66 & 0.35 & .06 \\
\hline New program & -1.53 & 0.48 & .002 \\
\hline \multicolumn{4}{|c|}{ Model 2: Facility rate by sense of evaluation ${ }^{4}$} \\
\hline Variable & Estimate & Standard Error & p value \\
\hline Intercept & 5.55 & 0.51 & -- \\
\hline Inj. norm (within facility effect) & 1.04 & 0.69 & .13 \\
\hline Inj. norm (between facility effect) & -0.19 & 1.88 & .92 \\
\hline Inj. norm (contextual effect) & -1.23 & 2.00 & .54 \\
\hline Evaluation (within facility effect) & 1.02 & 0.70 & .15 \\
\hline Evaluation (between facility effect) & 1.18 & 1.88 & .53 \\
\hline Evaluation (contextual effect) & 0.16 & 2.00 & .94 \\
\hline Evaluation and Inj. norm (within facility effect) & -0.22 & 0.70 & .75 \\
\hline Evaluation and Inj. norm (between facility effect) & 0.38 & 1.59 & .81 \\
\hline Evaluation and Inj. norm (contextual effect) & 0.61 & 1.73 & .73 \\
\hline Fac. rate & 0.07 & 0.06 & .23 \\
\hline Fac. rate $x$ Evaluation (within facility effect) & 0.05 & 0.13 & .73 \\
\hline Fac. rate $x$ Evaluation (between facility effect) & 0.39 & 0.26 & .13 \\
\hline Fac. rate $x$ Evaluation (contextual effect) & 0.34 & 0.29 & .24 \\
\hline New program & -1.53 & 0.49 & .002 \\
\hline
\end{tabular}

Abbreviations: Evaluation: sense of evaluation condition; Fac. Rate: facility rate of antipsychotic use; Inj. Norm: injunctive norm condition; New program: whether nurses indicated their facility had implemented a new program or policy about using antipsychotic or behavioral interventions

Notes:

${ }^{1}$ The within- facility effect indicates whether nurses with higher values on the predictor have higher outcome values than the other nurses in the same facility.

${ }^{2}$ The between- facility effect indicates whether facilities with higher predictor values than other facilities have higher outcome values.

${ }^{3}$ The contextual effect indicates whether after controlling for the nurse's score on the predictor, there is an incremental contribution of being a nurse in a facility with a higher facility mean of the predictor.

${ }^{4} \mathrm{n}=139$ due to missing data

Two post-hoc analyses were conducted to examine the lack of significant findings regarding the effect of an injunctive norm. One plausible explanation can be derived from the theory of psychological reactance (see Brehm \& Brehm, 1981) which would predict that when presented with a directive to do something (e.g., not utilize an antipsychotic), 
individuals who harbor more favorable attitudes towards the idea or thing (e.g., "I believe antipsychotics are appropriate") would react to the directive by increasing their use of something (e.g., antipsychotics) than individuals with less favorable attitudes. The findings did not show that attitudes towards antipsychotics moderated the effect of an injunctive norm.

Another plausible explanation may be that nurses' outcome expectancies influence the effect of an injunctive norm on antipsychotic initiation such that individuals with less favorable outcome expectancies for antipsychotics would be less likely to request an antipsychotic when presented with an injunctive norm than individuals with more favorable outcome expectancies. A post-hoc analysis did not demonstrate that outcome expectancies for antipsychotics moderated the effect of an injunctive norm on the initiation of an antipsychotic.

Time pressures, staffing, and self-efficacy. The staffing variable was dummy coded with the reference value being individuals who indicated they were undecided. Individuals who strongly disagreed that inadequate staffing hinders their ability to manage behavioral disruptions without medications were less likely to initiate an antipsychotic than individuals who were undecided (Table 5: Model 1). There was not a significant contextual effect. Individuals who disagreed, agreed, or strongly agreed were not significantly different from those who were undecided in terms of their intent to initiate an antipsychotic. A sensitivity analysis found that the effect of strongly disagreeing on antipsychotic initiation held after controlling for the effects of the nurses' perceived descriptive norm regarding antipsychotic use, recent facility program or policy change about the use of antipsychotics or behavioral interventions, nursing characteristics 
(pursuing advanced degree, race, shift, years as a nurse, job title), and a facility

characteristic (total number of licensed nursing staff minutes per resident per day) (Table

6). There were no significant relationships between staffing and self-efficacy, ${ }^{3}$ so the

final step in the mediation analysis was not undertaken.

The time pressures variable was negatively skewed, and was reflected and then

logarithmically transformed. There was not a significant relationship between time

pressures and antipsychotic initiation, and there were no contextual or between-group

effects (Table 5: Model 2). Because time pressure was not associated with the outcome, a mediation analysis with self-efficacy was not run.

Table 5. Antipsychotic initiation as a function of staffing and time pressures

\begin{tabular}{|c|c|c|c|}
\hline \multicolumn{4}{|c|}{ Model 1: Staffing } \\
\hline Variable & Estimate & Standard Error & p value \\
\hline Intercept & 6.10 & 0.67 & -- \\
\hline Staffing- Strongly disagree (within facility effect) ${ }^{1}$ & -2.18 & 1.07 & .04 \\
\hline Staffing- Strongly disagree (between facility effect) ${ }^{2}$ & -1.07 & 1.97 & .59 \\
\hline Staffing- Strongly disagree (contextual effect) ${ }^{3}$ & 1.10 & 2.24 & .62 \\
\hline Staffing- disagree (within facility effect) & -1.65 & 0.84 & .05 \\
\hline Staffing- disagree (between facility effect) & 0.44 & 1.76 & .81 \\
\hline Staffing- disagree (contextual effect) & 2.09 & 1.95 & .29 \\
\hline Staffing- agree (within facility effect) & -0.86 & 0.82 & .29 \\
\hline Staffing- agree (between facility effect) & -0.95 & 1.59 & .55 \\
\hline Staffing- agree (contextual effect) & -0.09 & 1.78 & .96 \\
\hline Staffing- Strongly agree (within facility effect) & -0.42 & 0.80 & .60 \\
\hline Staffing- Strongly agree (between facility effect) & -0.98 & 1.60 & .54 \\
\hline Staffing- Strongly agree (contextual effect) & -0.56 & 1.78 & .75 \\
\hline \multicolumn{4}{|c|}{ Model 2: Time pressures ${ }^{4}$} \\
\hline Variable & Estimate & Standard Error & p value \\
\hline Intercept & 5.23 & 0.27 & -- \\
\hline Time pressures (within facility effect) & 0.003 & 0.01 & .84 \\
\hline Time pressures (between facility effect) & 0.02 & 0.02 & .48 \\
\hline Time pressures (contextual effect) & 0.01 & 0.03 & .61 \\
\hline \multicolumn{4}{|l|}{ Notes: } \\
\hline \multicolumn{4}{|c|}{$\begin{array}{l}{ }^{1} \text { The within- facility effect indicates whether nurses with higher values on the predictor have higher } \\
\text { outcome values than the other nurses in the same facility. }\end{array}$} \\
\hline
\end{tabular}

\footnotetext{
${ }^{3}$ Results not included but can provide upon request.
} 
${ }^{3}$ The contextual effect indicates whether after controlling for the nurse's score on the predictor, there is an incremental contribution of being a nurse in a facility with a higher facility mean of the predictor.

${ }^{4} \mathrm{n}=156$ due to missing data 
Table 6. Antipsychotic initiation and staffing: Sensitivity analysis ${ }^{1}$

\begin{tabular}{|c|c|c|c|c|c|c|c|c|c|c|c|c|c|c|c|}
\hline \multicolumn{4}{|c|}{ Model 1: Staffing only } & \multicolumn{3}{|c|}{$\begin{array}{l}\text { Model 2: Descr } \\
\text { Norm }^{6}\end{array}$} & \multicolumn{3}{|c|}{$\begin{array}{l}\text { Model 3: New } \\
\text { program }^{7}\end{array}$} & \multicolumn{3}{|c|}{$\begin{array}{l}\text { Model } 4: R N \\
\text { characteristic }^{8}\end{array}$} & \multicolumn{3}{|c|}{$\begin{array}{l}\text { Model 5: Fac } \\
\text { characteristic }^{9}\end{array}$} \\
\hline Variable & Est & $S E$ & $p$ & Est & $S E$ & $p$ & $E s t$ & $S E$ & $p$ & Est & $S E$ & $p$ & Est & $S E$ & $p$ \\
\hline Intercept & 6.20 & 0.93 & -- & 5.32 & 1.00 & -- & 5.96 & 1.07 & -- & 5.47 & 1.28 & -- & 7.55 & 2.18 & -- \\
\hline SD $(\mathrm{WG})^{2}$ & -4.68 & 1.68 & .01 & -4.35 & 1.65 & .01 & -4.71 & 1.66 & .01 & -5.70 & 1.55 & .001 & -5.72 & 1.55 & $<.001$ \\
\hline SD $(B G)^{3}$ & 0.88 & 2.83 & .76 & 0.15 & 2.77 & .96 & -0.64 & 2.73 & .82 & 1.67 & 2.65 & .53 & 2.17 & 2.68 & .42 \\
\hline $\mathrm{SD}(\mathrm{Co})^{4}$ & 5.57 & 3.29 & .10 & 4.51 & 3.24 & .17 & 4.07 & 3.18 & .21 & 7.37 & 3.03 & .02 & 7.90 & 3.06 & .01 \\
\hline D (WG) & -0.74 & 1.19 & .53 & -0.83 & 1.17 & .48 & -0.69 & 1.17 & .56 & -1.36 & 1.10 & .22 & -1.26 & 1.10 & .26 \\
\hline D (BG) & 4.83 & 2.93 & .11 & 4.03 & 2.87 & .17 & 3.71 & 2.80 & .19 & 2.83 & 2.61 & .28 & 4.14 & 2.83 & .15 \\
\hline D (Co) & 5.57 & 3.16 & .09 & 4.87 & 3.09 & .12 & 4.41 & 3.03 & .15 & 4.19 & 2.82 & .14 & 5.39 & 3.00 & .08 \\
\hline A (WG) & -1.29 & 1.11 & .25 & -1.35 & 1.08 & .22 & -1.23 & 1.09 & .26 & -1.13 & 1.02 & .27 & -1.10 & 1.01 & .28 \\
\hline A (BG) & 1.91 & 2.74 & .49 & 1.45 & 2.67 & .59 & 0.56 & 2.64 & .83 & 1.28 & 2.54 & .62 & 2.70 & 2.81 & .34 \\
\hline $\mathbf{A}(\mathbf{C o})$ & 3.21 & 2.96 & .28 & 2.80 & 2.88 & .34 & 1.80 & 2.87 & .53 & 2.41 & 2.81 & .39 & 3.80 & 3.04 & .22 \\
\hline SA (WG) & -0.46 & 1.12 & .68 & -0.67 & 1.10 & .55 & -0.81 & 1.11 & .46 & -0.29 & 1.03 & .78 & -0.31 & 1.03 & .76 \\
\hline SA (BG) & 1.87 & 2.05 & .38 & 1.47 & 1.99 & .47 & 0.72 & 1.96 & .72 & 1.51 & 1.87 & .42 & 2.25 & 1.97 & .26 \\
\hline SA (Co) & 2.34 & 2.34 & .33 & 2.14 & 2.26 & .35 & 1.54 & 2.22 & .49 & 1.80 & 2.11 & .40 & 2.57 & 2.21 & .25 \\
\hline
\end{tabular}

Abbreviations: A: agree; BG: between-group effect; Co: contextual effect; D: disagree; Descr Norm: descriptive norm; Est: estimate; Fac: facility; RN: nurse; SA: strongly agree; SD: strongly disagree; SE: standard error; WG: within-group effect

Notes:

$\mathbf{1}$ This analysis included a total of 88 nurses due to missing data across the variables.

${ }^{2}$ The within- facility effect indicates whether nurses with higher values on the predictor have higher outcome values than the other nurses in the same facility.

${ }^{3}$ The between- facility effect indicates whether facilities with higher predictor values than other facilities have higher outcome values.

${ }^{4}$ The contextual effect indicates whether after controlling for the nurse's score on the predictor, there is an incremental contribution of being a nurse in a facility with a higher facility mean of the predictor.

${ }^{5}$ This analysis only included the staffing variable and served as the baseline model (model 1).

${ }^{6}$ This analysis controlled only for the descriptive norm.

${ }^{7}$ This analysis added the variable of whether a nurse indicated his/her facility had a new program or policy regarding the use of antipsychotics or behavioral interventions to model 2.

${ }^{8}$ This analysis added the following nurse characteristics to model 3: pursuing advanced degree, race, shift, years as a nurse, and job title.

${ }^{9}$ This analysis added the facility characteristic of total number of licensed nursing staff minutes per resident per day to model 4. 


\section{Behavioral Intervention Initiation}

Correlates. The nurses' intentions to initiate a new behavioral intervention did not vary as a function of whether the survey was on paper $(M d n=8.00)$ or online $(M d n=$ 9.00), $U=1254.00, z=-0.97, p=.33, r=-.08$. This finding held with the reflected and log-transformed version of the behavioral intervention variable, $F(1,156)=0.87, p=.35$, $\omega^{2}=.01$. The subsequent analyses utilize the sample as a whole. Nurses who had worked longer in a long-term care environment, $r=.17, p=.03, r^{2}=.03$, or who had worked longer in their current facility, $r=.17, p=.03, r^{2}=.03$, were more likely to intend to utilize a new behavioral intervention. No other nursing characteristics were related to the likelihood of initiating a behavioral intervention.

The nurses' intentions to initiate a new behavioral intervention were positively associated with their beliefs about the percentage of their fellow nurses who would try a new behavioral intervention, $r=.31, p<.001, r^{2}=.10$. Their beliefs about the percentage of the nurses in their facility who would request an antipsychotic, $r=-.22, p=.006, r^{2}=$ .05 , and their beliefs about the percentage of residents on an antipsychotic in their facility, $r=-.21, p=.01, r^{2}=.05$, were inversely related to their intentions to try a new behavioral intervention. Their attitudes towards behavioral interventions were positively correlated with behavioral intervention initiation, $r=.25, p=.006, r^{2}=.06$. Their intentions to try a new behavioral intervention were not associated with their self-efficacy to implement behavioral interventions, sense of time pressures, perceptions of inadequate staffing, and outcome expectancies of behavioral interventions.

After aggregating the nurses' responses at the facility level, facilities with a greater number of CMS stars for quality measures had greater levels of intended 
behavioral intervention initiation, $r=.51, p=.01, r^{2}=.26$. Although not statistically significant, there were moderate effect sizes for the number of beds $(r=-.30)$ and number of LPN minutes per resident per day $(r=-.38)$. However, caution is warranted in interpreting all of these facility-level values because of the small sample size (see Ioannidis, 2005).

Salience and evaluation. The behavioral intervention initiation responses were negatively skewed, and were subjected to reflection and then a logarithmic transformation for the following analyses. The intraclass correlation (ICC) for facility effect was .06 , indicating $6 \%$ of the variance in behavioral intervention initiation was between facilities. There was no main effect of an injunctive norm or a sense of being evaluated on the nurses' intention to initiate a different behavioral intervention (Table 7: Model 1). There was no interactive effect of being evaluated and presented with an injunctive norm on the nurses' intent to start a behavioral intervention. None of the between-facility or contextual effects were significant. Within a multilevel model, a posthoc analysis wherein the injunctive norm condition was dummy coded and the sense of evaluation variable was not entered did not reveal any significant differences between the salient and non-salient injunctive norm conditions in regards to the nurses' intention to initiate a new behavioral intervention.

The self-efficacy variable was negatively skewed, and subjected to reflection and then a square-root transformation for the following analysis. Self-efficacy did not moderate the effect of an injunctive norm on intention to try a new behavioral intervention, and there were no significant between-facility or contextual effects for the interaction (Table 7: Model 2). Within a multilevel model, a post-hoc analysis that 
Two a priori exploratory analyses examined whether descriptive norms about antipsychotic use and facility rates of antipsychotic use moderated the effect of an injunctive norm or sense of evaluation on the nurses' intent to utilize a behavioral intervention. There was not a significant interaction of facility rates with either an injunctive norm or sense of evaluation. The findings did not demonstrate a significant interaction of perceived descriptive norms with the salience of an injunctive norm or a sense of evaluation.

Two post-hoc analyses were conducted to examine the lack of significant findings regarding the effect of an injunctive norm. First, the injunctive norm against antipsychotic use presumes the nurse should utilize a different treatment approach. In the context of increasing pressure to reduce medication use and increase behavioral interventions use (CMS, 2014), it is possible the nurses would interpret the injunctive norm message to imply that they should utilize a behavioral intervention. In line with this reasoning, one explanation for the lack of findings may be that nurses' attitudes towards behavioral interventions influence their decision making such that nurses with more negative attitudes towards behavioral interventions are less likely to seek a behavioral intervention when presented with an injunctive norm than nurses with more positive attitudes. A post-hoc analysis did not find a significant moderation of attitudes on the effect of an injunctive norm.

Another plausible explanation may be that nurses' outcome expectancies influence the effect of an injunctive norm on behavioral intervention initiation such that individuals with more favorable outcome expectancies for behavioral interventions would 
be more likely to utilize a behavioral intervention when presented with an injunctive norm than individuals with less favorable outcome expectancies. A post-hoc analysis did not demonstrate that outcome expectancies for behavioral interventions moderated the effect of an injunctive norm on the initiation of a behavioral intervention.

Time pressures and staffing. The staffing variable was dummy coded with the reference value being individuals who indicated they were undecided. Individuals who strongly disagreed, disagreed, agreed, or strongly agreed were not significantly different from those who were undecided in terms of their intent to initiate a behavioral intervention. There were no significant contextual or between-group effects. As staffing was not associated with the intention to utilize a behavioral intervention, a mediation analysis with self-efficacy was not run.

The time pressures variable was negatively skewed, and was reflected and then logarithmically transformed. There was not a significant relationship between time pressures and behavioral intervention initiation, and there were no contextual or betweengroup effects. Because time pressure was not associated with the outcome, a mediation analysis with self-efficacy was not run. 


\section{DISCUSSSION}

This study of long-term care nurses began to examine the validity of a psychological model that seeks to understand healthcare providers' choices around antipsychotics and psychosocial interventions for individuals with dementia-related behaviors who live in long-term care facilities. The study aimed to examine whether an injunctive norm against antipsychotic use and a sense of being evaluated influenced nurses' intentions to initiate an antipsychotic or behavioral intervention when presented with a case study and to determine whether nurses' self-efficacy and descriptive norms about antipsychotic use moderated the influence of an injunctive norm or sense of evaluation. The study also sought to examine the interrelationships of perceived time pressures, perceived staffing, and self-efficacy as related to the nurses' intentions to request an antipsychotic or behavioral intervention. The following sections will summarize and interpret the findings.

\section{Antipsychotic initiation}

Salience and evaluation. It was hypothesized that nurses presented with a salient injunctive norm against antipsychotic use would have lower intentions to request an antipsychotic than nurses presented with a non-salient, information-only message about antipsychotics. The findings did not show that the salient message was associated with lower intentions to initiate an antipsychotic relative to a non-salient message. This finding is inconsistent with previous theoretical and empirical findings which have shown 
that salient injunctive norms against a specific behavior can effectively diminish a range of problematic behaviors (Cialdini et al., 1990; Cialdini et al., 2006; Kallgren et al., 2000; Reno et al., 1993; Schultz et al., 2007; Schultz et al., 2008).

The conceptual model proposed that the psychological principles expected to influence nurses' treatment choices may interact with each other. As a result, these interactions could lessen or enhance the effect of an injunctive norm and explain the null findings. Previous work has found that descriptive norms that conflict with an injunctive norm may be more likely to supersede the injunctive norm's effect in a distressing situation (Fischer et al., 2011; Latané \& Nida, 1981) and that a sense of being evaluated can moderate the influence of problematic descriptive norms (Garcia et al., 2009; Schwartz \& Gottlieb, 1976; van Bommel et al., 2012; van Bommel et al., 2013). In recognition of this research, this study sought to manipulate a sense of being evaluated, and hypothesized that there would be a stronger negative effect of a message with a salient injunctive norm on nurses' intentions when the nurses experienced a sense that their behavior was being evaluated. The results demonstrated that there was neither an interactive effect of being evaluated and presented with an injunctive norm nor a main effect of being evaluated on the nurses' intent to start an antipsychotic. Furthermore, there was not a significant interaction of actual (facility rates) or perceived descriptive norms and sense of evaluation as would be expected. However, these findings may not be valid as an internal validity analysis did not support the assumption that the manipulation of a sense of evaluation was effective. As a result, it remains an open question as to whether increasing a sense of evaluation may moderate the effect of an injunctive norm 
and counteract the effect of conflicting descriptive norms regarding the use of antipsychotics.

This study examined the influence of descriptive norms on the effect of an injunctive norm independent of a sense of being evaluated. Exploratory hypotheses proposed that an injunctive norm would be less influential with nurses who perceive higher rates of antipsychotic use in their facility or with nurses who work in facilities with higher rates of antipsychotic use. The results showed that individuals working in facilities with higher rates of antipsychotic use had greater intentions to utilize an antipsychotic when presented with an injunctive norm than individuals working in facilities with lower rates of antipsychotic use. However, perceived rates of antipsychotic use did not moderate the effect of an injunctive norm. The possibility that the presentation of an injunctive norm against antipsychotic use would increase intentions to use an antipsychotic is not consistent with the predictions proffered in the social psychology literature on norms. As an alternative, the theory of psychological reactance (see Brehm \& Brehm, 1981) would predict such a finding, but there was no evidence that attitudes towards antipsychotics moderated the effect of an injunctive norm. A second possibility is that the finding is an artifact of a small sample size of facilities. In the context of a lack of corroborating evidence when evaluating perceived descriptive norms, caution is warranted in interpreting the unexpected finding regarding facility rates of antipsychotic.

The conceptual model provides two other possible explanations for the lack of effect of an injunctive norm. Nurses with low self-efficacy to implement a behavioral intervention may have perceived that they lacked an alternative treatment approach to 
manage a behavioral disruption and thus felt they could not follow the injunctive norm. This explanation is consistent with an original study hypothesis that a salient injunctive norm would be more influential among nurses with greater self-efficacy to perform behavioral interventions. The analyses suggested that self-efficacy did not moderate the effect of an injunctive norm on intention to initiate an antipsychotic. This finding is tempered by the fact that the mean of the nurses' self-efficacy was quite high, introducing the possibility of a ceiling effect, which can limit variability and reduce the ability to detect differences among groups. However, it is also quite possible the mean approximates the truth. As such, only further study and measurement validation can disentangle this question.

Based on the work of Bandura (1977), the model distinguishes outcome expectancies and self-efficacy. Another scenario could have been that nurses' with less favorable outcome expectancies for antipsychotics would be less likely to request an antipsychotic when presented with an injunctive norm as they perceived such an approach would be ineffective. A post-hoc analysis did not demonstrate that outcome expectancies for antipsychotics moderated the effect of an injunctive norm.

Across these analyses, the conceptual model's psychological constructs do not provide a consistent or convincing explanation for the ineffectiveness of the injunctive norm to influence the nurses' intentions. There are two relevant methodological considerations. The previous studies that manipulated an injunctive norm created a clear sense of whether a behavior should occur or not (e.g., confederate picked up a piece of litter in front of participant, embedded message phrased as “...don't remove...”, or a bill included a sad/frown face when electricity usage was too high). The injunctive norm 
message in this study used the phrase "Avoid Using Antipsychotics With Our Residents." The word "avoid" does not establish a clear pronouncement against the use of antipsychotics as it implies its use may be acceptable in some situations. While this language is consistent with the extant approach to prescribing antipsychotics in nursing home residents with dementia-related behaviors, its ambiguity may limit its effectiveness in modifying problematic treatment decisions. The phrase conveying the injunctive norm was subjected to qualitative pilot testing with several long-term care nurses. The only change they suggested was dropping the word "please" from the phrase as they felt it was too friendly and less persuasive. While their choice presents some very preliminary and indirect evidence to support the hypothesis that the use of the word "avoid" may be a limiting factor, qualitative data was not collected about their perceptions of how different wording may influence their interpretation of the embedded norm.

Another methodological point is that the power analyses assumed the effect of an injunctive norm would be medium based on previous work demonstrating small-tomedium (e.g., Reno et al., 1993) or medium-to-large (e.g., Schultz et al., 2007) effects. It is possible that the effect of an injunctive norm on nurses' treatment decisions could be small and thus, the current sample size was insufficient resulting in a type II error. Only entering the injunctive norm condition as a predictor of antipsychotic use did not find an effect, though this approach to enhancing power is limited and cannot rule out the possibility of a small effect. While it remains uncertain whether a small effect may exist, it is important to consider that a small effect size would limit an injunctive norm's utility in influencing behaviors in an environment that is seeking efficient approaches to changing treatment decisions. 
The implications of these findings are that efforts to increase the visibility of a message against antipsychotic use prior to when a nurse makes a treatment decision may have limited utility in influencing nurses' intentions to utilize an antipsychotic. This outcome appears to be consistent irrespective of a nurses' self-efficacy to implement behavioral treatments, expectations regarding the effectiveness of an antipsychotic, and beliefs about the extent to which they favor antipsychotics as a treatment of dementiarelated behaviors. Furthermore, there is preliminary evidence to suggest that such messages may increase nurses' intentions to utilize antipsychotics in facilities with higher rates of antipsychotic use, raising concern that this approach may be counterproductive, not just ineffectual.

Time pressures, staffing, and self-efficacy. It was hypothesized that perceived time pressures would be positively associated with nurses' intentions to request an antipsychotic and that nurses' self-efficacy would mediate the relationship. The results did not show a significant relationship between time pressures and antipsychotic initiation. Previous qualitative evidence indicates that providers commonly cite time pressures as to why they choose antipsychotics over behavioral interventions (CohenMansfield et al., 2005; Cornegé-Blokland et al., 2012; Wood-Mitchell et al., 2008). It is unclear why this relationship was not found. One explanation for the null finding may be the presence of a sample bias leading to sampling error. One qualitative study found that antipsychotic initiation is perceived to be more likely among night-shift nurses (CornegéBlokland et al., 2012). It is possible that time pressures among night-shift nurses may be higher than among day-shift nurses due to higher resident caseloads. As a result, the sample's very small number of night-shift nurses could attenuate the variability in 
perceived time pressures leading to the null finding within this sample. A second reason for the null finding may be the relatively high mean of perceived time pressures, introducing the possibility of a ceiling effect. Another rationale may be the use of a selfreport, global measure of time pressures. The effect of perceived time pressures on intentions and behavior may be context dependent. In asking nurses to collapse their perceived time pressures across contexts, its effects on their behavioral intentions could be washed out. Thus, measuring perceived time pressures longitudinally within context may serve as a better test of its association with intentions and behavior.

The conceptual model proposed that perceived staffing, would be related to but distinct from time pressures and that lower perceived staffing would be associated with greater intentions among nurses to seek an antipsychotic. The results showed that perceived time pressures and staffing were positively related but distinguishable and that individuals who strongly disagreed that inadequate staffing hinders their ability to manage behavioral disruptions without medications were less likely to initiate an antipsychotic than individuals who were undecided. The effect was robust across multiple models within a sensitivity analysis. This finding is consistent with previous qualitative work suggesting that perceived staffing levels may affect treatment decisions (CohenMansfield et al., 2005; Cornegé-Blokland et al., 2012; Wood-Mitchell et al., 2008) and with some empirical studies that showed higher staffing levels are inversely associated with antipsychotic use (Hughes et al., 2000; Shorr et al., 1994).

Some caution is warranted in interpreting the findings regarding staffing. The individuals who strongly disagreed were only a small portion of the sample $(n=14)$, introducing the possibility they are a unique subset of nurses in long-term care. Evidence 
to support this contention can be found in that individuals who disagreed, agreed and strongly agreed were not more or less likely to seek an antipsychotic than those who were undecided as would be expected. Similar findings were found in the sensitivity analysis. The quite large estimates of the fixed effects in the group who disagreed relative to the other groups found in the original and sensitivity analyses provide additional evidence to support the idea that those who strongly disagreed may be a unique subset.

It was proposed that self-efficacy would mediate the relationship between staffing and nurses' intentions to initiate an antipsychotic. The test of mediation failed because there was not a significant relationship between staffing and self-efficacy when entered into a multilevel model. As described earlier, the mean of the nurses' self-efficacy was quite high, introducing the possibility of a ceiling effect.

The implications of these findings are that individuals who do not believe staffing hinders their ability to utilize behavioral interventions may be less likely to intend to seek an antipsychotic. Programs or policies that result in a modification of the extent to which staff believe staffing interferes with their use of psychosocial interventions could be beneficial. Time pressures are fairly high among long-term care nurses, and are related to but distinct from staffing concerns. It remains unclear whether time pressures are related to nurses' intentions. Although time pressures may present as a relative constant for longterm care nurses, reducing the ability to find a relationship with intentions and behavior, such a finding does not disprove the potential benefit a reduction in time pressures may have on their treatment decisions.

\section{Behavioral intervention initiation}


Salience and evaluation. It was hypothesized that nurses presented with a salient injunctive norm against antipsychotic use would have higher intentions to try a different behavioral intervention than nurses presented with an information-only list of antipsychotics. The findings did not show an effect of a salient injunctive norm on nurses' intentions. One explanation for this finding is that the vast majority of nurses indicated they had quite high intentions to try a different behavioral intervention. As a result, there was little room for an injunctive norm to influence their behavior upwards on the scale. There has been a significant national campaign to encourage nurses to manage behavioral disruptions with non-pharmacological approaches (CMS, 2014; Mitka, 2012), which, assuming it was effective, may have led to high intentions to utilize behavioral interventions. Such a conclusion is tempered by the fact that this sample may not be representative of the national population of long-term care nurses. Furthermore, without any prior studies that quantified nurses' intentions to utilize a behavioral intervention as a point of comparison, there remains uncertainty as to whether the sample's high intentions are reflective of the true mean.

There is an alternative methodological explanation for the lack of an effect. Prior research into injunctive norms has focused on presenting a norm about a specific behavior that is also the target of modification (see Cialdini et al., 1990; Cialdini et al., 2006; Kallgren et al., 2000; Reno et al., 1993; Schultz et al., 2007; Schultz et al., 2008). This study did not increase the salience of an injunctive norm promoting the use of behavioral interventions. Instead, it was assumed that if nurses were encouraged and then elected to avoid using antipsychotics, they would be more likely to turn to other available management approaches. There was an inverse relationship between the use of 
antipsychotics and behavioral interventions, but the effect was small $(r=-.16, p=.04)$. The small effect could be due to the limited variability in intentions to use a behavioral intervention, or the result could reflect the fact that the two treatment decisions are not associated to the extent assumed. If the latter were true, the presentation of a salient norm against antipsychotic use would be less likely to influence intentions to utilize behavioral interventions because the two behaviors were in fact not strongly correlated. Further research is needed to examine the interrelationships of nurses' intentions to employ different treatments and to test the effect of increasing the salience of a norm promoting behavioral interventions.

The conceptual model proposed that the psychological principles expected to influence nurses' treatment choices may interact with each other, and in spite of the discussed methodological limitations, it is plausible these moderators could explain the null findings. Prior research has demonstrated that a conflicting descriptive norm may reduce the effect of an injunctive norm in a distressing situation (Fischer et al., 2011; Latané \& Nida, 1981). In line with this finding, it was hypothesized that an injunctive norm would be less influential with nurses who perceive higher rates of antipsychotic use in their facility or with nurses who work in facilities with higher rates of antipsychotic use. The findings did not show an interactive effect of actual (facility rates) or perceived descriptive norms with a salient injunctive norm against antipsychotic use.

Based on previous work examining the moderators of descriptive norms, it was hypothesized that there would be a stronger positive effect of a message with a salient injunctive norm on nurses' intentions when the nurses experienced a sense that their behavior was being evaluated. The results did not show a significant interactive effect of 
a sense of evaluation and a salient injunctive norm. Additionally, there was not a significant interaction of actual (facility rates) or perceived descriptive norms and sense of evaluation as was expected. The failed internal validity analysis of the sense of evaluation manipulation tempers the validity of these findings. It is an open question as to whether manipulating a sense of evaluation can moderate the effect of an injunctive norm and counter conflicting descriptive norms about antipsychotic use.

Based on the model, three other psychological constructs could moderate the effect of an injunctive norm on intentions to initiate a behavioral intervention. When presented with an injunctive norm against using antipsychotics, nurses with low selfefficacy, outcome expectancies, or attitudes for behavioral interventions may have been less inclined to try a new behavioral intervention. Such reasoning is consistent with an original study hypothesis that a salient injunctive norm would be more influential among nurses with greater self-efficacy and post-hoc hypotheses that a salient injunctive norm would be more influential among nurses with higher outcome expectancies of and attitudes towards behavioral interventions. The analyses did not find evidence that selfefficacy, outcome expectancies, or attitudes moderated the effect of an injunctive norm. The null findings across the multiple moderators may reflect the limited variability in intentions to use behavioral interventions reducing the power to find an effect. Additionally, the emphasis on the injunctive and descriptive norms being focused on antipsychotic use, not behavioral intervention use, could be the source of their ineffectiveness in modifying intentions to employ a behavioral intervention.

The implications of these findings are that intentions to utilize behavioral interventions may be quite high among long-term care nurses, which suggests that the 
recent campaign (CMS, 2014; Mitka, 2012) may have been effective in promoting the adoption of behavioral interventions as a first-line management tool. Interestingly, the association between intentions to use a behavioral intervention and antipsychotic was small, and this small relationship may limit the likelihood that targeting one behavior (e.g., antipsychotic use) would necessarily promote a change in the other behavior (e.g., behavioral intervention use).

Time pressures, staffing, and self-efficacy. It was hypothesized that perceived time pressures would have an inverse relationship with intentions to employ a behavioral intervention and that perceived resources would be positively associated with intentions to use a behavioral intervention. The results did not find any significant relationships. As a result, the proposed mediation analyses with self-efficacy were not conducted. These findings are inconsistent with previous qualitative evidence suggesting a relationship between time pressures and behavioral interventions (Cohen-Mansfield et al., 2005; Cornegé-Blokland et al., 2012; Wood-Mitchell et al., 2008) and between perceived staffing and treatment decisions (Cohen-Mansfield et al., 2005; Cornegé-Blokland et al., 2012; Wood-Mitchell et al., 2008). As discussed in prior sections, the relatively high means of the nurses' perceived time pressures and intentions to use a behavioral intervention, the possible sampling bias due to limited numbers of night-shift nurses, and the use of a global-like measure of time pressures are potential methodological limitations that may account for the findings. It remains unclear whether time pressures and staffing are related to intentions to use a behavioral intervention and whether selfefficacy mediates these relationships.

\section{Limitations}


There are several limitations of this study that have yet to be discussed. The study elected to examine the conceptual model with long-term care nurses because nurses can influence treatment decisions for nursing home residents (Cohen-Mansfield et al., 2012; Cornegé-Blokland et al., 2012). Nursing assistants, however, are providing more direct care to residents, and as a result, are likely to act as intermediaries between residents and nurses, including being the individuals who conduct the behavioral interventions. Additionally, physicians are involved in treatment decisions. Because these important actors were not included as participants, the generalizability of the study's findings are limited to nurses.

The outcome of interest involved measuring behavioral intentions in response to a case study that included multiple known correlates of increased antipsychotic use. Behavioral intentions are strong but imperfect predictors of human behavior (Ajzen, 1991; Armitage \& Conner, 2001). The use of case studies has been validated as a method to investigate treatment decisions (e.g., Peabody, Luck, Glassman, Dresselhaus, \& Lee, 2000), but reactions to case studies can differ from those to standardized or actual patients. As a result, the generalizability of the study's findings to a wide range of context-specific behavioral disruptions that nursing home providers may encounter is unknown.

Most of the measures used in this study have not been previously validated. Although the reliability of the study's measures was at least acceptable, reliability is only one component of validating a measure. A correlational matrix of the measures demonstrated some expected associations between the measures but other relationships were unexpectedly not significant. Such inconsistent findings can indicate reduced 
validity of the measures due to measurement error. Further measurement validation is needed for the constructs of interest in the conceptual model.

\section{Conclusion and future directions}

This study represents an early effort to examine the interrelationships of specific psychological principles and long-term care nurses' intentions to utilize antipsychotics and behavioral interventions in the management of dementia-related behavioral disruptions. The results indicated that increasing the visibility of a message discouraging antipsychotic use may have limited utility in influencing nurses' intentions to use an antipsychotic and may even be detrimental in facilities with higher rates of antipsychotic use. Intentions to initiate behavioral interventions were quite high and had a small relationship with intentions to start an antipsychotic, suggesting that attempts to change one treatment behavior may not necessarily promote a change in another. The relationships between time pressures, perceived staffing, self-efficacy and intentions to utilize an antipsychotic or behavioral intervention remain unclear, and the lack of significant findings does not disprove the potential effect these constructs may have in treatment decisions.

The study's results and implications suggest a number of potential future directions. In working to refine the language of how to express an injunctive norm, qualitative work with long-term care nurses, nursing aides, and physicians may be able to enhance the effectiveness of the injunctive norm against antipsychotic use and develop a message conveying an injunctive norm supporting the implementation of behavioral interventions. Quantitative testing of the new injunctive norms could be expanded 
through the inclusion of nursing aides and physicians and of a greater diversity of case studies or standardized patients as the primary or secondary outcomes.

The development and validation of measures to assess providers' self-efficacy, perceived staffing, attitudes, and outcome expectancies is needed. Ideally, these studies would include all types of providers in nursing homes and examine the measures' validity over time and in the context of the providers' usual practice in nursing homes. Validity may also be enhanced through the inclusion of the measures in clinically driven programs seeking to improve the treatment of dementia-related behavioral disruptions, such as STAR-VA (Karel, Teri, McConnell, Visnic, \& Karlin, 2016; Karlin, Visnic, McGee, \& Teri, 2014).

The conceptual model's goal is to better understand providers' behavior (e.g., utilization of an antipsychotic and behavioral intervention). The development of practical and in situ methods to capture providers' behaviors would allow for an improved phenomenological examination of these outcomes and allow for a stronger test of the effects that the proposed psychological factors and their modification may have.

Nurses' attitudes, outcome expectancies, and descriptive norms were associated with their behavioral intentions, and suggest possible targets of future research. The study's manipulation of one method to modify problematic descriptive norms (e.g., increasing a sense of evaluation) failed an internal validity study, and further work is needed to determine effective methods to enhance a sense of evaluation. However, it may be preferable to design other methods to reduce the effect of problematic descriptive norms as the current nursing home environment and its providers are increasingly regulated and evaluated, which could reduce the effectiveness of such an approach and 
possibly augment strain on the staff. Approaches to changing attitudes and outcome expectancies have been studied in other domains, and could be tested within this population as methods to modify intentions and behavior. 


\section{REFERENCES}

Ajzen, I. (1991). The theory of planned behavior. Organizational Behavior and Human Decision Processes, 50, 179-211.

Ajzen, I. (2001). Nature and operation of attitudes. Annual Review of Psychology, 52, 2758.

Anthierens, S., Grypdonck, M., De Pauw, L., \& Christiaens, T. (2009). Perceptions of nurses in nursing homes on the usage of benzodiazepines. Journal of Clinical Nursing, 18, 3098-3106.

Armitage, C. J. \& Conner, M. (2001). Efficacy of the theory of planning behavior: A meta-analytic review. British Journal of Social Psychology, 40, 471-499.

Asch, S. E. (1956). Studies of independence and conformity: I. a minority of one against a unanimous majority. Psychological Monographs: General and Applied, 70, 1-70.

Avorn, J., Soumerai, S. B., Everitt, D. E., Ross-Degnan, D., Beers, M. H., Sherman, D., ... Fields, D. (1992). A randomized trial of a program to reduce the use of 
psychoactive drugs in nursing homes. The New England Journal of Medicine, 327. 168173.

Aylward, S., Stolee, P., Keat, N., Johncox, V. (2003). Effectiveness of continuing education in long-term care: A literature review. The Gerontologist, 43, 259-271.

Bandura, A. (1969). Principles of Behavior Modification. Holt, Rinehart, and Winston, Inc.: New York.

Bandura, A. (1977). Self-efficacy: Toward a unifying theory of behavioral change. Psychological Review, 84, 191-215.

Bandura, A. (1982). Self-efficacy mechanism in human agency. American Psychologist, $37,122-147$.

Bandura, A. (2006). Guide for constructing self-efficacy scales. In F. Pajares \& T. Urdan (Eds.), Self-Efficacy Beliefs of Adolescents (307-337). Greenwich, CT: Information Age Publishing.

Baron, R. M. \& Kenny, D. A. (1986). The moderator-mediator variable distinction in social psychological research: Conceptual, strategic, and statistical considerations. Journal of Personality and Social Psychology, 51, 1173-1182. 
Bischoff, W. E., Reynolds, T. M., Sessler, C. N., Edmond, M. B., \& Wenzel, R. P. (2000). Handwashing compliance by health care workers: The impact of introducing an accessible, alcohol-based hand antiseptic. Archives of Internal Medicine, 160, 1017-1021.

Brehm, S. S. \& Brehm, J. W. (1981). Psychological reactance: A theory of freedom and control. New York, NY: Academic Press.

Briesacher, B., Limcangco, R., Simoni-Wastila, L., Doshi, J., \& Gurwitz, J. (2005a). Evaluation of nationally mandated drug use reviews to improve patient safety in nursing homes: A natural experiment. Journal of the American Geriatrics Society, $53,991-996$.

Briesacher, B. A., Limcangco, M. R., Simoni-Wastila, L., Doshi, J. A., Levens, S. R., Shea, D. G., \& Stuart, B. (2005b). The quality of antipsychotic drug prescribing in nursing homes. Archives of Internal Medicine, 165, 1280-1285.

Brodaty, H. \& Arasaratnam, C. (2012). Meta-analysis of nonpharmacological interventions for neuropsychiatric symptoms of dementia. American Journal of Psychiatry, 169, 946-953. 
Burgio, L. D., Sinnott, J., Janosky, J. E., \& Hohman, M. J. (1992). Physicians’ acceptance of behavioral treatments and pharmacotherapy for behavioral disturbances in older adults. The Gerontologist, 32, 546-551.

Cabana, M. D., Rand, C. S., Powe, N. R., Wu, A. W., Wilson, M. H., Abboud, P. C., \& Rubin, H. R. (1999). Why don’t physicians follow clinical practice guidelines? A framework for improvement. Journal of the American Medical Association, 282, 1458-1465.

Centers for Medicare and Medicaid Services (2013). Advanced Copy: Dementia Care in Nursing Homes: Clarification to Appendix P State Operations Manual (SOM) and Appendix PP in the SOM for F309 - Quality of Care and F329 - Unnecessary Drugs. http://www.cms.gov/Medicare/Provider-Enrollment-andCertification/SurveyCertificationGenInfo/Downloads/Survey-and-Cert-Letter-1335.pdf

Centers for Medicare and Medicaid Services (2014). Nursing Home Compare. Retrieved from http://www.medicare.gov/nursinghomecompare/search.html

Chen, Y., Briesacher, B. A., Field, T. S., Tjia, J., Lau, D. T., \& Gurwitz, J. H. (2010). Unexplained variation across US nursing homes in antipsychotic prescribing rates. Archives of Internal Medicine, 170, 89-95. 
Cialdini, R. B. (1995). Principles and techniques of social influence. In A. Tesser (Ed.), Advanced Social Psychology (pp. 257-281). Boston, MA: McGraw Hill.

Cialdini, R. B., Demaine, L. J., Sagarin, B. J., Barrett, D. W., Rhoads, K., \& Winter, P. L. (2006). Managing social norms for persuasive impact. Social Influence, 1, 3-15.

Cialdini, R. B., Reno, R. R., \& Kallgren, C. A. (1990). A focus theory of normative conduct: Recycling the concept of norms to reduce littering in public places. Journal of Personality \& Social Psychology, 58, 1015-1026.

Cohen-Mansfield, J. \& Jensen, B. (2008). Physicians' perceptions of their role in treating dementia-related behavior problems in the nursing home: Actual practice and the ideal. Journal of the American Medical Directors Association, 9, 552-557.

Cohen-Mansfield, J., Jensen, B., Resnick, B., \& Norris, M. (2011). Knowledge of and attitudes toward nonpharmacological interventions for treatment of behavior symptoms associated with dementia: A comparison of physicians, psychologists, and nurse practitioners. The Gerontologist, 52, 34-45.

Cohen-Mansfield, J., Jensen, B., Resnick, B., \& Norris, M. (2012). Assessment and treatment of behavior problems in dementia in nursing home residents: A 
comparison of the approaches of physicians, psychologists, and nurse practitioners. International Journal of Geriatric Psychiatry, 27, 135-145.

Cohen-Mansfield, J., Lipson, S., Patel, D., Tomsko-Nay, P., Alvarez, C., Wilks, G., ... Smith, M. (2005). Wisdom from the front lines: Clinicians' descriptions of treating agitation in the nursing home, a pilot study. Journal of the American Medical Directors, 6, 257-264.

Conner, M. \& Armitage, C. J. (1998). Extending the theory of planned behavior: A review and avenues for further research. Journal of Applied Social Psychology, 28, 1429-1464.

Cornegé-Blokland, E., Kleijer, B. C., Hertogh, C. M. \& van Marum, R. J. (2012).

Reasons to prescribe antipsychotics for the behavioral symptoms of dementia: A survey in Dutch nursing homes among physicians, nurses, and family caregivers. Journal of the American Medical Directors Association, 13, 80.e1-80.e6.

Craighead, W. E., Kazdin, A. E., \& Mahoney, M. J. (1981). Behavior Modification: Principles, Issues, and Applications ( $2^{\text {nd }}$ ed.). Boston, MA: Houghton Mifflin Company. 
Darley, J. M. \& Batson, C. D. (1973). "From Jerusalem to Jericho": A study of situational and dispositional variables in helping behavior. Journal of Personality \& Social Psychology, 27, 100-108.

Darley, J. M. \& Latané, B. (1968). Bystander intervention in emergencies: Diffusion of responsibility. Journal of Personality and Social Psychology, 8, 377-383.

Dunn, T. J., Baguley, T., \& Brunsden, V. (2014). From alpha to omega: A practical solution to the pervasive problem of internal consistency estimation. British Journal of Psychology, 105, 399-412.

Edwards, K. (1990). The interplay of affect and cognition in attitude formation and change. Journal of Personality and Social Psychology, 59, 202-216.

Everitt, D. E., Fields, D. R., Soumerai, S. S., \& Avorn, J. (1991). Resident behavior and staff distress in the nursing home. Journal of the American Geriatrics Society, 39, 792-798.

Faul, F., Erdfelder, E., Buchner, A., \& Lang, A. G. (2009). Statistical power analyses using G*Power 3.1: Tests for correlation and regression analyses. Behavior Research Methods, 41, 1149-1160. 
Festinger, L. \& Carlsmith, J. M. (1959). Cognitive consequences of forced compliance. The Journal of Abnormal and Social Psychology, 58, 203-210.

Fischer, P., Krueger, J. I., Greitmeyer, T., Vogrincic, C., Kastenmiller, A., Frey, D., ...Kainbacher, M. (2011). The bystander-effect: A meta-analytic review on bystander intervention in dangerous and non-dangerous emergencies. Psychological Bulletin, 137, 517-537.

Fiske, S. T. (2010). Social beings: Core motives in social psychology $\left(2^{\text {nd }}\right.$ ed.). Hoboken, NJ: John Wiley \& Sons, Inc.

Fossey, J., Ballard, C., Juszczak, E., James, I., Alder, N., Jacoby, R., \& Howard, R. (2006). Effect of enhanced psychosocial care on antipsychotic use in nursing home residents with severe dementia: Cluster randomized trial. $B M J, 332,756-761$.

Galbraith, S., Daniel, J. A., \& Vissel, B. (2010). A study of clustered data and approaches to its analysis. The Journal of Neuroscience, 30, 10601-10608.

Garcia, S. M., Weaver, K., Moskowitz, G. B., \& Darley, J. M. (2002). Crowded minds: The implicit bystander effect. Journal of Personality and Social Psychology, 83, 843-853. 
Garcia, S. M., Weaver, K., Darley, J. M., \& Spence, B. T. (2009). Dual effects of implicit bystanders: Inhibiting vs. facilitating helping behavior. Journal of Consumer Psychology, 19, 215-224.

Garrard, J., Chen, V., \& Dowd, B. (1995). The impact of the 1987 federal regulations on the use of psychotropic drugs in Minnesota nursing homes. American Journal of Public Health, 85, 771-776.

Godin, G., Bélandger-Gravel, A., Eccles, M., \& Grimshaw, J. (2008). Healthcare professionals' intentions and behaviours: A systematic review of studies based on social cognitive theories. Implementation Science, 3 (36), 1-12.

Goldstein, N. J., Cialdini, R. B., \& Griskevicius, V. (2008). A room with a viewpoint: Using social norms to motivate environmental conservation in hotels. Journal of Consumer Research, 35, 472-482.

Gollwitzer, P. M. (1999). Implementation intentions: Strong effects of simple plans. American Psychologist, 54, 493-503.

Gollwitzer, P. M. \& Brandstätter, V. (1997). Implementation intentions and effective goal pursuit. Journal of Personality and Social Psychology, 73, 186-199. 
Grunier, A. \& Lapane, K. L. (2008). It is time to assess the role of organizational culture in nursing home prescribing patterns. Archives of Internal Medicine, 168, 238-239.

Gurvich, T. \& Cunningham, J. A. (2000). Appropriate use of psychotropic drugs in nursing homes. American Family Physician, 61, 1437-1446.

Hagen, B. F., Armstrong-Esther, C., Quail, P., Williams, R. J., Norton, P., Le Navenec, C., ... \& Zieb, R. (2005). Neuroleptic and benzodiazepine use in long-term care in urban and rural Alberta: Characteristics and results of an education intervention to ensure appropriate use. International Psychogeriatrics, 17(4), 631-652.

Haines, M. \& Spear, S. F. (1996). Changing the perception of the norm: A strategy to decrease binge drinking among college students. Journal of American College Health, 45, 134-140.

Hawes, C., Mor, V., Phillips, C. D., Fries, B. E., Morris, J. N., Steele-Friedlob, E., ... Nennstiel, M. (1997). The OBRA-87 nursing home regulations and implementation of the resident assessment instrument: Effects on process quality. Journal of the American Geriatric Society, 45, 977-985.

Hughes, C. M., Lapane, K. L., \& Mor, V. (2000). Influence of facility characteristics on use of antipsychotic medications in nursing homes. Medical Care, 38, 1164-1173. 
Hugonnet, S., Perneger, T. V., \& Pittet, D. (2002). Alcohol-based handrub improves compliance with hand hygiene in intensive care units. Archives of Internal Medicine, 162, 1037-1043.

Hysong, S. J. (2009). Meta-analysis: Audit and feedback features impact effectiveness on care quality. Medical Care, 47, 356-363.

Iacobucci, D. \& Duhachek, A. (2003). Advancing alpha: Measuring reliability with confidence. Journal of Consumer Psychology, 13, 478-487.

Ioannidis, J. P. (2005). Why most published research findings are false. PLoS Medicine, $2, \mathrm{e} 124$.

Ivers, N., Jamtvedt, G., Flottorp, S., Young, J. M., Odgaard-Jensen, J. , French, S. D., ... Oxman, A. D. (2012). Audit and feedback: Effects on professional practice and healthcare outcomes. Cochrane Database of Systematic Reviews, 2012(1), 1-227.

Jacobs, R. C. \& Campbell, D. T. (1961). The perpetuation of an arbitrary tradition through several generations of a laboratory microculture. Journal of Abnormal and Social Psychology, 62, 649-658. 
Kallgren, C. A., Reno, R. R., \& Cialdini, R. B. (2000). A focus theory of normative conduct: When norms do and do not affect behavior. Personality and Social Psychology Bulletin, 26, 1002-1012.

Karel, M. J., Teri, L., McConnell, E., Visnic, S., \& Karlin, B. E. (2016). Effectiveness of expanded implementation of STAR-VA for managing dementia-related behaviors among veterans. The Gerontologist, 56, 126-134.

Karlin, B. E., Visnic, S., McGee, J. S., \& Teri, L. (2014). Results from the multisite implementation of STAR-VA: A multicomponent psychosocial intervention for managing challenging dementia-related behaviors of veterans. Psychological Services, 11, 200-208.

Klainin, P. (2009). Stress and health outcomes: The mediating role of negative affectivity in female health care workers. International Journal of Stress Management, 16, $45-64$.

Kramer, M. \& Schmalenberg, C. (2005). Revising the essentials of magnetism tool. Journal of Nursing Administration, 35, 188-198.

Kretzer, E. K. \& Larson, E. L. (1998). Behavioral interventions to improve infection control practices. American Journal of Infection Control, 26, 245-253. 
Latané, B. \& Darley, J. M. (1968). Group inhibition of bystander intervention in emergencies. Journal of Personality and Social Psychology, 10, 215-221.

Latané, B. \& Nida, S. (1981). Ten years of research on group size and helping. Psychological Bulletin, 89, 308-324.

Lee, K. J., \& Thompson, S. G. (2005). The use of random effects models to allow for clustering in individually randomized trials. Clinical Trials, 2, 163-173.

Leventhal, H., Singer, R., \& Jones, S. (1965). Effects of fear and specificity of recommendation upon attitudes and behavior. Journal of Personality and Social Psychology, 2, 20-29.

Logsdon, R. G., McCurry, S. M., \& Teri, L. (2007). Evidence-based psychological treatments for disruptive behaviors in individuals with dementia. Psychology and Aging, 22, 28-36.

Mark, B. A. (2002). What explains nurses' perceptions of staffing adequacy? Journal of Nursing Administration, 32, 234-242.

Mazis, M. B. (1975). Antipollution measures and psychological reactance theory: A field experiment. Journal of Personality and Social Psychology, 31, 654-660. 
Meador, K. G., Taylor, J. A., Thapa, P. B., Fought, R. L., \& Ray, W. A. (1997). Predictors of antipsychotic withdrawal or dose reduction in a randomized controlled trial of provider education. Journal of the American Geriatrics Society, 45(2): 6 .

Mitka, M. (2012). CMS seeks to reduce antipsychotic use in nursing home residents with dementia. Journal of the American Medical Association, 308, 119-121.

Monette, J., Champoux, N., Monette, M., Fournier, L., Wolfson, C., Galbaud du Fort, G., ... \& Gore, B. (2008). Effect of an interdisciplinary educational program on antipsychotic prescribing among nursing home residents with dementia. International Journal of Geriatric Psychiatry, 23, 574-579.

Newcomb, T. M. (1967). Persistence and change: Bennington College and its students after twenty-five years. New York, NY: Wiley.

Nishtala, P. S., McLachlan, A. J., Bell, J. S., \& Chen, T. F. (2008). Psychotropic prescribing in long-term care facilities: Impact of medication reviews and educational interventions. American Journal of Geriatric Psychiatry, 16 (8), 621632. 
Nolan, J. M., Schultz, P. W., Cialdini, R. B., Goldstein, N. J., \& Griskevicius, V. (2008). Normative social influence is underdetected. Personality and Social Psychology Bulletin, 34, 913.

O’Brien, M. A., Rogers, S., Jamtvedt, G., Oxman, A. D., Odgaard-Jensen, J., Kristoffersen, D. T., ... Harvey, E. (2007). Educational outreach visits: Effects on professional practice and health care outcomes. Cochrane Database of Systematic Reviews, 2007(4), 1-80.

Office of Inspector General (1997). Prescription drug use in nursing homes: Report 2, An inside view by consultant pharmacists. Department of Health and Human Services.

Omnibus Budget Reconciliation Act of 1987. Pub. L. 100-203, 101 Stat. 1330-1339, codified as amended at 42 USC $§ 1396$.

O’Neil, M., Freeman M., Christensen V., Telerant A., Addleman A., \& Kansagara D. (2011). Non-pharmacological Interventions for Behavioral Symptoms of Dementia: A Systematic Review of the Evidence. Washington, DC: Department of Veterans Affairs.

Patterson, S. M., Hughes, C. M., Crealey, G., Cardwell, C., \& Lapane, K. L. (2010). An evaluation of an adapted U.S. model of pharmaceutical care to improve psychoactive prescribing for nursing home residents in Northern Ireland 
(Fleetwood Northern Ireland Study). Journal of the American Geriatrics Society, $58,44-53$.

Peabody, J. W., Luck, J., Glassman, P., Dresselhaus, T. R., \& Lee, M. (2000). Comparison of vignettes, standardized patients, and chart abstraction: A prospective validation study of 3 methods for measuring quality. Journal of the American Medical Association, 283, 1715-1722.

Perkins, H. W., Haines, M. P., \& Rice, R. (2005). Misperceiving the college drinking norm and related problems: A nationwide study of exposure to prevention information, perceived norms and student alcohol misuse. Journal of Studies on Alcohol, 66, 470-478.

Perkins, M. B., Jensen, P. S., Jaccard, J., Gollwitzer, P., Oettingen, G., Pappadopulos, E., \& Hoagwood, K. E. (2007). Applying theory-drive approaches to understanding and modifying clinicians' behavior: What do we know? Psychiatric Services, 58, $342-348$.

Pittet, D., Hugonnet, S., Harbarth, S., Mourouga, P., Sauvan, V., Touveneau, S.,...members of the Infection Control Programme (2000). Effectiveness of a hospital-wide programme to improve compliance with hand hygiene. The Lancet, $356,1307-1312$. 
Pittet, D., Mourouga, P., Perneger, T. V., \& the Members of the Infection Control Program (1999). Compliance with handwashing in a teaching hospital. Annals of Internal Medicine, 130, 126-130.

Prentice-Dunn, S. \& Rogers, R. W. (1982). Effects of public and private self-awareness on deindividuation and aggression. Journal of Personality and Social Psychology, $43,503-513$.

Ray, W. A., Blazer, D. G., Schaffner, W., \& Federspiel, C.F. (1987). Reducing antipsychotic drug prescribing for nursing home patients: A controlled trial of the effect of an educational visit. American Journal of Public Health, 77 (11), 14481450.

Ray, W. A., Federspiel, C. F., \& Schaffner, W. (1980). A study of antipsychotic drug use in nursing homes: Epidemiologic evidence suggesting misuse. American Journal of Public Health, 70, 485-491.

Ray, W. A., Taylor, J. A., Meador, K. G., Lichtenstein, M. J., Griffin, M. R., Fought, R., ... Blazer, D. G. (1993). Reducing antipsychotic drug use in nursing homes: A controlled trial of provider education. Archives of Internal Medicine, 153, 713-721.

Reno, R. R., Cialdini, R. B., \& Kallgren, C. A. (1993). The transsituational influence of social norms. Journal of Personality and Social Psychology, 64, 104-112. 
Resnick, B., Galik, E., Prezer-Aboff, I., Rogers, V., \& Gruber-Baldini, A. L. (2008). Testing the reliability and validity of self-efficacy and outcome expectations of restorative care performed by nursing assistants. Journal of Nursing Care Quality, $23,162-169$.

Resnick, B. \& Simpson, M. (2003). Restorative care nursing activities: Pilot testing selfefficacy and outcome expectation measures. Geriatric Nursing, 24, 82-89.

Richter, T., Meyer, G., Moehler, R., \& Koepke, S. (2012). Psychosocial interventions for reducing antipsychotic medication in care home residents. Cochrane Database of Systematic Reviews, 2012(12), 1-43.

Rochon, P. A., Stukel, T. A., Bronskill, S. E., Gomes, T., Sykora, K., Wodchis, W. P., ... Anderson, G. M. (2007). Variation in nursing home antipsychotic prescribing rates. Archives of Internal Medicine, 167, 676-683.

Rovner, B. W., Edelman, B. A., Cox, M. P., \& Shmuely, Y. (1992). The impact of antipsychotic drug regulations on psychotropic prescribing practices in nursing homes. American Journal of Psychiatry, 149, 1390-1392.

Schmidt, I., Claesson, C. B., Westerholm, B., Nilsson, L. G., \& Svarstad, B. L. (1998). The impact of regular multidisciplinary team interventions on psychotropic 
prescribing in Swedish nursing homes. Journal of the American Geriatrics Society, $46(1), 11$.

Schneider, L. S., Dagerman, K. S., \& Insel, P. (2005). Risk of death with atypical antipsychotic drug treatment for dementia: Meta-analysis of randomized placebocontrolled trials. Journal of the American Medical Association, 294(15), 19341943.

Schneider, L. S., Dagerman, K., \& Insel, P. S. (2006a). Efficacy and adverse effects of atypical antipsychotics for dementia: Meta-analysis of randomized, placebocontrolled trials. American Journal of Geriatric Psychiatry, 14, 191-210.

Schneider, L. S., Tariot, P. N., Dagerman, K. S., Davis, S. M., Hsiao, J. K., Ismail, M. S., ...Lieberman, J. A. (2006b). Effectiveness of atypical antipsychotic drugs in patients with Alzheimer's disease. The New England Journal of Medicine, 355, $1525-1538$.

Schultz, P. W. (1998). Changing behavior with normative feedback interventions: A field experiment on curbside recycling. Basic and Applied Social Psychology, 21, 2536. 
Schultz, P. W., Nolan, J. M., Cialdini, R. B., Goldstein, N. J., \& Griskevicius, V. (2007). The constructive, destructive, and reconstructive power of social norms. Psychological Science, 18, 429-434.

Schultz, P. W., Khazian, A. M., \& Zaleski, A. C. (2008). Using normative social influence to promote conservation among hotel guests. Social Influence, 3, 4-23.

Schwartz, S. H. \& Gottlieb, A. (1976). Bystander reactions to a violent theft: Crime in Jerusalem. Journal of Personality and Social Psychology, 34, 1188-1199.

Selbaek, G., Engedal, K., \& Bergh, S. (2013). The prevalence and course of neuropsychiatric symptoms in nursing home patients with dementia: A systematic review. Journal of the American Medical Directors Association, 14, 161-169.

Sherif, M. (1936). The psychology of social norms. Oxford, England: Harper.

Shorr, R. I., Fought, R. L., \& Ray, W.A. (1994). Changes in antipsychotic drug use in nursing homes during implementation of the OBRA-87 regulations. The Journal of American Medical Association, 271, 358-362.

Sonntag, A., Matschinger, H., Angermeyer, M. C., \& Riedel-Heller, S. G. (2006). Does context matter? Utilization of sedative drugs in nursing homes- a multilevel analysis. Pharmacopsychiatry, 39, 142-149. 
Spector, P. E. \& Jex, S. M. (1998). Development of four self-report measures of job stressors and strain: Interpersonal conflict at work scale, organizational constraints scale, quantitative workload inventory, and physical symptoms inventory. Journal of Occupational and Health Psychology, 3, 356-367.

Stevenson, D. G., Decker, S. L., Dwyer, L. L., Huskamp, H. A., Grabowski, D. C., Metzger, E. D., \& Mitchell, S. L. (2010). Antipsychotic and benzodiazepine use among nursing home residents: Findings from the 2004 National Nursing Home Survey. American Journal of Geriatric Psychiatry, 18, 1078-1092.

Tjia, J., Gurwitz, J. H., Briesacher, B. A. (2012). Challenge of changing nursing home prescribing culture. The American Journal of geriatric pharmacotherapy, 10, 3746.

Unruh, L. \& Zhang, N. J. (2013). The role of work environment in keeping newly licensed RNs in nursing: A questionnaire survey. International Journal of Nursing Studies, 50, 1678-1688.

van Bommel, M., van Prooijen, J., Elffers, H., \& Van Lange, P. A. (2012). Be aware to care: Public self-awareness leads to a reversal of the bystander effect. Journal of Experimental Social Psychology, 48, 926-930. 
van Bommel, M., van Prooijen, J., Elffers, H., \& Van Lange, P. A. (2013). Intervene to be seen: The power of a camera in attenuating the bystander effect. Social Psychological and Personality Science, 1-8.

Vigen, C. L., Mack, W. J., Keefe, R. S., Sano, M., Sultzer, D. L., Stroup, T. S., ...Schneider, L. S. (2011). Cognitive effects of atypical antipsychotic medications in patients with Alzheimer's disease: Outcomes from CATIE-AD. American Journal of Psychiatry, 168 (8), 831-839.

Voss, A. \& Widmer, A. F. (1997). No time for handwashing!? Handwashing versus alcoholic rub: Can we afford $100 \%$ compliance? Infection Control and Hospital Epidemiology, 18, 205-208.

West, S. G. (1975). Increasing the attractiveness of college cafeteria food: A reactance theory perspective. Journal of Applied Psychology, 60, 656-658.

Westbury, J., Jackson, S., Gee, P., \& Peterson, G. (2010). An effective approach to decrease antipsychotic and benzodiazepine use in nursing homes: The RedUSe project. International Psychogeriatrics, 22, 26-36.

Wood-Mitchell, A., James, I. A., Waterworth, A., Swann, A., \& Ballard, C. (2008). Factors influencing the prescribing of medications by old age psychiatrists for 
behavioural and psychological symptoms of dementia: A qualitative study. Age and Ageing, 37, 547-552.

Zuidema, S. U., de Jonghe, J., Verhey, F., \& Koopmans, R. (2011). Psychotropic drug prescription in nursing home patients with dementia: Influence of environmental correlates and staff distress on physicians' prescription behavior. International Psychogeriatrics, 23, 1632-1639. 


\section{APPENDICES}

\section{Appendix A}

a) What is today's date: __

b) What is your age?

c) What is your gender? (check one)
1) $\square$ Male
3) Other:

2) $\square$ Female

d) Are you Hispanic, Latino, or of Spanish origin? (check one)
1) $\square$ No
2) $\square$ Yes, Mexican, Mexican American, or Chicano
3) $\square$ Yes, Puerto Rican
4) $\square$ Yes, Cuban
5) $\square$ Yes, another Hispanic, Latino, or Spanish origin:

e) What is your race/ethnicity? (check one)
1) $\square$ White
9) $\square$ Vietnamese
2) $\square$ Black or African American
10) $\square$ Other Asian:
3) $\square$ American Indian or Alaska Native
11) $\square$ Native Hawaiian
4) $\square$ Asian Indian
12) $\square$ Guamanian or Chamorro
5) $\square$ Chinese
13) $\square$ Samoan
6) $\square$ Filipino
14) $\square$ Other Pacific Islander
7) $\square$ Japanese
15) $\square$ Some other race:
8) $\square$ Korean
16) $\square$ Multiple:

f) What type of nursing degree do you have? (check the highest degree you have earned)

1) $\square$ Associates Degree in Nursing (ADN)

2) $\square$ Bachelors of Science in Nursing (BSN)

3) $\square$ Masters of Science in Nursing (MSN) 
4) $\square$ Doctor of Philosophy in Nursing (PhD)

5) $\square$ LPN diploma or certificate (LPN)

g) Are you currently pursuing a more advanced nursing degree?

1) $\square$ No

2) $\square$ Yes -- Please specify degree:

h) What type of nursing license do you practice under? (check all that apply)

1) $\square$ Licensed Practical Nurse (LPN)

2) $\square$ Registered Nurse (RN)

3) $\square$ Advanced Practice Registered Nurse (APRN)

i) Do you work full-time or part-time in a long-term care facility?
1) $\square$ Full-time
2) $\square$ Part-time

j) What shift do you work most often? (check one)

1) $\square$ 12-hour day shift (eg. 7a to 7p)

2) $\square$ 12-hour night shift (eg. 7p to 7a)

3) $\square$ 8-hour first shift (eg. 7a to 3p)

4) $\square$ 8-hour second shift (eg. 3p to 11p)

5) $\square$ 8-hour third shift (eg. 11p to 7a)

6) $\square$ My regular schedule involves rotating between these shifts

k) How long have you worked as a nurse?

1) How long have you worked in a long-term care environment? 
m) What is the name of the facility in which you work?

n) How long have you worked in the current facility?

o) What is your current job title (e.g., DON, MDS nurse, floor nurse)? 
Appendix B

\section{Avoid Using Antipsychotics With Our Residents}

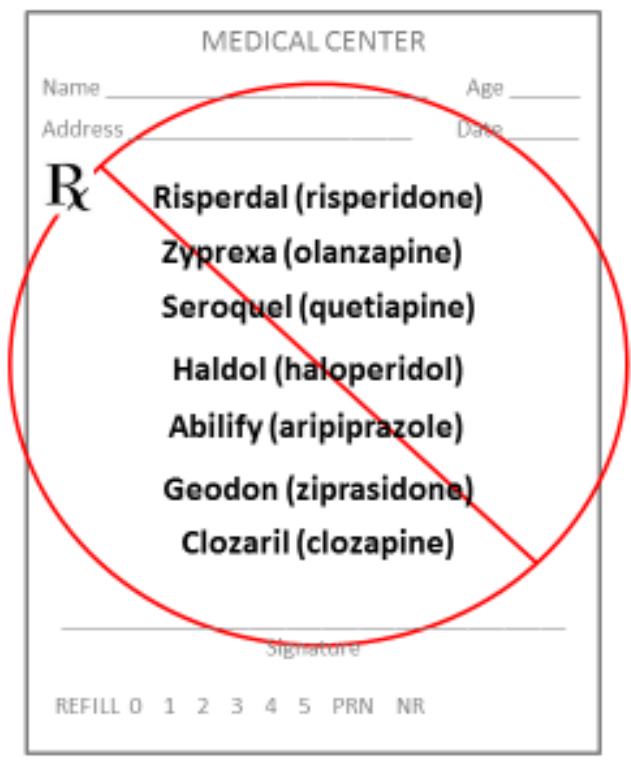


Appendix C

\title{
Examples of Antipsychotics
}

\author{
Risperdal (risperidone) \\ Zyprexa (olanzapine) \\ Seroquel (quetiapine) \\ Haldol (haloperidol) \\ Abilify (aripiprazole) \\ Geodon (ziprasidone) \\ Clozaril (clozapine)
}




\section{Appendix D}

Instructions: We are interested in how confident you are that you can do certain activities. Please complete the practice item first, and then complete the remaining questions.

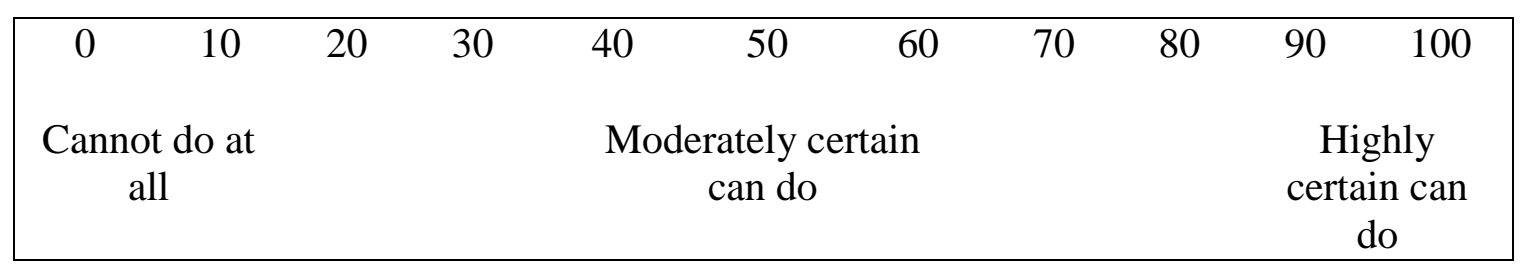

\section{A. Practice Rating}

If you were asked to lift objects of different weights right now, how confident are you that you can safely lift each of the weights described below without assistance?

Using the scale provided above, please rate your degree of confidence by recording a number from 0 to 100.

\section{CONFIDENCE (0-100)}

1. Lift a 10 pound object

2. Lift a 50 pound object

3. Lift a 100 pound object

4. Lift a 250 pound object

\section{B. Skills in Providing Behavioral Interventions:}

Please rate how confident you are, as of right now, that you can perform each intervention listed below without assistance, in order to manage behavioral disturbances (e.g., cursing, hitting, resisting care, or restlessness) exhibited by residents with dementia. Using the scale provided above, record a number from 0 to 100 to indicate your current level of confidence.

a. Redirect a resident

b. Change how stimulating the environment is 
Please rate how confident you are, as of right now, that you can perform each intervention listed below without assistance, in order to manage behavioral disturbances (e.g., cursing, hitting, resisting care, or restlessness) exhibited by residents with dementia. Using the scale provided above, record a number from 0 to 100 to indicate your current level of confidence.

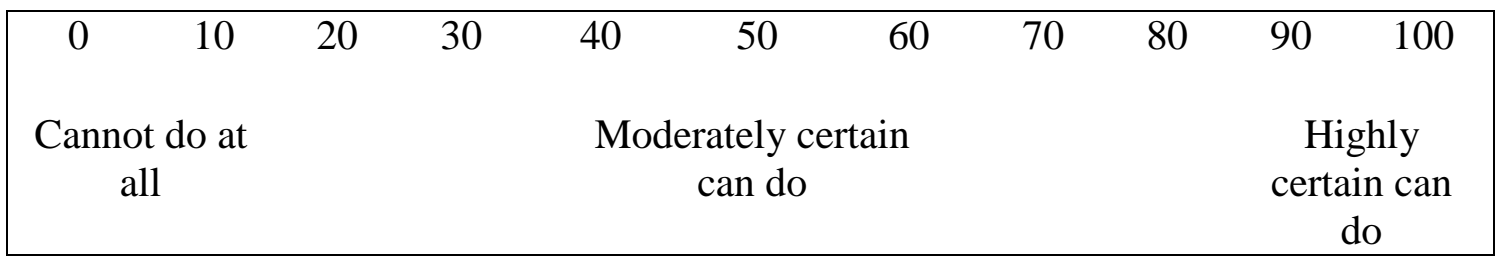

c. Identify and manage medical or physical causes of behavior (e.g., pain, hunger, thirst)

d. Help a resident identify and participate in enjoyable activities...

e. Change how and when nursing care activities, such as bathing or repositioning, are provided.

f. Implement music therapy

g. Perform massage or touch therapy.

h. Change the environment to accommodate the behavior

i. Increase the consistency of nursing assistant-to-resident assignments.

j. Implement methods to work around residents' cognitive difficulties (e.g., use memory cues or non-verbal gestures)......

k. Identify how what occurs after a behavior may reinforce the behavior and then modify these consequences

1. Implement differential reinforcement (e.g., praise patient for positive behavior and ignore resident's negative behavior)...... 


\section{Appendix E}

Instructions: Below is a list of statements about your workload. Think about your shifts over the past two weeks. Please indicate the percentage of time that each statement occurred during an average shift by recording a number from 0 to 100 . For example, if you choose 100 for the first item, this indicates you work very fast every moment $(100 \%)$ of an average shift. However, if you choose 50, this would indicate you work very fast about half $(50 \%)$ of your average shift.

\begin{tabular}{|ccccccccccc|}
\hline 0 & 10 & 20 & 30 & 40 & 50 & 60 & 70 & 80 & 90 & 100 \\
& & & & & & & & & \\
Rever & & Rarely & & Sometimes & & Often & & Always \\
\hline
\end{tabular}

a) How often does your job require you to work very fast................

b) How often does your job require you to work very hard....

c) How often does your job leave you with little time to get things done..

d) How often is there a great deal to be done..........................

e) How often do you have to do more work than you can do well.

(C) 1997, Paul E. Spector and Steve M. Jex, All rights reserved. $\overline{\text { Modified with permission. }}$ 


\section{Appendix F}

Instructions: Please read the following statement, and indicate to what extent you agree.

\begin{tabular}{|ccccc|}
\hline 1 & 2 & 3 & 4 & 5 \\
$\begin{array}{l}\text { Strongly } \\
\text { Disagree }\end{array}$ & Disagree & Undecided & Agree & Strongly Agree \\
\hline
\end{tabular}

a) Inadequate staffing hinders my ability to manage behavioral disruptions without medications............................................... 


\section{Appendix G}

Instructions: Below is the case study you just read. Please answer the following questions by providing a number from 0 to 100 .

1. Mr. Smith is a 65-year-old resident who has been diagnosed with dementia, and has difficulty recalling what occurred earlier in the day. He is taking memantine, lisinopril, metoprolol, and omeprazole. Over the past month, his behavior has progressively worsened. Currently, he appears restless as he paces around his room and wrings his hands. He is quick to anger. His fellow residents and the staff report he has cursed at and been rude to them, and he has threatened to hit fellow residents. He is increasingly resistant to bathing, and has attempted to hit the nursing aides as they bathe him. Over time, several behavioral interventions implemented by you and others have failed to improve his behavior. Medical causes, such as pain, UTI, and delirium, have been ruled out.

\begin{tabular}{|c|c|}
\hline & $\begin{array}{l}\text { Percentage } \\
(0-100)\end{array}$ \\
\hline $\begin{array}{l}\text { a. What percentage of nurses at your facility would request an } \\
\text { antipsychotic in this case................................. }\end{array}$ & \\
\hline $\begin{array}{l}\text { b. What percentage of nurses at your facility would try a different } \\
\text { behavioral intervention in this case.......................... }\end{array}$ & \\
\hline
\end{tabular}

Instructions: Please answer the following question by providing a number from 0 to 100 .

\begin{tabular}{|c|c|}
\hline & $\begin{array}{c}\text { Percentage } \\
(0-100)\end{array}$ \\
\hline $\begin{array}{l}\text { a. What percentage of long-term care residents at your facility are } \\
\text { currently prescribed an antipsychotic.......................... }\end{array}$ & - - \\
\hline
\end{tabular}




\section{Appendix H}

Instructions: Please read the following statements, and then indicate to what extent you agree using the following scale.

\begin{tabular}{|ccccc|}
\hline 1 & 2 & 3 & 4 & 5 \\
$\begin{array}{l}\text { Strongly } \\
\text { Disagree }\end{array}$ & Disagree & Undecided & Agree & Strongly Agree \\
\hline
\end{tabular}

1. For residents with dementia and behavioral problems,

a. I believe behavioral interventions should be used more frequently..

b. I believe antipsychotics should be avoided and their use restricted...

c. I believe greater use of behavioral intervention is an indicator of higher quality of care.

d. I believe antipsychotics are prescribed too often.....................

e. I believe behavioral treatments should be a first-line treatment.........

f. I believe lower rates of antipsychotic use are an indicator of higher quality of care 
Appendix I

Instructions: Please read the following statements, and indicate to what extent you agree.

\begin{tabular}{|ccccc|}
\hline 1 & 2 & 3 & 4 & 5 \\
$\begin{array}{c}\text { Strongly } \\
\text { Disagree }\end{array}$ & Disagree & Undecided & Agree & $\begin{array}{c}\text { Strongly } \\
\text { Agree }\end{array}$ \\
\hline
\end{tabular}

1. For residents with dementia, antipsychotics can...

a. Manage hallucinations and delusions.

b. Reduce a resident's distress quickly.

c. Be easily implemented.

d. Manage verbal aggression.

e. Reduce my own stress that is related to a resident's behavior.

f. Be quickly implemented

g. Be associated with serious side effects

h. Make it easier to care for a resident with behavioral problems.......

i. Manage physical aggression.

j. Treat the etiology of a resident's behavioral problem.

k. Be difficult to implement during nights and weekends.

1. Be less effective at night and on weekends.

2. For residents with dementia, behavioral interventions can...

a. Manage hallucinations and delusions.

b. Reduce a resident's distress quickly....

c. Be easily implemented.

d. Manage verbal aggression. 


\begin{tabular}{|ccccc|}
\hline 1 & 2 & 3 & 4 & 5 \\
$\begin{array}{l}\text { Strongly } \\
\text { Disagree }\end{array}$ & Disagree & Undecided & Agree & $\begin{array}{c}\text { Strongly } \\
\text { Agree }\end{array}$ \\
\hline
\end{tabular}

For residents with dementia, behavioral interventions can...

e. Reduce my own stress that is related to a resident's behavior.....

f. Be quickly implemented........................................

g. Be associated with serious side effects..........................

h. Make it easier to care for a resident with behavioral problems.......

i. Manage physical aggression....................................

j. Treat the etiology of a resident's behavioral problem................ _

k. Be difficult to implement during nights and weekends................ _ _

1. Be less effective at night and on weekends........................ 
Instructions: Please read the following statements, and indicate to what extent each outcome is important to you.

\begin{tabular}{|ccccc|}
\hline 1 & 2 & 3 & 4 & 5 \\
$\begin{array}{l}\text { Not at all } \\
\text { important }\end{array}$ & $\begin{array}{c}\text { Somewhat not } \\
\text { important }\end{array}$ & Neutral & $\begin{array}{c}\text { Somewhat } \\
\text { important }\end{array}$ & Very important \\
\hline
\end{tabular}

1. How important is it that an intervention could...

a. Manage hallucinations and delusions

b. Reduce a resident's distress quickly

c. Be easily implemented

d. Manage verbal aggression.

e. Reduce my own stress that is related to a resident's behavior........

f. Be quickly implemented.

g. Be associated with serious side effects

h. Make it easier to care for a resident with behavioral problems

i. Manage physical aggression.

j. Treat the etiology of a resident's behavioral problem

k. Be difficult to implement during nights and weekends

1. Be less effective at night and on weekends. 


\section{Appendix $\mathbf{J}$}

Instructions: Please imagine that this case is about a resident living at your facility. After reading the following case study, think about how you would handle a case like this as a nurse at your facility, and answer the following questions by circling a number on the provided scale.

Mr. Smith is a 65-year-old resident who has been diagnosed with dementia, and has difficulty recalling what occurred earlier in the day. He is taking memantine, lisinopril, metoprolol, and omeprazole. Over the past month, his behavior has progressively worsened. Currently, he appears restless as he paces around his room and wrings his hands. He is quick to anger. His fellow residents and the staff report he has cursed at and been rude to them, and he has threatened to hit fellow residents. He is increasingly resistant to bathing, and has attempted to hit the nursing aides as they bathe him. Over time, several behavioral interventions implemented by you and others have failed to improve his behavior. Medical causes, such as pain, UTI, and delirium, have been ruled out.

1) In order to manage and prevent his behavior, how likely is it that you would call a physician and ask for an antipsychotic (e.g. Haldol, Risperdal, Zyprexa, Seroquel, etc.)?

\begin{tabular}{|c|c|c|c|c|c|c|c|}
\hline 2 & 3 & 4 & 5 & 6 & 7 & 8 & 10 \\
\hline $\begin{array}{c}\text { Not at all } \\
\text { likely }\end{array}$ & & & & & & & Highly likely \\
\hline
\end{tabular}

2) In order to manage and prevent his behavior, how likely is it that you would try a different behavioral intervention with this resident?

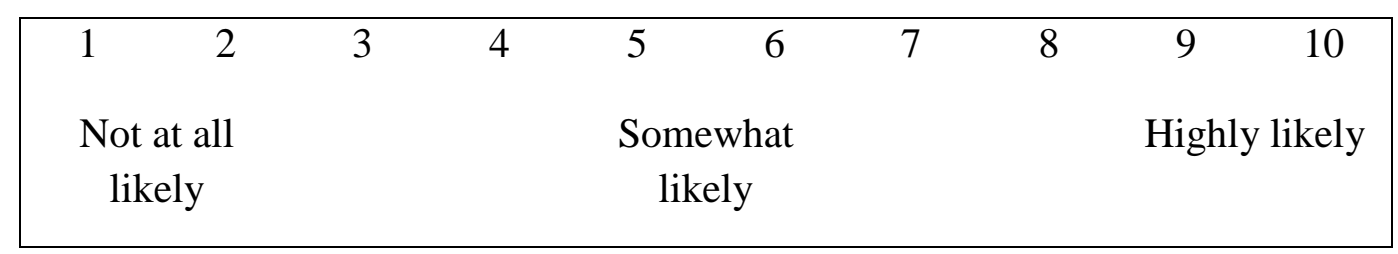


CURRICULUM VITA

\author{
Brian M. Ludwin, M.A.
}

\title{
PERSONAL INFORMATION
}

Professional Address:

Department of Psychological and Brain Scienc

University of Louisville

Louisville, KY 40292

Phone: 513-235-4879

E-mail: brian.ludwin@louisville.edu

\section{Home Address:}

753 Boylston St. \#3

Chestnut Hill, MA 02467

\section{EDUCATION}

Ph.D., Clinical Psychology, 2011- current, University of Louisville, Louisville, KY Dissertation title: "Nurses' intentions to initiate an antipsychotic or behavioral intervention with nursing home residents: The role of norms, being evaluated, self-efficacy, time pressures, and staffing"

Faculty mentor: Suzanne Meeks, Ph.D.

Internship: 2015-current, VA Boston Internship in Clinical Psychology, Boston, MA

M.A., Clinical Psychology, 2013, University of Louisville, Louisville, KY

B.S., Nursing, 2009, Emory University, Atlanta, GA

B.A., Psychology, 2007, Miami University, Oxford, OH

\section{PROFESSIONAL APPOINTMENTS}

September 2015- Clinical Fellow

Current Department of Psychiatry, Harvard Medical School, Boston, MA

September 2015- Teaching Fellow

Current Department of Psychiatry, Boston University School of Medicine, Boston, $M A$ 


\begin{abstract}
September 2015- Geropsychology Rotation, Psychology Intern
Current VA Boston Internship in Clinical Psychology, Boston, MA

Community Living Center: Complete brief psychological evaluations of veterans residing in rehabilitative, long-term care, and palliative care settings. Provide brief psychotherapy within an integrative, evidence-based, and biopsychosocial framework. Co-lead a group focused on enhancing motivation and setting goals. Conduct capacity and brief cognitive evaluations, and produce integrated reports. Collaborate with a multidisciplinary team in treatment planning. Supervisor: Kate Hinrichs, Ph.D., ABPP

Outpatient Geriatric Mental Health Clinic: Complete intake assessments of older veterans presenting with acute and chronic psychological and cognitive difficulties. Provide psychotherapy within an integrative, evidence-based, and biopsychosocial framework. Colead groups for cancer support, cognitive-behavioral therapy for insomnia, and veterans with cognitive impairment. Collaborate with an interdisciplinary team in treatment planning. Supervisors: Elizabeth Mulligan, Ph.D., ABPP and Jennifer Moye, Ph.D., ABPP
\end{abstract}

\title{
September 2015 - Psychosocial Rehabilitation and Recovery Center, Psychology Intern
}

Current VA Boston Internship in Clinical Psychology, Boston, MA

Provide integrative and evidence-based psychotherapy to veterans with serious and persistent psychological and social difficulties in the context of a person-centered, recovery-oriented program. Co-lead a group focused on developing coping mechanisms for negative affect through the use of mindfulness, relaxation, and behavioral activation. Supervisor: David Topor, Ph.D.

May 2016 -

Neuropsychology Rotation, Psychology Intern

August 2016 VA Boston Internship in Clinical Psychology, Boston, MA Will conduct neuropsychological evaluations for a variety of services and clinics, such as polytrauma, epilepsy, medical inpatient, neurology, and primary care.

Supervisor: Laura Grande, Ph.D., ABPP

September 2013 - Neuropsychology and Psychology Services, Practicum Student July 2015 Frazier Rehab Institute, Louisville, $K Y$ Conducted neuropsychological assessments in an outpatient rehabilitation clinic with adults who presented with dementia, traumatic brain injury, Parkinson's disease, Huntington's disease, 
brain tumors, and severe mental illness. Selected and administered a flexible battery, and produced integrated reports.

Supervisor: Brandon Dennis, Psy.D.

August 2013 -

July 2015

May 2012 -

July 2015

January 2012 -

July 2015

August 2012 -

August 2013

April 2012 -

June 2013

\section{Integrative Interventions Team, Student Clinician}

University of Louisville Psychological Services Center, Louisville, KY

Provided integrative and evidence-based psychotherapy to adult clients presenting to an outpatient mental-health clinic with mood and anxiety disorders. Developed collaborative, evidence-based, and biopsychosocial case formulations and treatment plans. Supervised other students on the team.

Supervisor: Richard Lewine, Ph.D.

\section{Psychological Assessment Service, Student Clinician}

University of Louisville Psychological Service Center, Louisville, KY

Conducted intellectual assessments for school-age children seeking advanced placement status, and provided psychodiagnostic and ADHD assessments for adults. Produced integrated reports, and provided feedback to clients.

Supervisors: Bernadette Walter, Ph.D. and David Winsch, Ph.D.

\section{Psychology Services, Practicum Student}

Wedgewood Healthcare Center, Louisville, KY

Completed intake assessments of chronically ill nursing home patients, and provided individual psychotherapy. Collaborated with nursing and social service department to implement psychological interventions.

Supervisor: Suzanne Meeks, Ph.D.

\section{Geropsychology Team, Student Clinician}

University of Louisville Geriatric Clinic, Louisville, $K Y$

Completed neuropsychological assessments with older adults in a geriatric primary care clinic presenting with cognitive impairment and mood disorders. Produced integrated reports, and provided feedback to patients and their family.

Supervisor: Benjamin Mast, Ph.D., ABPP

\section{Psychology Services, Practicum Student}

University of Louisville Pain Management Center, Louisville, KY

Conducted intake assessments of chronic pain patients, and provided

brief psychotherapy. Completed evaluations of client readiness for surgical procedures, and produced integrated reports. Consulted with medical staff.

Supervisor: Brian Monsma, Ph.D.

August 2011 - Mindfulness Team, Student Clinician

August 2012

University of Louisville Psychological Service Center, Louisville, KY 
Provided mindfulness-based psychotherapy to adult clients presenting to an outpatient mental-health clinic with mood and anxiety disorders. Designed collaborative case formulations and treatment plans.

Supervisor: Paul Salmon, Ph.D.

\title{
RESEARCH EXPERIENCE
}

\begin{abstract}
September 2015- Providers' Perceptions of STAR-VA Outcomes, Psychology Intern

Current PI: Michele Karel, Ph.D., ABPP (VA Central Office) Supervisor: Kate Hinrichs, Ph.D., ABPP (VA Boston)

STAR-VA is an interdisciplinary behavioral approach to managing dementia-related behaviors in nursing home residents. Collaborate with Dr. Karel to evaluate providers' qualitative feedback about veteran outcomes and to examine the interrelationships of veteran outcomes and providers' perceptions of change and use of specific techniques.
\end{abstract}

November 2014- Predicting Nurses' Care Practices for Nursing Home Residents Current with Dementia, Co-investigator PI: Suzanne Meeks, Ph.D. (University of Louisville) This study is examining the influence of norms, self-efficacy, perceived staffing, time pressures, attitudes, and outcome expectancies on long-term care nurses' intentions to initiate an antipsychotic or a behavioral intervention. Designed the study, wrote the IRB protocol, developed and administered the survey, and analyzed the data.

August 2012 - Flourishing and Failing in Nursing Homes, Graduate Research Assistant

August 2015 PI: Suzanne Meeks, Ph.D. (University of Louisville)

Flourishing is a NIMH R01 study designed to determine what psychological, social, and physical factors predict mortality or flourishing during the first six months after entry into a nursing home. Conducted medical chart reviews and rated the CIRS-G. Administered the SCID and brief cognitive testing. Participated in SCID consensus diagnosis. Performed phlebotomy and processed blood samples.

May 2013 -

Nurse Decision-Making, Co-investigator

August 2014

PI: Suzanne Meeks, Ph.D. (University of Louisville)

This study examined what factors influence the decision of a nurse to use antipsychotics or benzodiazepines in the management of behavior problems related to dementia. Designed the study, wrote 
the IRB protocol, and developed an online questionnaire.

Supervised an undergraduate assistant in recruitment.

May 2012 - $\quad$ Sleep Changes with Entry into a Nursing Home, Graduate Research Assistant

April 2013 PI: Suzanne Meeks, Ph.D. (University of Louisville)

This study examined the relationship between sleep, mood, and restactivity rhythms upon entry into a nursing home. Recruited participants, and supervised undergraduate assistants.

January 2011 - $\quad$ BE-ACTIV, Graduate Research Assistant

August $2013 \quad$ PI: Suzanne Meeks, Ph.D. (University of Louisville)

BE-ACTIV was a NIMH RO1 study examining the efficacy of a ten-week behavioral activation intervention to treat depression in nursing home residents. Received training to deliver the manualized treatment, administered questionnaires, and completed chart reviews.

July 2011 -

December 2011

iPod-Based Coping Skills for Breast Cancer Patients, Graduate Research Assistant

PI: Sandra Sephton, Ph.D. (University of Louisville)

This study examined whether mindfulness meditation could effectively modify bio-behavioral responses in people newly diagnosed with breast cancer. Recruited patients, administered questionnaires, and processed blood specimens.

May 2009 -

August 2009

August 2006 -

May 2007
MASTER, Research Assistant

PI: Susan Bauer-Wu, Ph.D. (Emory University)

The MASTER study was a NIH-funded study examining the biobehavioral effects of mindfulness meditation in people completing an autologous bone marrow transplant. Administered questionnaires.

\section{Change Not Charity, Co-investigator} Supervisor: Kathleen Knight-Abowitz, Ph.D. (Miami University) This research project involved designing a developmental model for encouraging Miami University students to become active citizens in the local community. Completed a literature review and developed and disseminated the model to relevant university stakeholders. 
Meeks, S., Getz, B., Hess, L., Kostiwa, I., Ludwin, B., Rodgers, J., \& Shah, S. (2015). Th BE-ACTIV project: How research, professional training, education, and practice were integrated in a single clinical trial. Gerontology \& Geriatrics Education.

Meeks, S., Ludwin, B., \& Looney, S. W. (Under review). Falls as adverse events in the psychosocial treatment of depression: Findings from a clinical trial in nursing homes.

Ludwin, B., Meeks, S., \& Mast, B. T. (In preparation). Reducing antipsychotic use in nursing home residents: A psychological and behavioral model for intervening wit healthcare providers.

\section{PROFESSIONAL PRESENTATIONS}

Andrew, N., Ludwin, B. M., Smith, R., Reyes, R. A., \& Meeks, S. (2015). The relationship between social support and quality of life in newly admitted longterm care residents. Poster presented at the Gerontological Society of America's 68th Annual Scientific Meeting. Orlando, FL.

Getz, B. G., Kostiwa, I., Shah, S. N., Ludwin, B. M., \& Meeks, S. (2012). Employee perception of employer expectation and its relation to job satisfaction in the nursing home. Poster presented at the Gerontological Society of America's 65th Annual Scientific Meeting. San Diego, CA.

Ludwin, B. M., Mast, B. T., Smith, R., Andrew, N., Reyes, R. A., \& Meeks, S. (2015). Hope, cognition, and depression as related to quality of life in nursing home residents. Poster presented at the Gerontological Society of America's 68th Annual Scientific Meeting. Orlando, FL.

Ludwin, B. M. \& Meeks, S. (2013). Facility-level predictors of antipsychotic medication use in nursing home residents. Paper presented at the Gerontological Society of America's 66th Annual Scientific Meeting. New Orleans, LA.

Ludwin, B. M. \& Meeks, S. (2013). Predictors of antipsychotic medication use in nursing home residents. Poster presented at the American Association for Geriatric Psychiatry's 2013 Annual Meeting. Los Angeles, CA.

Reyes, R. A., Andrew, N. D., Smith, R. W., Midden, A., Ludwin, B., Mast, B., \& Meeks, S. (2015). Community nursing home as a clinical training and consultation laboratory for studying behavioral interventions. Symposium presented at the Gerontological Society of America's 68th Annual Scientific Meeting. Orlando, FL.

Shah, S. N., Getz, B., Ludwin, B. M., Kostiwa, I., \& Meeks, S. (2012). An examination of the utility of the Revised Memory and Behavior Problems Checklist-Nursing 
Home version (RMBPC-NH) in a depressed long-term care resident sample. Poster presented at the Gerontological Society of America's 65th Annual Scientific Meeting. San Diego, CA.

Smith, R. W., Ludwin, B. M., Reyes, R., Andrew, N., \& Meeks, S. (2015). Mental health and service utilization or avoidance in a pre-Medicare sample. Poster presented at the Gerontological Society of America's 68th Annual Scientific Meeting. Orlando, FL.

\title{
INTRAMURAL FUNDING
}

Ludwin, B. M. \& Meeks, S. Graduate Student Research and Creative Activities. University of Louisville College of Arts and Sciences. Funded \$500 from July 1, 2015 to June 30, 2016.

Ludwin, B. M. \& Meeks, S. Graduate Student Union. University of Louisville. Funded $\$ 100$ from September 2013 to June 2014.

\section{HONORS}

Excellence in Clinical Work, University of Louisville, 2015

University Fellowship, University of Louisville, 2011-2012, 2014-2015

Robert M. Woodruff Fellowship, Emory University, 2009

Dean's Leadership Scholarship, Emory University, 2007-2009

Summa cum laude, Emory University, 2009

Summa cum laude, Miami University, 2007

Graduated University Honors with Distinction, Miami University, 2007

President's Distinguished Service Award, Miami University, 2007

\section{PROFESSIONAL SERVICE}

\author{
December 2015 - Psychologists in Long Term Care, Student Representative Elect \\ current \\ Boston, $M A$ \\ Will assist the PLTC Board with ongoing projects over a two-year term. \\ Specific \\ duties to be determined when term begins January 2016.
}

July 2012 - $\quad$ Graduate Student Peer Mentor Program, Mentor

July 2013 University of Louisville, Louisville, KY

Provided mentoring to first-year graduate student. 
March \&

November 2012

December 2011
Multiple Sclerosis Society Family Retreat Weekend, Facilitator

Louisville, $K Y$

Helped to facilitate a day-long, group-based program for people with multiple sclerosis and their families focused on communication, expressing emotions, and identifying strengths.

\section{Wayside Christian Mission, Facilitator}

Louisville, $K Y$

Provided weekly skills training in mindfulness meditation and stress reduction to individuals actively recovering from substance abuse. Collaborated with staff to integrate the program into the general recovery program.

\section{TEACHING EXPERIENCE}

July 2009 -

October 2009

July 2008

July 2009
Office of University and Community Partnerships, Graduate Fellor Emory University, Atlanta, GA

Served as a teaching assistant, and guided students through community building practicum.

Emory University Center for Science Education, Graduate Fellow Emory University, Atlanta, GA

Collaborated with local high school teacher to develop a health curriculum.

\section{PROFESSIONAL AFFILIATIONS}

American Psychological Association: student member

Society of Clinical Geropsychology (APA Div. 12-2): student member

Society for Clinical Neuropsychology (APA Div. 40): student member

Gerontological Society of America: student member

Sigma Theta Tau: member

\section{RELEVANT PROFESSIONAL EXPERIENCE}

April 2010 -

May 2011
Adult Bone Marrow Transplant Unit, Staff Nurse

Duke University Hospital, Durham, NC

Assessed, stabilized, and treated acutely and chronically ill bone marrow transplant patients. Member of the journal club and education committees. Completed the Nurse Residency Program for new-graduate nurses. 


\section{LICENSURE}

\section{Registered Nurse}

Kentucky: 1132963 (active)

Indiana: 28204472A (active)

North Carolina: 237788 (inactive)

Georgia: RN203473 (inactive)

PROFESSIONAL REFERENCES

Suzanne Meeks, Ph.D.

Chair and Professor

Department of Psychological and Brain Sciences

University of Louisville

Louisville, KY 40292

Phone: 502-852-6068

E-mail: smeeks@louisville.edu

Kate L. M. Hinrichs, Ph.D., ABPP

Psychologist, Community Living Center

VA Boston Healthcare System

Brockton, MA 02301

Phone: 774-826-3451

E-mail: kate.hinrichs@va.gov

Benjamin Mast, Ph.D., ABPP

Associate Professor

Department of Psychological and Brain Sciences

University of Louisville

Louisville, KY 40292

Phone: 502-852-3280

E-mail: b.mast@louisville.edu

Brandon Dennis, Psy.D.

Neuropsychologist

Frazier Rehab Institute

Louisville, KY 40202

Phone: 502-585-3472

E-mail: brandondennis@kentuckyonehealth.org 